\title{
LUNA FULLIN
}

Solution Styrene

Polymerization in a Millireactor 


\section{LUNA FULLIN}

\section{Solution Styrene}

Polymerization in a Millireactor

Thesis Submitted to the School of

Engineering of the University of São

Paulo for the Master of Science Degree

São Paulo

2014 


\section{LUNA FULLIN}

\section{Solution Styrene}

Polymerization in a Millireactor

Thesis Submitted to the School of Engineering of the University of São

Paulo for the Master of Science Degree

Concentration Area: Chemical Engineering

Advised by: Prof. Dr. Ardson dos Santos Vianna Jr. 
Este exemplar foi revisado e corrigido em relação à versão original, sob responsabilidade única do autor e com a anuência de seu orientador.

São Paulo, de agosto de 2014.

Assinatura do autor

Assinatura do orientador

Catalogação-na-publicação

Fullin, Luna

Solution styrene polymerization in a millireactor / L. Fullin.

-- versão corr. -- São Paulo, 2014. $108 \mathrm{p}$.

Dissertação (Mestrado) - Escola Politécnica da Universidade de São Paulo. Departamento de Engenharia Química.

1.Polimerização I.Universidade de São Paulo. Escola Politécnica. Departamento de Engenharia Química Il.t. 


\section{ACKNOWLEDGMENTS}

Grazie nonne, grazie zia, per il supporto, l'affetto e la saggezza.

Grazie Ste, amico e cognato sempre presente.

Grazie agli amici, vecchi e nuovi, senza cui la vita non avrebbe sapore:

Ely, amorevole e premurosa, che sa sentire ciò che non appare; Titty, con cui ho condiviso tappe dall'infanzia; Elly e Fede, con cui formo un trio a cui sono molto legata; Kia, con cui riesco a lasciarmi andare ed essere spontanea; Bre, con cui "filosofeggiare"; Ale, compagna di fatiche ma tanti divertimenti; Marta, con cui spartire passioni artistiche;

Bea, la mia sorella brasilo-colombiana, con cui condividere tutto; Giulia, da cui imparare indipendenza e determinazione; François, compagno di carte e vino; Lucas e Esmar, con cui essere amico è dare il 101\%.

Grazie alla danza nel nome di Renata, con cui ho potuto continuare la mia grande passione.

Grazie a tutti coloro che hanno incrociato il mio percorso fino a qui. 


\section{RESUMO}

As características inovadoras dos microreatores permitem a produção de novos materiais. O presente trabalho analisa o comportamento do milirreator ASIA da Syrris para a polimerização de estireno em solução. Realizaram-se polimerizações á $100{ }^{\circ} \mathrm{C}$ e $115{ }^{\circ} \mathrm{C}$, usando peróxido de benzoíla como iniciador e tolueno como solvente. Testaram-se diferentes razões monômero - solvente e diferentes quantidades de iniciador, além de variar o tempo de residência entre 5 e 80 minutos. As variações dos parâmetros envolvidos nesse milirreator proporcionou conversões de $9 \%$ até quase $70 \%$, com pesos moleculares numéricos entre 6,000 e 50,000 $\mathrm{g} / \mathrm{mol}$. Não houve entupimento no reator, permitindo a aplicação de condições mais agressivas e melhor controladas. Fez-se uma primeira tentativa de modelagem, usando o modelo do PFR e, em seguida, da dispersão axial. Usou-se o método dos momentos para computar as médias da distribuição do peso molecular. As simulações forneceram uma razoável previsão da conversão e do peso molecular médio para os experimentos mais diluídos, mas se distanciaram para os casos com maior concentração de monômero e com maior polidispersão, sendo isso provavelmente resultado do desvio do comportamento de fluxo em pistão.

Portanto, o milirreator ASIA é capaz de controlar bem as reações de polimerização, (proporcionando baixos valores do índice de polidispersão), além de fornecer valores satisfatórios de conversão (tendo em conta do seu pequeno tamanho). O sucesso no controle das polimerizações pode certamente permitir o scale-up de um reator com tais características, de forma a empregá-lo para produtividades maiores de polímeros com boa qualidade.

Palavras-chave: Polimerização em solução. Microreator. Intensificação de processo. 


\begin{abstract}
The innovative characteristics of microreactors allow producing new materials. The present work analyses the behavior of the Syrris ASIA millireactor for the solution polymerization of styrene. The polymerizations were carried out at $100{ }^{\circ} \mathrm{C}$ and 115 ${ }^{\circ} \mathrm{C}$, using benzoyl peroxide as initiator and toluene as solvent. Different monomer to solvent ratios and initiator quantities have been tested, besides varying the residence time from 5 to 80 minutes. The variations of the parameters involved in this millireactor gave conversions from $9 \%$ to almost $70 \%$, with numerical molecular weights ranging from 6,000 to $50,000 \mathrm{~g} / \mathrm{mol}$. No plugging happened, opening the possibility of more aggressive and well controlled applications. A first attempt of modeling was made, using the PFR model and the dispersion model. The method of moments was adopted to compute the means of the molecular weight distribution. The simulations gave a good prediction of conversion and average molecular weight for the more diluted experiments, but partially deviated for higher monomer contents with larger polydispersities, meaning a larger discrepancy from plug flow for the millireactor.

In general, the millireactor ASIA can be concluded to control polymerization reactions well (giving low polydispersity index values), besides giving satisfactory conversion values (considering its small size). Succeeding in controlling polymerizations can provide a reactor with characteristics of being scaled up and employed in greater productivities, ensuring good polymer qualities.
\end{abstract}

Keywords: Solution polymerization. Microreactor. Process intensification. 


\section{LIST OF FIGURES}

Figure 1 - Distribution of molecular weights in a typical polymer sample ................23

Figure 2 - Molecular weight range that can be separated by a column ....................25

Figure 3 - Conversion vs. time (or residence time) with and without gel effect.........29

Figure 4 - Continuous solution polymerization of styrene ..................................33

Figure 5 - Influence of the microfluidic reactor geometry on hydrodynamics, thermal and mass transfer. 40

Figure 6 - Map showing which flow models should be used in any situation

Figure 7 - Comparison of the RTD of the pure diffusion model, the pure convection model and the dispersion model

Figure 8 - Comparison between convection model and plug flow model. 44

Figure 9 - Polydispersity index as a function of monomer conversion for a free-radical polymerization 48

Figure 10 - Microreactor system for polymerization; M1: T-shape micromixer, R1, R2, R3 microtube reactors .53

Figure 11 - Representation of the reactor configuration .54

Figure 12 - The Syrris complete microreactor .58

Figure 13 - The tubular millireactor. .59

Figure 14 - The bottles pressurizing modulus...... .59

Figure 15 - The system pressurizer. 60

Figure 16 - Reactor operation scheme 62

Figure 17 - Temperature profiles for the polymerization of undiluted styrene in a tubular reactor with good radial mixing. $\mathrm{T}_{\text {in }}=135^{\circ} \mathrm{C}, \mathrm{T}_{\mathrm{w}}=20^{\circ} \mathrm{C}$; the parameter in the plot is the tube diameter in meters .66

Figure 18 - Mean conversion values with confidence intervals ...............................76

Figure 19 - Mean conversion values varying residence time .................................77

Figure 20 - Initiator effects on conversion and Mn........................................... 78

Figure 21 - Residence time effects on conversion.............................................

Figure 22 - Mw dependence on initiator and monomer contents .............................80

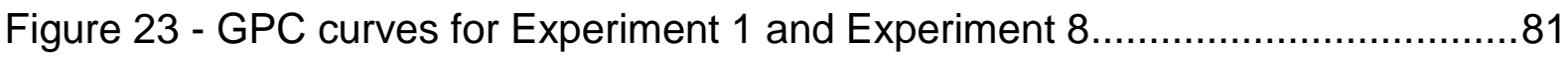

Figure 24 - Conversion: experiments vs. models ………................................. 82

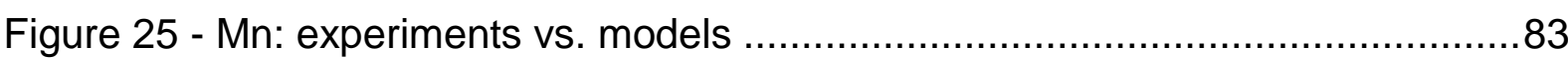




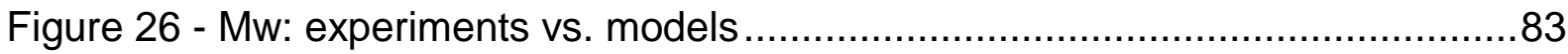

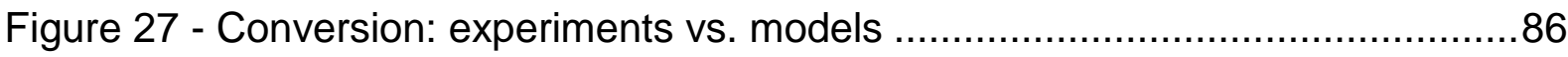

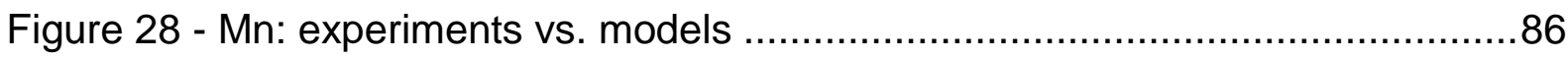

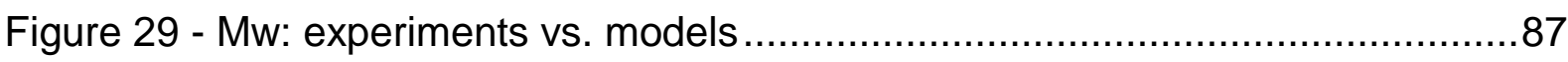

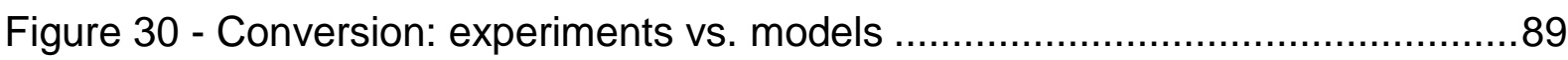

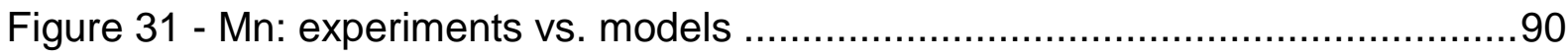

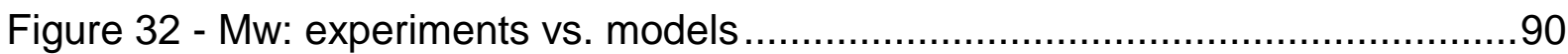

Figure 33 - Comparison between dispersion model results and experiments; the model results are represented by markers, the experimental ones by their confidence

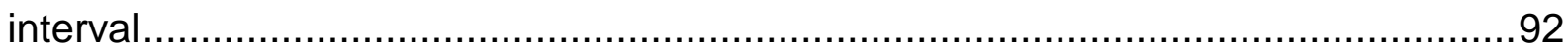

Figure 34 - Comparison between dispersion model results and experiments 9 and 10, with gel effect; the model results are represented by markers, the experimental ones by their confidence interval .93 


\section{LIST OF TABLES}

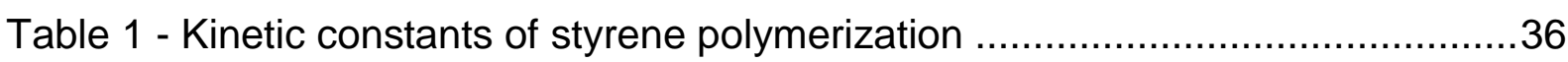

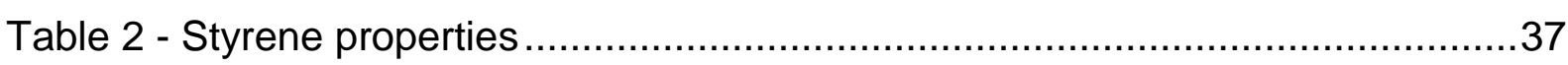

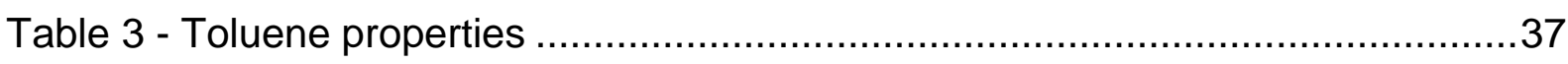

Table 4 - Polystyrene properties......................................................................... 37

Table 5 - Differences between processes in microreactors and conventional reactors 39

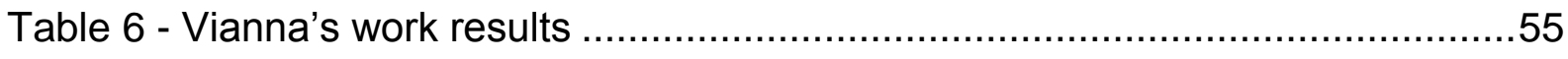

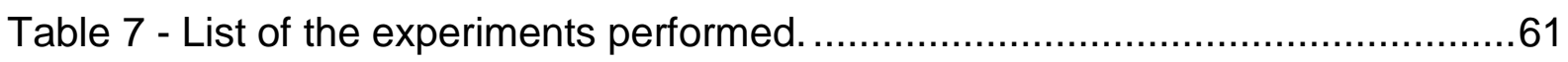

Table 8 - Density-Temperature dependence correlation for various monomer/solvent feed volumetric ratios

Table 9 - Diffusional values in the millireactor under the experimental conditions performed. .68

Table 10 - Conversions for the first group of experiments ....................................71

Table 11 - Conversions for the second group of experiments ................................. 71

Table 12 - Conversions for the third group of experiments....................................72

Table 13 - Molecular weights for the first group of experiments ..............................73

Table 14 - Molecular weights for the second group of experiments .........................74

Table 15 - Molecular weights for the third group of experiments ............................74

Table 16 - Viscosity changes for the Experiments............................................... 75

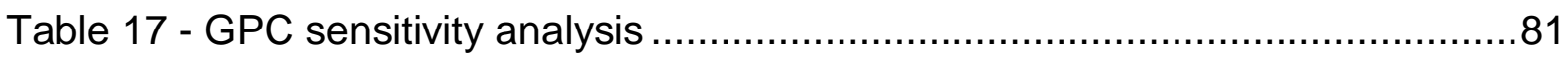

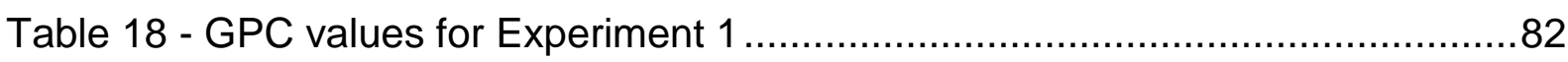

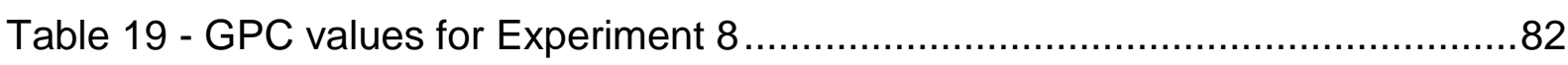

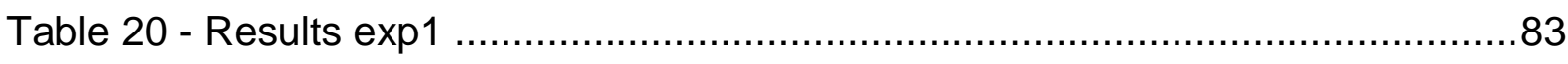

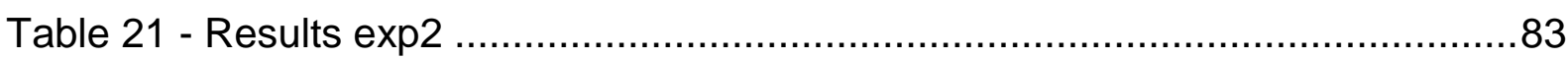

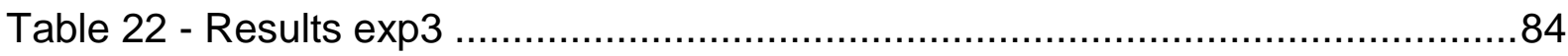

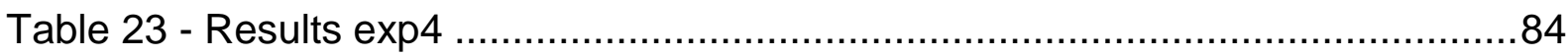

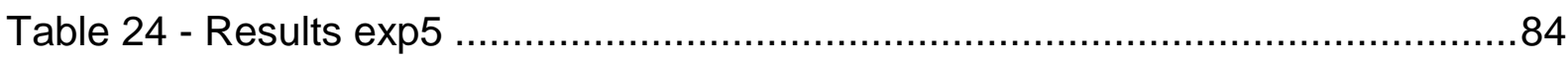

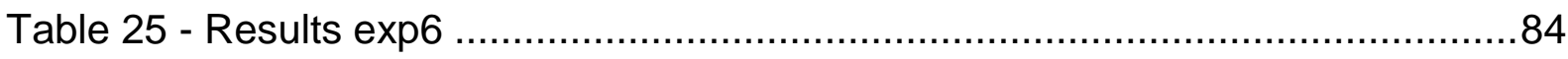

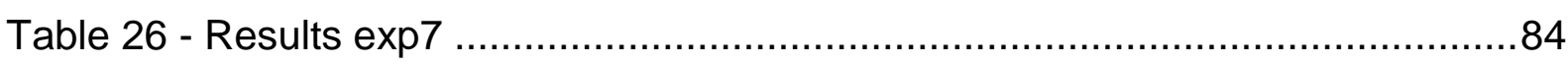

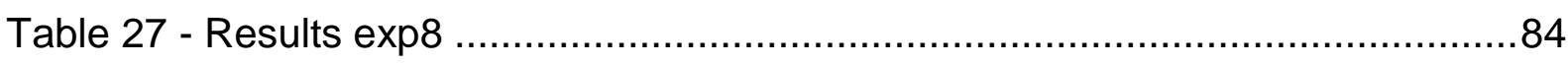

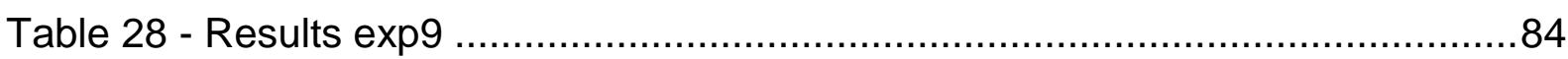

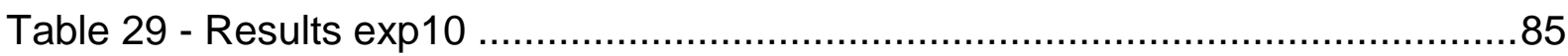


Table 30 - Results exp1

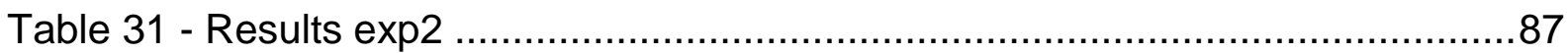

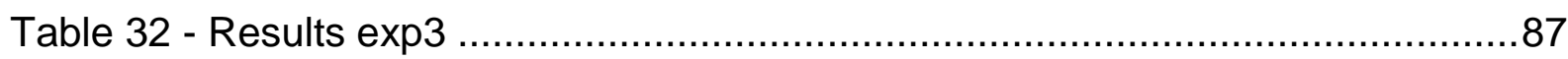

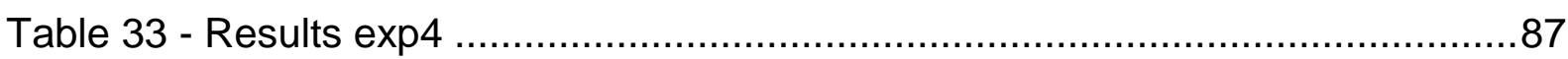

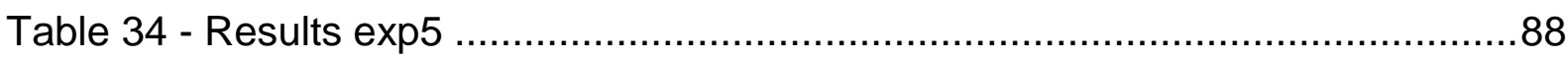

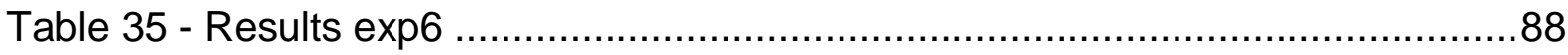

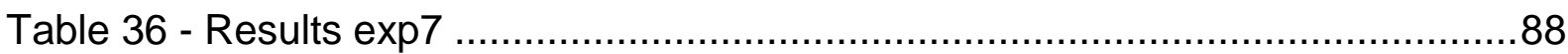

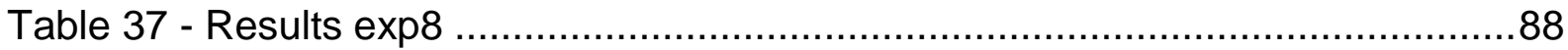

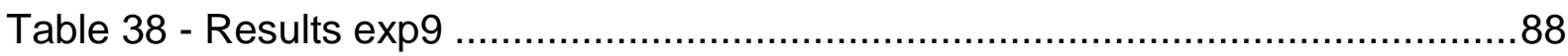

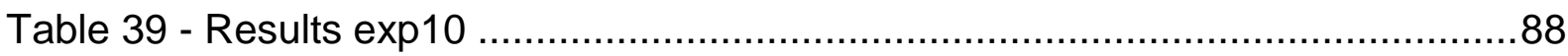

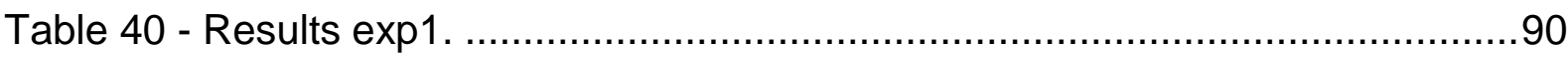

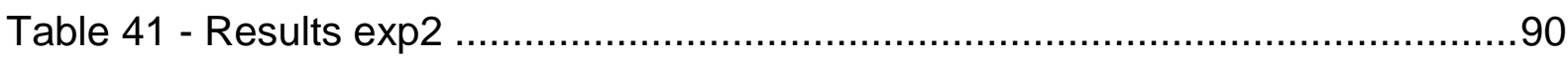

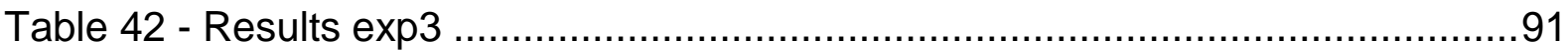

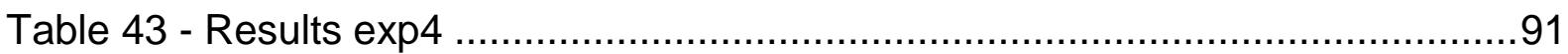

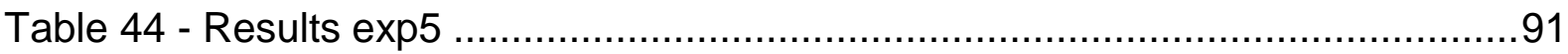

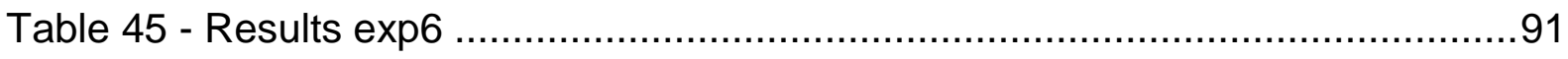

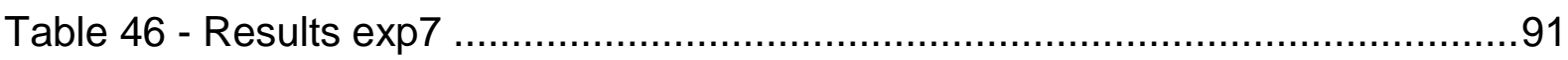

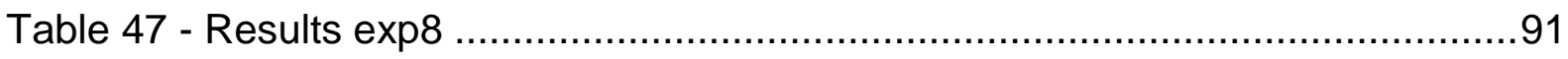

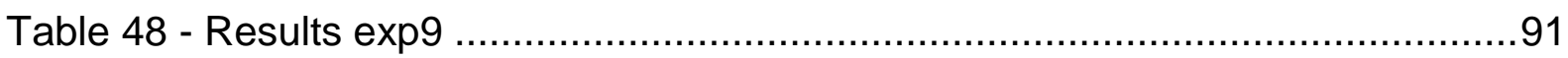

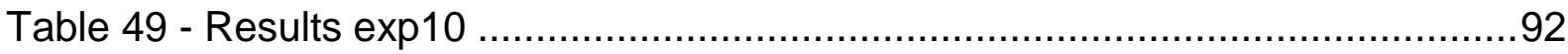

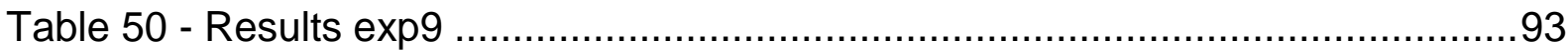

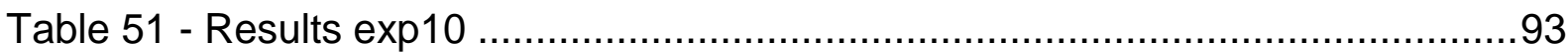

Table 52 - Effective dispersion coefficient after optimization ....................................

Table 53 - Mixing lengths and times for the first group of experiments ....................97

Table 54 - Mixing lengths and times for the second group of experiments................97

Table 55 - Space time yields for the Asia millireactor ............................................98

Table 56 - Space time yields obtained by Vianna (2003) .....................................99

Table 57 - Space time yields obtained by various authors with different reactors .....99 


\section{LIST OF ABBREVIATIONS}

CFD computational flow dynamics

CSTR continuous stirred tank reactor

DP degree of polymerization

GPC gel permeation chromatography

i.d. internal diameter

in inch

IV intrinsic viscosity (detector)

LALS low angle light scattering

MMA methyl methacrylate

MWD molecular weight distribution

NFR newtonian laminar flow reactor

ODE ordinary differential equation

PD or PDI polispersity index

PFR plug flow reactor

PS polystyrene

PSSA pseudo-steady-state approximation

QSSA quasi-steady-state approximation

RALS right angle light scattering

$\mathrm{RI}$ refractive index

RTD residence time distribution

SEC size exclusion chromatography

THF tetrahydrofuran

TIPNO tert-butyl isopropyl phenyl nitroxide 


\section{LIST OF SYMBOLS}

$a$ molecular weight constant or surface to volume ratio $\left[\mathrm{m}^{-1}\right]$

$A$ reactor area, $\left[m^{2}\right]$

A1, A2, A3 empirical parameters

Bo Bodenstein number

$c_{\text {init }}, c_{s t y}, c_{t o l}$ initiator, styrene and toluene concentrations, $\left[\mathrm{mol} \mathrm{m}^{-3}\right]$

$c_{v}$ specific heat value $\left[\mathrm{Jmol}^{-1} \mathrm{~K}^{-1}\right]$

$\mathrm{Da}$ Dalton, molecular weight measuring unity, $[\mathrm{g} / \mathrm{mol}]$

$D_{a x}, D_{m o l}$ axial dispersion coefficient and molecular diffusivity, $\left[\mathrm{m}^{2} \mathrm{~s}^{-1}\right]$

$\left[D_{n}\right]$ dead polymer concentration of a molecule having $\mathrm{n}$ repeat units, $\left[\mathrm{mol} \mathrm{m}^{-3}\right]$

$d_{t}$ reactor diameter, $[m]$

$f$ initiator efficiency

Fo Fourier number

$[I]$ initiator concentration, $\left[\mathrm{mol} \mathrm{m}^{-3}\right]$

$[I]_{0}$ concentration of initiator at $\mathrm{t}=0,\left[\mathrm{~mol} \mathrm{~m}^{-3}\right]$

$k$ thermal conductivity, $\left[\mathrm{Wm}^{-1} \mathrm{~K}^{-1}\right]$

$K_{c}$ film coefficient, $\left[\mathrm{m} \mathrm{s}^{-1}\right]$

$k_{d}$ rate constant for initiation in presence of the gel and glass effects, $\left[s^{-1}\right]$

$k_{p}, k_{t}, k_{t c}, k_{t d}, k_{t m}, k_{t s}$ rate constants for propagation, termination, termination by

combination, termination by disproportionation, chain transfer to monomer and solvent $\left[\mathrm{m}^{3} \mathrm{~mol}^{-1} \mathrm{~s}^{-1}\right]$

$k_{t 0}$ termination rate constant without gel effect

$k_{t i}$ thermal initiation rate constant

$l$ size of the system, $[\mathrm{m}]$

$L$ reactor length, $[\mathrm{m}]$

$L_{T}$ entrance length, $[m]$

$m_{\text {mon }}, m_{\text {pol }}$ mass of monomer and polymer at time t or conversion $\mathrm{x},[\mathrm{kg}]$

$[M]$ monomer concentration in the liquid phase, $\left[\mathrm{mol} \mathrm{m}^{-3}\right]$

$M_{0}$ initial mass of monomer, $[\mathrm{kg}]$

$M i$ molecular mass of the molecule of type i, $[\mathrm{kg} / \mathrm{kmol}]$

$M W$ molecular weight, $[\mathrm{kg} / \mathrm{kmol}]$

$\mathrm{Mn}$ number average molecular weight of polymer, $[\mathrm{kg} / \mathrm{kmol}]$ 
$M_{p}$ peak apex molecular weight, $[\mathrm{kg} / \mathrm{kmol}]$

$M v$ viscosity average molecular weight of polymer, $[\mathrm{kg} / \mathrm{kmol}]$

$M w$ weight average molecular weight of polymer, $[\mathrm{kg} / \mathrm{kmol}]$

$M W_{\text {mon }}$ molecular weight of the monomer, $[\mathrm{kg} / \mathrm{kmol}]$

$\mathrm{Ni}$ number of molecules of type i

$n_{i}$ moles of the $i$ species, $[\mathrm{kmol}]$

$n_{i, 0}$ moles of the $i$ species at $\mathrm{t}=0,[\mathrm{kmol}]$

Pe Péclet number

$Q$ volumetric flow rate, $\left[\mathrm{m}^{3} \mathrm{~s}^{-1}\right]$

$Q_{0}$ initial volumetric flow rate, $\left[\mathrm{m}^{3} \mathrm{~s}^{-1}\right]$

$\left[R_{1} \cdot\right]$ radical concentration of a molecule of unitary length, $\left[\mathrm{mol} \mathrm{m}^{-3}\right]$

$\left[R_{\text {in }} \cdot\right]$ initiator radical concentration, $\left[\mathrm{mol} \mathrm{m}^{-3}\right]$

$\left[R_{n} \cdot\right]$ living polymer concentration of a molecule having $\mathrm{n}$ repeat units, $\left[\mathrm{mol} \mathrm{m}^{-3}\right]$

$R_{i}$ rate of initiation, $\left[s^{-1}\right]$

$R_{p}$ rate of polymerization, $\left[\mathrm{mol} \mathrm{m} \mathrm{m}^{-3} \mathrm{~s}^{-1}\right.$ ]

$R_{t}$ rate of termination, $\left[\mathrm{mol} \mathrm{m} \mathrm{m}^{-3} \mathrm{~s}^{-1}\right.$ ]

Re Reynolds number

$[S]$ solvent concentration in the liquid phase, $\left[\mathrm{mol} \mathrm{m}^{-3}\right]$

$[S \cdot]$ radical solvent concentration, $\left[\mathrm{mol} \mathrm{m}^{-3}\right]$

Sc Schmidt number

$t, t_{a x}$ time, axial dispersion time [ $\left.\mathrm{min}\right]$ or $[s]$

$T$ temperature of the reaction mixture, $[K]$

$T_{g}$ glass transition temperature, $[K]$

$T_{r}$ reference temperature, $[K]$

$v$ fluid velocity, $\left[\mathrm{m} \mathrm{s}^{-1}\right]$

$v_{z}$ fluid velocity in the axial direction, $\left[\mathrm{m} \mathrm{s}^{-1}\right]$

$V$ volume of liquid at time $t$ or conversion $x,\left[\mathrm{~m}^{3}\right]$

$V_{0}$ volume of liquid at $\mathrm{t}=0,\left[\mathrm{~m}^{3}\right]$

$V_{t}, V_{i}, V_{0}, V_{g}$ total volume, volume of solvent held in pores, free volume outside of the

particles and volume of the polymer gel $\left[\mathrm{m}^{3}\right]$

$V_{t o l}, V_{\text {sty }}$ volume of toluene and styrene, $\left[\mathrm{m}^{3}\right]$

$w_{i}$ weight fraction of the $i$ species

$z$ reactor length coordinate, $[m]$ 


\section{Greek letters}

$\beta$ empirical parameter

$\epsilon$ volume contraction factor

$\lambda_{k}(k=0,1,2), \mu_{k}(k=0,1,2)$ moment of live and dead polymer, $\left[\mathrm{mol} \mathrm{m}^{-3}\right]$

$\mu$ mixture viscosity, $[c P]$

$\rho$ mixture density, $\left[\mathrm{kg} / \mathrm{m}^{3}\right]$

$\rho_{\text {tol }}, \rho_{\text {sty }}, \rho_{\text {pol }}$ density of pure toluene, styrene and polymer, $\left[\mathrm{kg} / \mathrm{m}^{3}\right]$ or $\left[\mathrm{g} / \mathrm{cm}^{3}\right]$

$\sigma_{P}$ space time yield, $\left[\mathrm{kgm}^{-3} \mathrm{~s}^{-1}\right]$

$\tau$ residence time, [ $\mathrm{min}]$

$\varphi$ monomer to solvent volumetric ratio

$\Phi_{t o l}$ volumetric fraction of toluene

$\chi$ monomer conversion (molar) at time $\mathrm{t}$ 


\section{TABLE OF CONTENTS}

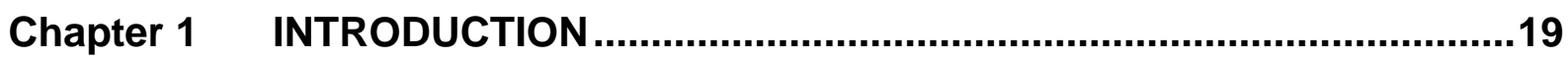

1.1 Overviews on polymer production ....................................................19

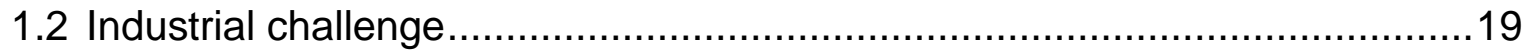

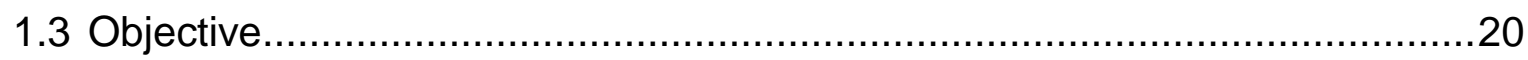

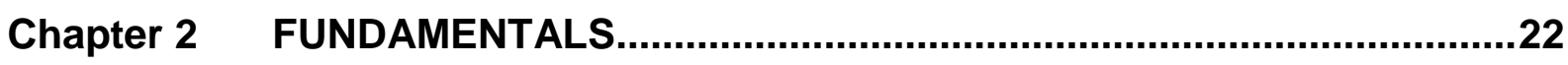

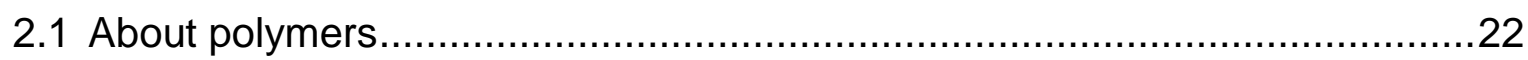

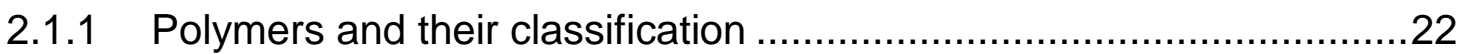

2.1.2 Molecular weight and molecular weight distribution ........................22

2.1.3 Determination of molecular weights and GPC technique .................24

2.1.4 Radical chain polymerization: steps of reaction..............................26

2.1.5 Gel effect (or Trommsdorf effect) ………….............................29

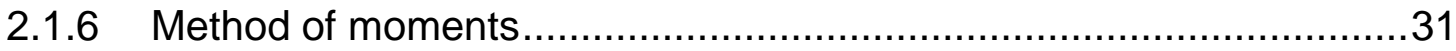

2.1.7 Different techniques for radical polymerization ..................................31

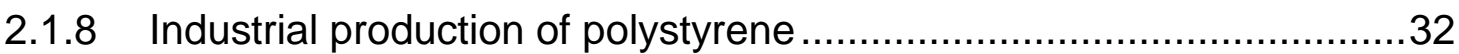

2.1.9 Batch or CSTR vs. tubular reactor in polymerization processes..........33

2.1.10 Mass balances for the tubular reactor ...........................................34

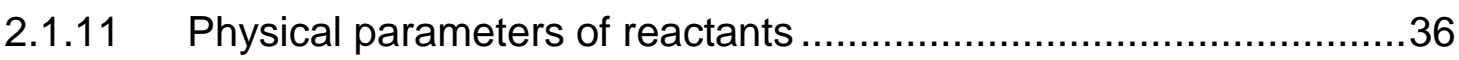

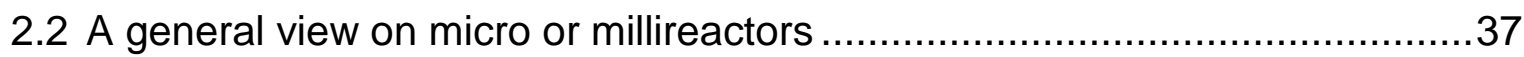

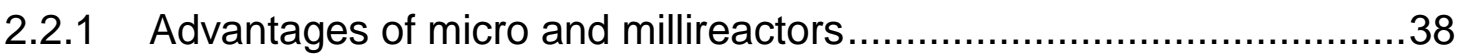

2.2.2 Dimensionless numbers in microspace ........................................ 41

2.2.3 Microreactors and deviations from the ideal plug flow model .............42

2.2.4 Considerations about other tubular reactors models .........................46

2.2.5 Considerations about micromixing and the dispersion model............47

2.2.6 Considering the micromixing degree by an effective axial dispersion coefficient. 


\section{Chapter 3 LITERATURE REVIEW.} .50

3.1 Solution styrene polymerization in tubular reactors .50

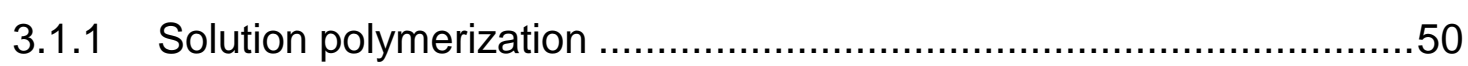

3.2 Examples of tubular millireactors for styrene polymerization .........................51

3.2.1 Wallis, Ritter and Andre's work, 1975 ..........................................51

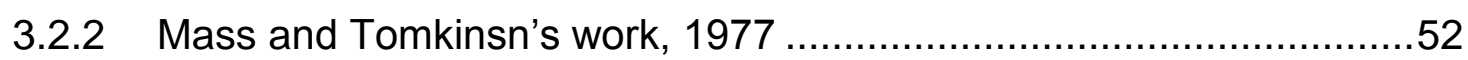

3.2.3 Serra et al.'s work, 2005 ................................................................

3.2.4 Iwasaki and Yoshida's work, 2005: no great advantages ..................53

3.2.5 Rosenfeld et al.'s work, 2007: good improvements ...........................53

3.2.6 Vianna's work, 2011: three different configurations ............................54

3.2.7 Mandal et al.'s work, 2010: coiled reactor .......................................55

3.3 Polymerizing in microreactors: many potential improvements .......................56

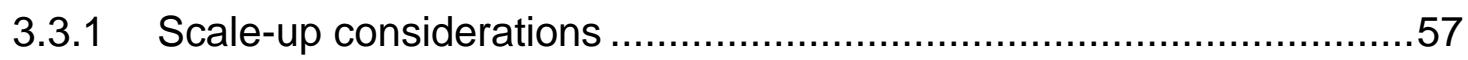

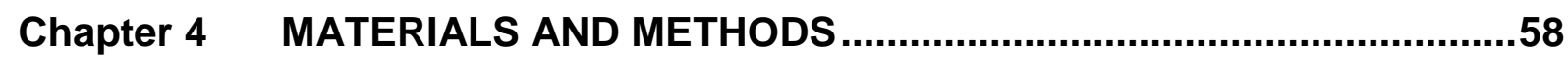

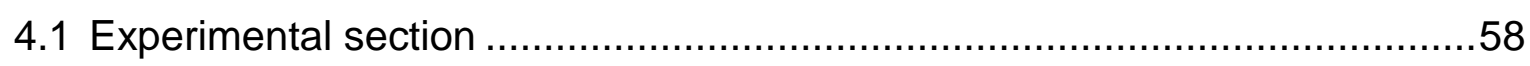

4.1.1 The Syrris microreactor "ASIA 120"..............................................

4.1.2 Adopted chemical materials ........................................................6

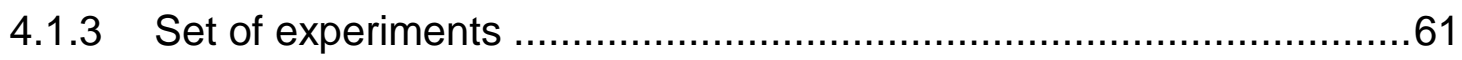

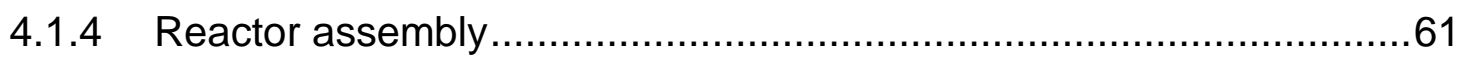

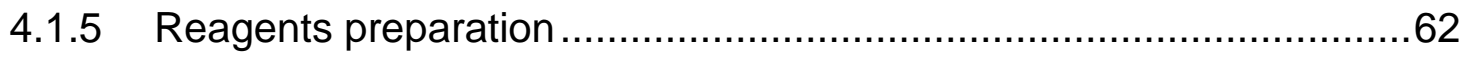

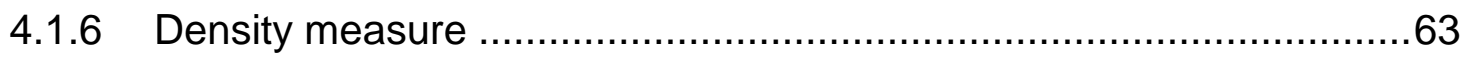

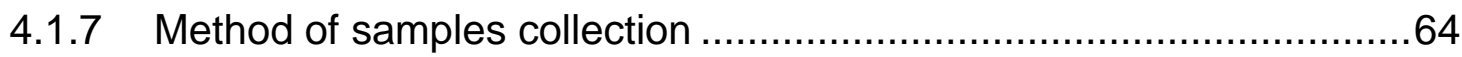

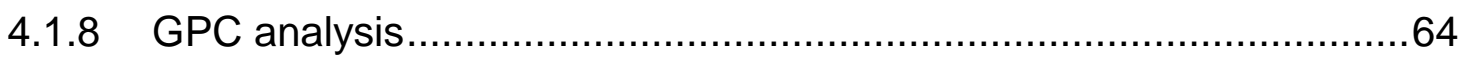

4.2 Modeling the polymerization reaction in the millireactor: the plug flow model64

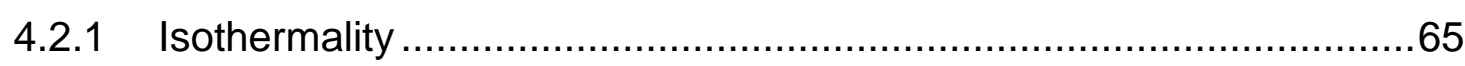

4.2.2 Deviation from the ideal plug flow model .......................................67

Chapter 5 RESULTS AND DISCUSSION......................................................

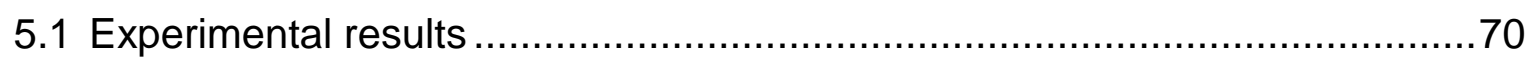


5.1.1 Reactor steady state behavior ............................................. 75

5.1.2 Statistical analysis on conversion data ...................................... 75

5.1.3 Effects of reaction parameters............................................... 77

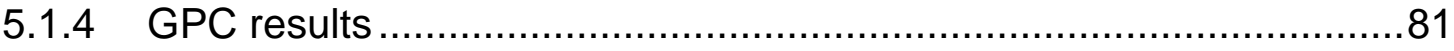

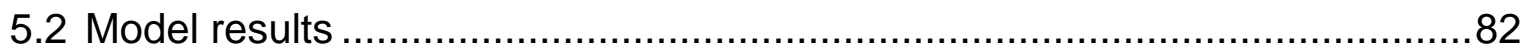

5.2.1 Experimental results vs. model results using Fontoura et al.'s gel effect correlation .85

5.2.2 Experimental results vs. model results without gel effect .................89

5.2.3 Mixing considerations ......................................................... 94

5.3 Efficiency comparison among the millireactor and other reactors performance.

Chapter 6 CONCLUSIONS ..........................................................................101

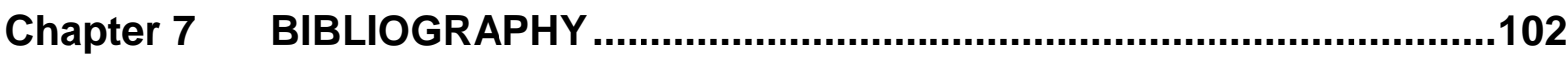

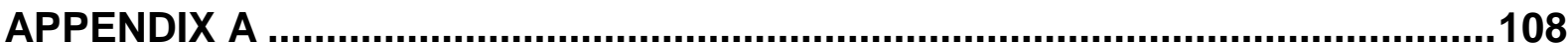




\section{Chapter 1 INTRODUCTION}

\subsection{Overviews on polymer production}

According to Vega; Lima and Pinto (1997), batch reactors are still the polymerization systems used most frequently for manufacturing commercial polymers. Nevertheless, the study of continuous polymerization processes has gained attention due to the increasing demand for high-capacity polymerization plants. Free radical polymerization reactions in conventional macroscale batch reactors, however, often suffer from inefficient heat removal and lack of homogeneity of the reactor temperature, which eventually give rise to low level of molecular weight distribution control. Thus, a major concern with this type of polymerization (more exothermic than the other ones) is the control of the reaction temperature.

Efficient heat transfer seems to be one of the most important features for free radical polymerization. Generally, the heat generation rate increases proportionally to the reactor volume, while the heat removal capacity, which depends on the exchange area, increases with the volume raised to the 2/3 power. As the reactor size decreases, heat transfer becomes faster and the temperature control becomes more efficient, leading to a better control of the molecular weight distribution (VEGA; LIMA; PINTO, 1997).

Decreasing reactor dimensions implies working with unconventional devices: microreactors. Different types of fluid dynamics, such as slug (GHAINI; MESCHER; AGAR, 2011) and Taylor flow (WANG et al., 2012), can be developed; moreover, their particular behavior allows the production of new materials (STEINBACHER; MCQUADE, 2006). If one phase mean is used, the polymerization is stable and operates continuously without issues such as clogging. Additionally, by succeeding in keeping isothermal conditions, product properties are enhanced.

\subsection{Industrial challenge}

For industrial purposes and interests, it is important to produce a polymer with a narrow curve of weight distribution and with sufficiently high molecular mass in order to achieve specific mechanical properties. To ensure the best control over polymerization, Serra et al. (2005) list three conditions that have to be fulfilled: 
1) the residence time distribution (RTD) must be as narrow as possible;

2) the mixing must be good enough to avoid local chemical species concentration fluctuations;

3) there must be no temperature gradient within the reactor.

If one of these conditions is not satisfied, the molecular weight distribution broadens and the polydispersity index increases.

Because of all the conditions aforementioned, a continuous tubular microreactor would represent a good solution: if a plug flow regime was approximately reached (thanks to a good radial mixing), there would be a very narrow residence time distribution inside the reactor; moreover, the high surface to volume ratios would guarantee the absence of temperature gradients, leading to a narrow MWD.

\subsection{Objective}

The purpose of this work is to evaluate the behavior of the microreactor for the solution polymerization of styrene. In particular, the reaction will be studied in the Syrris millireactor "ASIA 120", having an i.d. of $0.5 \mathrm{~mm}$. The principle focus will be to demonstrate the possibility of using a reactor having unconventional characteristics to perform polymerization and produce a good quality polymer.

The starting point is to "explore" the reactor behavior with a well-known reaction, which would hopefully simplify its understanding. Moreover, since polystyrene is one of the most widespread polymers in the world, it could be interesting to find another efficient process for its production.

Such a small diameter could lead to one of the greatest problems of dealing with microreactors, which is clogging, in particular if the reaction is a polymerization (HESSEL; HARDT; LÖWE, 2004). In order to make feasible a polymer production in this microreaction system, it is necessary to decrease the fluid viscosity in order to prevent damage to the equipment. Two ways are possible:

- using high temperature reaction conditions;

- adding an organic solvent, i.e. solution polymerization.

Both ways are adopted in this work; the choice of setting quite a high temperature would also aim to accelerate the propagation reaction, rising conversion, too.

No studies have been performed before on this specific reactor, which has a very precise feed and temperature control. The device presents an i.d. of just $0.5 \mathrm{~mm}$, 
thus having geometrical characteristics which are not conventional in the industry, and a $20.37 \mathrm{~m}$ length. Potential advantages of carrying out exothermic reactions are being tested, giving a good control over conversions and polymer properties. The styrene polymerization is performed in toluene (benzoyl peroxide as initiator); the presence of solvent is required in order to use quite aggressive reaction conditions: solvent, in fact, decreases the overall viscosity, thus preventing the reactor from plugging.

The work developed, besides aiming to test the millireactor unknown behavior, gives continuity to the experimental study already carried out by Vianna in 2003, who tested the polystyrene reaction in a stainless steel tubular reactor of 0.25 in diameter. The Syrris reactor will be shown to yield better results, also thanks to more risky conditions that it can withstand.

The experimental data obtained will be analyzed and discussed; two models will be tested in order to reproduce the results, while trying to understand the fluid dynamic behavior of this unconventional reactor.

Finally, a comparison in terms of yield with other reactors of similar size will be made; the good reactor performance can be concluded to be promising. Further process intensification appears to be possible and efficient. 


\section{Chapter 2 FUNDAMENTALS}

\subsection{About polymers}

\subsubsection{Polymers and their classification}

Billmeyer (1984) defines a polymer as a large molecule built up by the repetition of small, simple chemical units; the polymeric chains can be linear, branched or interconnected to form three-dimensional networks.

As reported by Mano (1999), polymers have repeated units covalently linked; their number is called "degree of polymerization" (DP). Usually, the molecular weight reaches values of $10^{4}-10^{6}$ Dalton $(\mathrm{Da})$.

The chemical reaction that leads to the formation of polymers (starting from monomers) is called polymerization. Two mechanisms are possible:

- Step polymerization

According to Odian (2003), step polymerizations proceed by the stepwise reaction between the functional groups of reactants; the size of the polymer molecules increases relatively slowly, proceeding from monomer to dimer, trimer, tetramer, pentamer, and so on. The reaction can occur between any of the species present in the reaction system.

- Chain polymerization

In chain polymerization an initiator is used to produce an initiator species $\mathrm{R} \cdot$ with a reactive center (it may be a free radical, cation, or anion). Polymerization takes place by the propagation of the reactive center, which adds large numbers of monomer molecules in a chain reaction. Monomer does not react with monomer and the different-sized species such as dimer, trimer, tetramer, and n-mer do not react with each other (ODIAN, 2003).

\subsubsection{Molecular weight and molecular weight distribution}

Odian (2003) points out that the molecular weight of a polymer is of prime importance in the polymer synthesis and application. The interesting and useful mechanical properties associated with polymeric materials are a consequence of their high molecular weight. Polymers are mixtures of molecules of different length: the reason 
for the polydispersity of polymers lies in the statistical variations present in the polymerization processes.

The number average molecular weight (mole weight) is calculated through the equation:

$$
\overline{M_{n}}=\frac{\sum_{i=1}^{\infty} M_{i} N_{i}}{\sum_{i=1}^{\infty} N_{i}}
$$

where $N_{i}$ is the number of molecules whose weight is $M_{i}$.

The weight average molecular weight $M_{w}$, instead, is defined as:

$$
\overline{M_{w}}=\frac{\sum_{i=1}^{\infty} M_{i}^{2} N_{i}}{\sum_{i=1}^{\infty} N_{i}}=\sum_{i=1}^{\infty} w_{i} M_{i}
$$

where $w_{i}$ is the weight fraction of molecules whose weight is $M_{i}$.

Finally, the viscosity average molecular weight has the following expression (eq.(3)):

$$
\overline{M_{v}}=\left(\frac{\sum_{i=1}^{\infty} M_{i}^{a+1} N_{i}}{\sum_{i=1}^{\infty} N_{i}}\right)^{1 / a}
$$

Constant $a$ is usually in the range of $0.5-0.9$ and varies with polymer, solvent and temperature (ODIAN, 2003).

Figure 1 - Distribution of molecular weights in a typical polymer sample

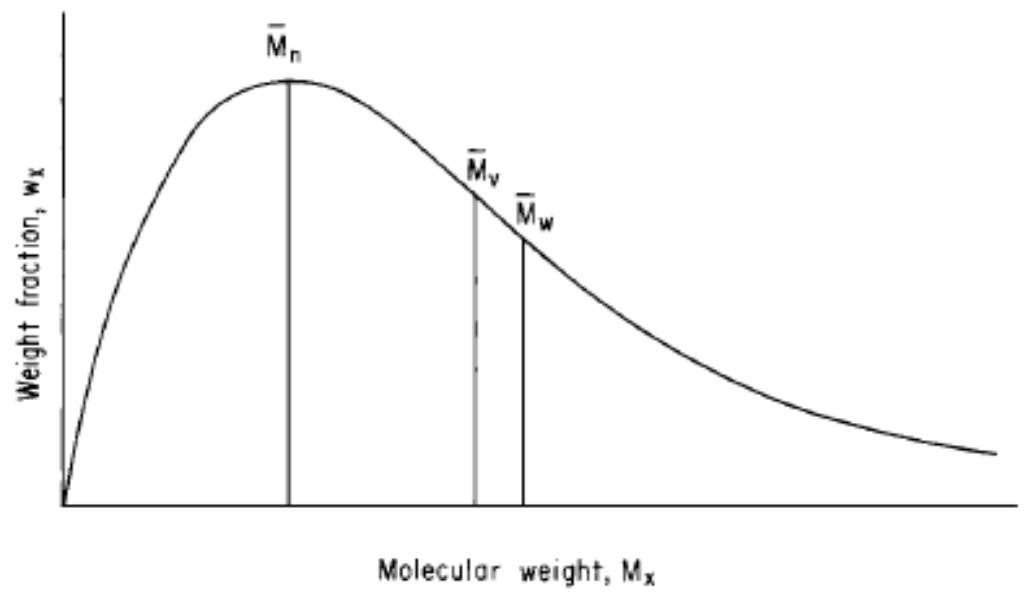

Source: Odian, 2003

According to Mano (1999), products from polyaddition (usually chain reactions) have ten times the molecular weight of those from polycondensation (step reactions), because of the different mechanisms of polymerization. Since polymers are not 
"pure" substances, it is important to know the weight distribution curve and the three average molecular weights of the product.

Billmeyer (1984) states that each molecule contributes to the weight-average molecular weight in proportion to the square of its mass; heavier molecules thus contribute more than lighter ones: $M_{w}>M_{n}$ (the two values are identical when all the weights are the same).

The polydispersity index PDI is calculated as shown in eq.(4):

$$
P D I=\frac{M_{w}}{M_{n}}
$$

and it grows as the heterogeneity increases (industrial polymers usually have polydispersity of 2 or more). Having a good control over polymerization means producing a polymer which has a low polydispersity index (MANO, 1999). Low PDI materials, in fact, have high strength properties, are easy to be processed and start melting at higher temperatures.

\subsubsection{Determination of molecular weights and GPC technique}

Mano (1999) explains the different techniques to measure polymers molecular weights:

- to determine $M_{n}$, there are processes that measure colligative properties (which depend on the number of molecules) and need very diluted solution (in order to apply Raoult's law): cryoscopy, ebullioscopy, vapor pressure osmometry, isothermal distillation, membrane osmometry and gel permeation chromatography (or GPC), the latter needing a standard polymer as a reference;

- to determine $M_{w}$, there are processes of light scattering, ultracentrifugation and gel permeation chromatography (GPC);

- to determine $M_{v}$, a viscosimeter and the knowledge of specific constants are necessary.

Since the GPC technique succeeds in extrapolating the entire distribution curve of molecular weights, it is usually the most powerful and most used tool for polymers analysis. It is a liquid chromatography in which columns with a proper filling are used. It is based on the separation of the components of different molecular weight: the 
polymeric solution is introduced in a column with porous particles; the polymer is called the moving phase, while the solvent is the stationary phase (SKOOG; HOLLER; NIEMAN, 2000).

The smaller analytes succeed in entering the pores more easily and therefore spend more time in these pores, increasing their retention time; thus they are eluted with the volume of solvent held in the pores $\left(V_{i}\right)$. Larger molecules, instead, spend less time in permeating the columns and, if not retained, they are eluted with the void fraction of the packed column $\left(V_{0}\right)$, exiting the column first. The total volume can be calculated by eq.(5), where $V_{g}$ is the volume of the polymer gel and $V_{t}$ is the total volume (SKOOG; HOLLER; NIEMAN, 2000):

$$
V_{t}=V_{i}+V_{0}+V_{g}
$$

Figure 2 reports a diagram that shows the dependence between molecular weight and eluted volume:

Figure 2 - Molecular weight range that can be separated by a column

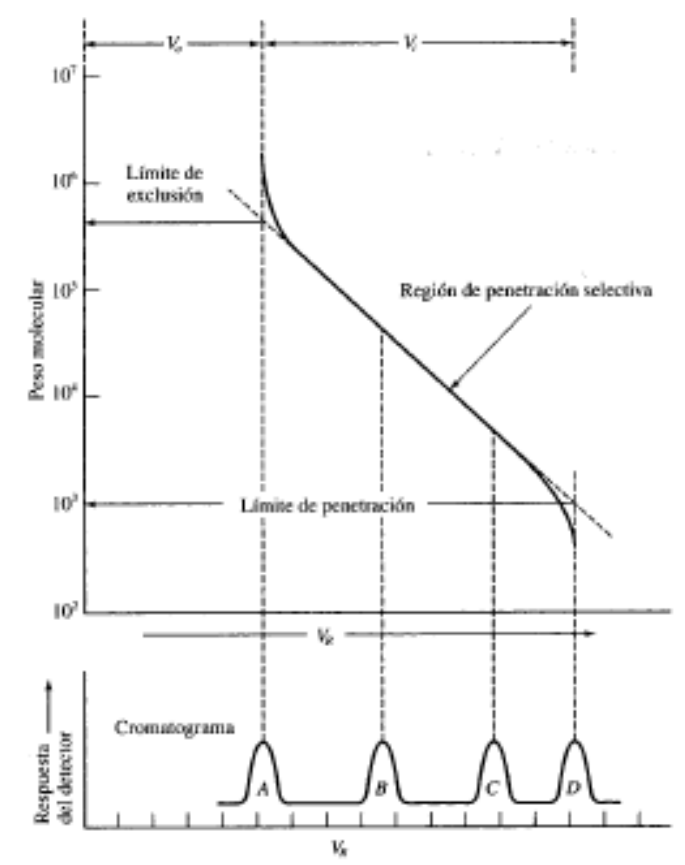

Source: Skoog; Holler and Nieman (2000) 


\subsubsection{Radical chain polymerization: steps of reaction}

Radical chain polymerization is a reaction whose mechanism classifies it into a chain or polyaddition reaction. In free radical polymerization, "at any instant, the reaction mixture contains only monomer, high polymer and growing chains; the molecular weight of the polymer is relatively unchanged during the reaction, while the overall conversion of monomer increases with time" (ODIAN, 2003, p.199).

The three steps of radical polymerization are (ODIAN, 2003):

\section{i. Initiation}

a) homolytic dissociation of a chemical initiator $I$ to yield a pair of radicals $R_{\text {in }}$ :

$$
I \stackrel{k_{d}, f}{\longrightarrow} 2 R_{\text {in }}
$$

where $k_{d}$ is the rate constant for the initiator dissociation;

b) addition of the radical to the first monomer molecule to produce the chain initiating radical $R_{1}:$

$$
R_{\text {in }} \cdot+M \stackrel{k_{i}}{\longrightarrow} R_{1}
$$

where $k_{i}$ is the rate constant for the initiation step.

Another type of initiation is the thermal one, where the radical is naturally generated by the monomer:

$$
3 M \stackrel{k_{i t}}{\longrightarrow} 2 R_{1}
$$

The rate of production of radical $R_{\text {in }}$. can be expressed by associating the processes a) and b) and introducing the PSSA hypothesis:

$$
\frac{d\left[R_{i n} \cdot\right]}{d t}=2 f k_{d}[I]-k_{i}[M]\left[R_{\text {in }} \cdot\right] \approx 0
$$

$f$ is called initiator efficiency and is defined as the fraction of radicals formed in the primary step of the initiator decomposition, which are successful in initiating polymerization. The value of $f$ for most initiators lies in the range 0.3-0.8: it is less than unity because of the presence of a solvent cage, which 
traps the radicals for some short period before they diffuse apart, giving them time to recombine (ODIAN, 2003).

The rate of initiation thus becomes:

$$
R_{i}=k_{i}[M]\left[R_{\text {in }} \cdot\right]=2 f k_{d}[I]
$$

\section{ii. Propagation}

growth of $R_{1}$. by the successive additions of large numbers of monomer molecules:

$$
R_{n} \cdot+M \stackrel{k_{p}}{\longrightarrow} R_{n+1}
$$

iii. Termination

a) combination of two radicals:

$$
R_{n} \cdot+R_{m} \cdot \stackrel{k_{t c}}{\longrightarrow} D_{n+m}
$$

b) disproportionation, in which a hydrogen radical that is beta to one radical center is transferred to another radical center, forming two polymer molecules - one saturated and one unsaturated:

$$
R_{n} \cdot+R_{m} \cdot \stackrel{k_{t d}}{\longrightarrow} D_{n}+D_{m}
$$

"The much greater value of $k_{t}$ (whether $k_{t c}$ or $k_{t d}$ ) compared to $k_{p}$ does not prevent propagation because the radical species are present in very low concentrations and because the polymerization rate is dependent on only the one-half power of $k_{t}$ " (ODIAN, 2003, p.206).

Also, other steps can take place in the reaction, for example, chain transfer (transfer of an atom between the radical and monomer or radical and solvent) (MANO, 1999):

$$
\begin{aligned}
& R_{n} \cdot+M \stackrel{k_{t m}}{\longrightarrow} R_{1} \cdot+D_{n} \\
& R_{n} \cdot+S \stackrel{k_{t s}}{\longrightarrow} S \cdot+D_{n}
\end{aligned}
$$

Globally, the kinetic scheme is:

Chemical initiation:

$$
\begin{aligned}
I \stackrel{k_{d} f}{\longrightarrow} & 2 R_{\text {in }} . \\
R_{\text {in }} \cdot+M \stackrel{k_{i}}{\longrightarrow} & R_{1} .
\end{aligned}
$$


Thermal initiation:

$$
\begin{aligned}
& I \stackrel{k_{t i}}{\longrightarrow} 2 R_{i n} . \\
& 3 M \stackrel{k_{i t}}{\longrightarrow} 2 R_{1} .
\end{aligned}
$$

Propagation:

$$
R_{n} \cdot+M \stackrel{k_{p}}{\longrightarrow} R_{n+1}
$$

Chain transfer to monomer:

$$
\begin{aligned}
& R_{n} \cdot+M \stackrel{k_{t m}}{\longrightarrow} R_{1} \cdot+D_{n} \\
& R_{n} \cdot+S \stackrel{k_{t s}}{\longrightarrow} S \cdot+D_{n} \\
& S \cdot+M \stackrel{k_{t s}}{\longrightarrow} S+R_{1} .
\end{aligned}
$$

Termination by combination: $\quad R_{n} \cdot+R_{m} \cdot \stackrel{k_{t c}}{\longrightarrow} D_{n+m}$

Termination by disproportionation: $\quad R_{n} \cdot+R_{m} \cdot \stackrel{k_{t d}}{\longrightarrow} D_{n}+D_{m}$

Neglecting the chain transfer reactions, the rate of polymerization is given by the expression:

$$
-\frac{d[M]}{d t}=R_{i}+R_{p}
$$

where $R_{i}$ and $R_{p}$ are the rates of initiation and propagation, respectively. However, the number of monomer molecules reacting in the initiation step is far less than the number in the propagation step for a process producing high polymer; $R_{i}$ can hence be neglected (ODIAN, 2003):

$$
\frac{d[M]}{d t}=-R_{p}
$$

As reported by Odian (2003), since the rate constants for all the propagation steps are the same, the polymerization rate can be expressed by:

$$
R_{p}=k_{p} \sum_{i=1}^{\infty}\left[R \cdot r_{i}\right][M]
$$

Radical concentrations are difficult values to obtain, because they are very low; since these concentrations do usually not vary too much throughout the reaction (typical polymerizations achieve a steady-state after a period, which may be at most a minute), the steady state approximation can be assumed for them; this is equivalent to stating that the rates of initiation and termination are equal: 


$$
R_{i}=R_{t}=2\left(k_{t c}+k_{t d}\right)\left(\sum_{i=1}^{\infty}[R \cdot i]\right)^{2}
$$

$\sum_{i=1}^{\infty}\left[R \cdot{ }_{i}\right]$ can be expressed by:

$$
\sum_{i=1}^{\infty}\left[R \cdot{ }_{i}\right]=\left(\frac{R_{i}}{2\left(k_{t c}+k_{t d}\right)}\right)^{1 / 2}
$$

and the rate of polymerization finally becomes:

$$
R_{p}=k_{p}[M]\left(\frac{R_{i}}{2 k_{t}}\right)^{1 / 2}
$$

It is interesting to note that doubling the rate of initiation does not double the polymerization rate, but increases it by a factor $\sqrt{2}$ (ODIAN, 2003).

\subsubsection{Gel effect (or Trommsdorf effect)}

The gel effect consists of an autoacceleration of the rate of polymerization due to diffusion limitations, which slow down the termination reaction. It causes a fast and dramatic increase of temperature (scale-up problems), leading to instabilities, hot spots and possible runaway. The main feature of the gel effect is that the polymerization rate increases with conversion instead of decreasing as monomer is consumed. Under isothermal conditions this rate increase is attributed to a decrease in the termination rate constant $\left(k_{t}\right)$, which results in an increase in radical concentration and, consequently, in the propagation rate (BRAUN, 2005).

Figure 3 - Conversion vs. time (or residence time) with and without gel effect

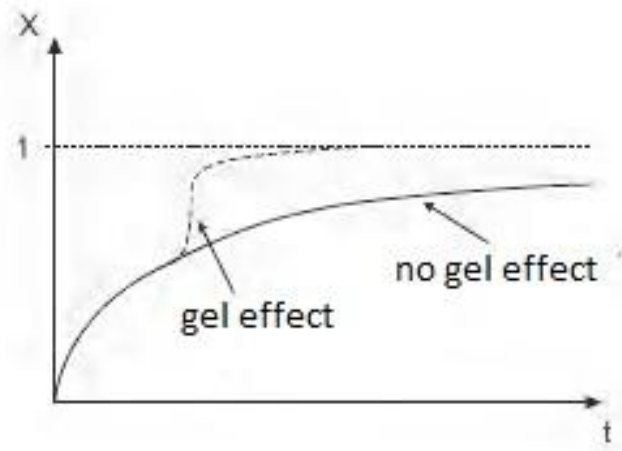

Source: Morbidelli (2012) 
Styrene polymerization is a reaction that is subject to this autoacceleration, even if this phenomenon is not as strong as it is for MMA (methyl-methacrylate) polymerization.

Hui and Hamielec ${ }^{1}$ (1972, apud CABRAL, 2003) proposed the following expression for the gel effect of styrene:

$$
k_{t}=k_{t_{0}} \exp \left(-2\left(A_{1} w_{\text {pol }}+A_{2} w_{\text {pol }}{ }^{2}+A_{3} w_{\text {pol }}{ }^{3}\right)\right)
$$

where $w_{p o l}$ is the polymer weight fraction, and the constants are thus calculated:

$$
\begin{gathered}
A_{1}=2.57-5.05 * 10^{-3} \mathrm{~T} \\
A_{2}=9.56-1.76 * 10^{-2} \mathrm{~T} \\
A_{3}=-3.03+7.85 * 10^{-3} \mathrm{~T}
\end{gathered}
$$

The same parameters can be used in a similar formula derived from a modification of Hamielec's, reported in eq.(30). The modification, proposed by Hamer et al. (1981), can be taken from the work by Kim and Choi (1988) (eq.(34)):

$$
k_{t}=k_{t_{0}} \exp \left(-2\left(A_{1} X+A_{2} X^{2}+A_{3} X^{3}\right)\right)
$$

with $X=\chi\left(1-\Phi_{t o l}\right)$, where $\chi$ is the monomer conversion and $\Phi_{t o l}$ the volumetric fraction of toluene.

Another gel effect correlation, which can be found in Fontoura et al.'s work (2003), depends on conversion (eq.(35)) and has the parameters shown in eq.(36-38):

$$
\begin{gathered}
k_{t}=k_{t_{0}}\left(A_{1}+A_{2} \chi+A_{3} \chi^{2}\right)^{2} \\
A_{1}=0.5093 \\
A_{2}=2.2395 \\
A_{3}=3.0943
\end{gathered}
$$

\footnotetext{
${ }^{1} \mathrm{HUI}$, A. W.; HAMIELEC, A. E. Thermal polymerization of styrene at high conversions an temperatures. An experimental study. Journal of Applied Polymer Science, 1972, 16(3), 749-769.
} 


\subsubsection{Method of moments}

The method of moments permits to calculate averages of the molecular weight distribution for the polymerization reaction. Wulkow (1996, p.398) defines this method "[...] as an approach that does not compute distributions, but only describes certain aspects of distributions expressed in terms of the statistical moments"; for living polymers, the statistical moments are conventionally named $\lambda_{k}(k=0,1,2 \ldots)$ and for dead polymers $\mu_{k}(k=0,1,2 \ldots)$ :

$$
\lambda_{k}=\sum_{n=1}^{\infty} n^{k}\left[R_{n} \cdot\right] \quad(41) \quad \mu_{k}=\sum_{n=1}^{\infty} n^{k}\left[D_{n} \cdot\right]
$$

In general, the complete distribution of polymeric chains can only be reconstructed by its moments, if all infinite moments are known. Otherwise, additional assumptions are required, which are usually based on the expected type of the molecular weight distribution. The choice of a basic distribution is the crucial point in such a method. Thus, the moments are mainly used to compute the different mean values of a distribution.

From the first three moments $(k=0,1,2)$, it is possible to obtain the number and weight average molecular weight by calculating:

$$
\bar{M}_{n}=\frac{\mu_{1}}{\mu_{0}} M W_{m o n}
$$

$$
\bar{M}_{w}=\frac{\mu_{2}}{\mu_{1}} M W_{m o n}
$$

Thanks to this method, only a few mass balances have to be solved in order to obtain the most important information about the reaction.

\subsubsection{Different techniques for radical polymerization}

Polymerizations can be performed both in homogeneous or heterogeneous systems. The first type includes bulk polymerization and solution polymerization; the second includes slurry polymerization, emulsion polymerization, suspension polymerization and gas-phase polymerization. In several polymerization techniques, the initiator has to be soluble in the medium in which the reaction would occur: thus, an organicsoluble initiator is required for bulk or suspension reactions, while a water-soluble one for emulsion reactions (MANO, 1999). 
In solution polymerization, specifically, the reaction occurs in the presence of monomer, initiator and solvent, without byproducts; the difference between this technique and the bulk one is that the solvent dilutes, controls temperature and reduces viscosity; the industrial use is limited because of the difficulty in dealing with solvent and its evaporation after polymerization (MANO, 1999). Besides, other problems may arise from chain transfer reactions.

\subsubsection{Industrial production of polystyrene}

Continuous solution polymerization is the most important method for the commercial production of polystyrene, although batch polymerization is also used.

Odian (2003, p.302-303) describes the actual processes as

[...] formed by up to five reactors in series; processes with only one reactor are sometimes used. Styrene, solvent (usually ethylbenzene in amounts of 2-30\%), and occasionally initiator are fed to the first reactor. Solvent is used primarily for viscosity control, [...but also] for control of molecular weight by chain transfer. [...] The reactors are run at successively increasing temperatures, up to $180^{\circ} \mathrm{C}$ in the last reactor. For thermal, self-initiated polymerization, the first reactor is run at $120^{\circ} \mathrm{C}$, while it lowers at $90^{\circ} \mathrm{C}$ when initiators are used. [...] Final conversions of $60-90 \%$ are achieved in the last reactor.

Commercial polystyrenes (PS) have number-average molecular weights in the range of $50,000-150,000 \mathrm{~g} / \mathrm{mol}$. Although completely amorphous at ambient temperature, their bulky rigid chains impart good strength; PS is a very good electrical insulator, has excellent optical clarity and has good resistance to aqueous acids and bases; on the other hand, it can be attacked by hydrocarbon solvents, it is brittle, it has poor impact strength and the upper temperature limit for its usage is low because of the lack of crystallinity and low $\mathrm{Tg}$ (glass transition temperature). Solvent resistance can be improved by compounding with glass fiber, while other properties can be enhanced by copolymerization or polymer blends (ODIAN, 2003). 
Figure 4 - Continuous solution polymerization of styrene

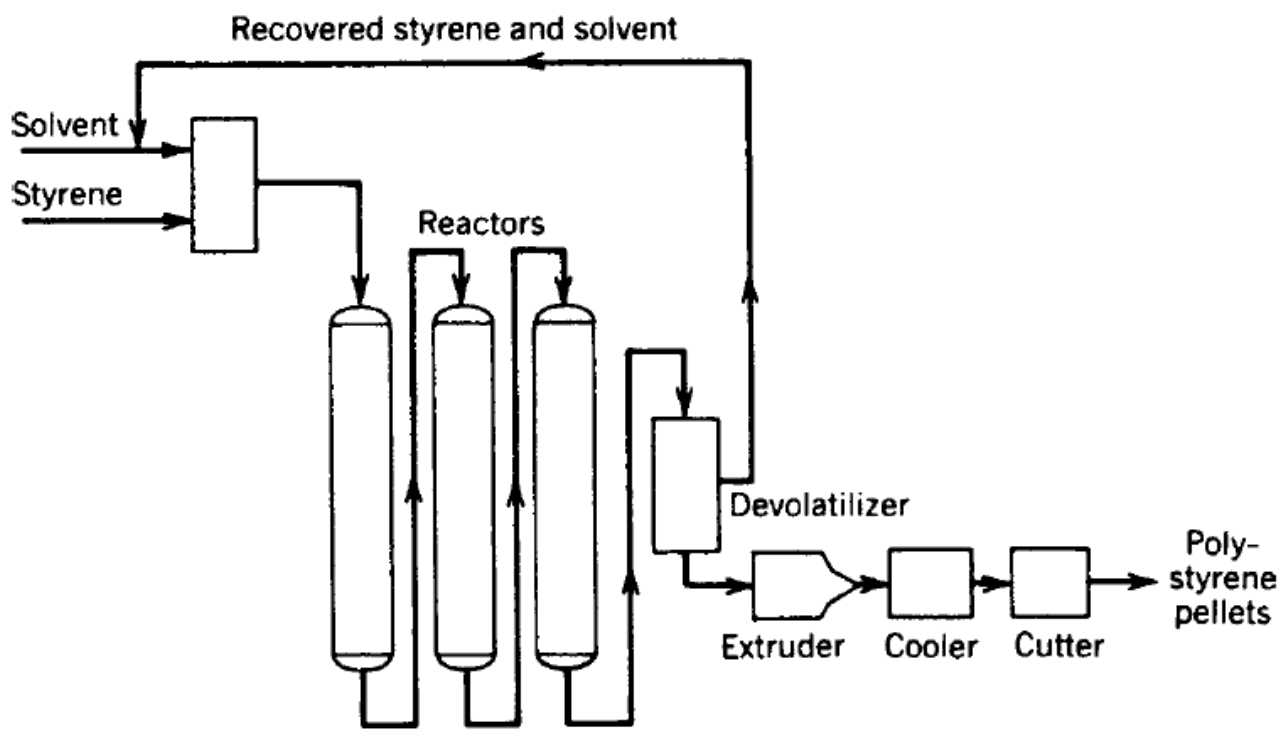

Source: Odian (2003), p.303

\subsubsection{Batch or CSTR vs. tubular reactor in polymerization processes}

As explained in the introduction, batch reactors are still the polymerization systems used most frequently for manufacturing commercial polymers, but productivity is limited and heat transfer is not efficient.

The continuous process choice leads to the possibility of producing polymers in tank reactors or in tubular reactors. Tubular reactors for polymerization have been used as an alternative to the CSTR in order to overcome the problems related to heat transfer and temperature control. Portillo (2011) points out how besides high heat transfer capabilities, additionally tubular reactors offer simple geometry, low cost of operation/maintenance and, depending on the flow regime, they can achieve flat velocity profiles; this provides narrow residence time distributions (if a good radial mixing is assured). Moreover, due to their small hold-up, they enhance process safety compared to a process carried out in a CSTR.

Vega; Lima and Pinto (1997) present the following advantages of tubular reactors:

1) they allow the decrease of fixed and operational costs due to the simplicity of their geometry;

2) they allow an increase of polymer productivity, as start-up, shut-down and cleaning procedures are much simpler and shorter; 
3) monomer conversions may reach higher values in tubular reactors than in CSTR, in which conversions above $60 \%$ would require too much energy for adequate stirring to be carried out;

4) heat transfer capacity is usually larger due to higher surface to volume ratios.

However, the disadvantages that must be considered are:

1) the operation of such reactors is not well understood because of the complex rheological behavior of the flowing polymer solution;

2) the existence of large viscosity variations along the reactor leads to large residence time distributions and heterogeneous polymer products;

3) depending on the fluid dynamic, material near the reactor center may move faster than if it was near the reactor walls, reaching smaller conversion values. As polymer concentrations increase faster near the walls, the solution becomes very viscous, leading to very high residence times at these regions. The entering fluid stream initially presents a parabolic velocity profile, which is quickly distorted to an elongated bell-like profile. This causes the polymer to have a variety of molecular weights.

\subsubsection{Mass balances for the tubular reactor}

Tubular reactors are usually represented by steady-state balances depending on the length or residence time of the reactor itself. In the most simplified case, the PFR equations are obtained to describe mass and energy balances.

Mass balances should be written for all the species present in the system; in the case of styrene polymerization in toluene, the species are the initiator (benzoyl peroxide), styrene and toluene. In addition, in order to assess the averages of the molecular weight distribution, six mass balances should be written for the zeroth, first and second moments of radicals and dead polymers.

The volume change during the reaction can be taken into account through a contraction factor, $\epsilon$, defined by Tulig and Tirrell (1981) as:

$$
\varepsilon=\frac{V(\chi=0)-V(\chi=1)}{V(\chi=0)}
$$

The volume at generic residence time $\tau$ can thus be written as shown in eq.(44). 


$$
V(\tau)=V_{0}(1-\epsilon \chi(\tau)) \cong V_{0, t o l}+V_{0, s t y}(1-\epsilon \chi(\tau))
$$

Similarly, the volumetric flow rate is:

$$
Q(\tau) \cong Q_{0, t o l}+Q_{0, s t y}(1-\epsilon \chi(\tau))
$$

From the kinetic mechanism written for solution polymerization in section 2.1.4, recalling eq.(9) and taking into account simplifications and the moments definition, the balance equations of each species can be deduced for styrene polymerization:

$$
\begin{gathered}
\frac{d\left(v_{z} c_{i}\right)}{d z}=r_{i} \\
v_{z}=Q_{A} \approx \frac{Q_{t o l_{0}}+Q_{s t y_{0}}(1-\epsilon \chi)}{A} \rightarrow d\left(v_{z}\right)=-\frac{Q_{s t y_{0}}}{A} \epsilon * d(\chi) \\
\rightarrow \frac{d\left(c_{i}\right)}{d z}=\frac{1}{v_{z}} r_{i}+\frac{1}{v_{z}} \frac{c_{i} Q_{s t y_{0}}}{A} \frac{d \chi}{d z}
\end{gathered}
$$

For the conversion, it is:

$$
\frac{d(\chi)}{d z}=-\frac{d\left(c_{s t y} V\right)}{n_{s t y_{0}} d z}=-\frac{V d\left(c_{s t y}\right)-c_{s t y} V_{s t y_{0}} \epsilon d(\chi)}{n_{s t y_{0}} d z}
$$

Rearranging, the equations become:

$$
\begin{gathered}
\frac{d\left(c_{\text {init }}\right)}{d z}=-\frac{1}{v_{z}} k_{d} c_{\text {init }}+\frac{1}{v_{z}} \frac{c_{\text {init }} Q_{s t y_{0}} \epsilon}{A} \frac{d \chi}{d z} \\
\frac{d\left(c_{s t y}\right)}{d z}=\frac{1}{v_{z}}\left[-2 f k_{d} c_{\text {init }}-\left(k_{p}+k_{t m}\right) c_{s t y} \lambda_{0}-k_{t i} c_{s t y}{ }^{3}\right]+\frac{1}{v_{z}} \frac{c_{s t y} Q_{s t y_{0}}}{A} \frac{d \chi}{d z} \\
\frac{d\left(c_{t o l}\right)}{d z}=\frac{1}{v_{z}}\left(-k_{t s} c_{t o l} \lambda_{0}\right)+\frac{1}{v_{z}} \frac{c_{t o l} Q_{s t y}}{A} \frac{d \chi}{d z} \\
\frac{d\left(\lambda_{1}\right)}{d z}=\frac{1}{v_{z}}\left[2 f k_{d} c_{\text {init }}+k_{p} c_{s t y} \lambda_{0}+\left(k_{t s} c_{t o l}+k_{t m} c_{s t y}\right)\left(\lambda_{0}-\lambda_{1}\right)+k_{t i} c_{s t y}{ }^{3}-k_{t} \lambda_{0} \lambda_{1}\right]+ \\
\frac{1}{v_{z}} \frac{\lambda_{1} Q_{s t y_{0}}}{A} \frac{d \chi}{d z}
\end{gathered}
$$




$$
\begin{gathered}
\frac{d\left(\lambda_{2}\right)}{d z}=\frac{1}{v_{z}}\left[2 f k_{d} c_{\text {init }}+k_{p} c_{s t y}\left(\lambda_{0}+2 \lambda_{1}\right)+\left(k_{t s} c_{t o l}+k_{t m} c_{s t y}\right)\left(\lambda_{0}-\lambda_{2}\right)+k_{t i} c_{s t y}{ }^{3}-\right. \\
k t \lambda 0 \lambda 1+1 v z \lambda 2 Q s t y 0 \epsilon A d \chi d z \\
\frac{d\left(\mu_{0}\right)}{d z}=\frac{1}{v_{z}}\left[\left(k_{t s} c_{t o l}+k_{t m} c_{s t y}\right) \lambda_{0}+k_{t} \frac{\lambda_{0}^{2}}{2}\right]+\frac{1}{v_{z}} \frac{\mu_{0} Q_{s t y_{0}} \epsilon}{A} \frac{d \chi}{d z} \\
\frac{d\left(\mu_{1}\right)}{d z}=\frac{1}{v_{z}}\left[\left(k_{t s} c_{t o l}+k_{t m} c_{s t y}\right) \lambda_{1}+k_{t} \lambda_{0} \lambda_{1}\right]+\frac{1}{v_{z}} \frac{\mu_{1} Q_{s t y_{0}} \epsilon}{A} \frac{d \chi}{d z} \\
\frac{d\left(\mu_{2}\right)}{d z}=\frac{1}{v_{z}}\left[\left(k_{t s} c_{t o l}+k_{t m} c_{s t y}\right) \lambda_{2}+k_{t}\left(\lambda_{1}{ }^{2}+\lambda_{0} \lambda_{2}\right)\right]+\frac{1}{v_{z}} \frac{\mu_{2} Q_{s t y_{0}}}{A} \frac{d \chi}{d z} \\
\frac{d(\chi)}{d z}=-\frac{v}{n_{s t y_{0}-V_{s t y} c_{s t y} \epsilon}} \frac{d c_{s t y}}{d z}
\end{gathered}
$$

The expression for volume $V$ can be obtained from eq.(46).

The kinetic constants for styrene polymerization are presented in Table 1 and are taken from the work by Cabral et al. (2004).

Table 1 - Kinetic constants of styrene polymerization

\begin{tabular}{ccccc}
\hline Step & Symbol & Unit & Equation & Reference \\
\hline $\begin{array}{c}\text { Thermal Initiation } \\
\text { Initiation with initiator }\end{array}$ & $\mathrm{k}_{\mathrm{ti}}$ & $\mathrm{m}^{6} / \mathrm{kgmol}^{2} / \mathrm{s}$ & $1.99 \mathrm{E}+06 \mathrm{exp}(-14842 / \mathrm{T})$ & Cutter\&Drexler(1982) \\
$\begin{array}{c}\text { Propagation } \\
\mathrm{k}_{\mathrm{i}}\end{array}$ & $\mathrm{k}_{\mathrm{p}}$ & $\mathrm{m} / \mathrm{s} / \mathrm{kgmol} / \mathrm{s}$ & $1.051 \mathrm{E}+07 \mathrm{exp}(-3577 / \mathrm{T})$ & Hui\&Hamielec(1972) \\
$\begin{array}{c}\text { Chain transfer to solvent } \\
\begin{array}{c}\text { Chain transfer to } \\
\text { monomer }\end{array}\end{array}$ & $\mathrm{k}_{\mathrm{ts}}$ & $\mathrm{m}^{3} / \mathrm{kgmol} / \mathrm{s}$ & $7 \mathrm{E}-05 \mathrm{k}_{\mathrm{p}}$ & Brandrup\&Immergut(1989) \\
$\begin{array}{c}\text { Termination by } \\
\text { combination }\end{array}$ & $\mathrm{k}_{\mathrm{tm}}$ & $\mathrm{m}^{3} / \mathrm{kgmol} / \mathrm{s}$ & $1.2 \mathrm{E}-05 \mathrm{k}_{\mathrm{p}}$ & Brandrup\&Immergut(1989) \\
& $\mathrm{k}_{\mathrm{tc}}$ & $\mathrm{m}^{3} / \mathrm{kgmol} / \mathrm{s}$ & $1.255 \mathrm{E}+09 \exp (-844 / \mathrm{T})$ & Hui\&Hamielec(1972) \\
\hline
\end{tabular}

Source: Cabral et al. (2004)

\subsubsection{Physical parameters of reactants}

In the previous mass balances, data about density, molecular weight and viscosity are necessary to describe the polymerization system. The following values were 
taken from chemical tables; the density variation with temperature was reported by Stevens $^{2}$ (1988, apud Fontoura et al., 2002).

Table 2 - Styrene properties

\begin{tabular}{ccccc}
\hline MW [g/mol] & $\begin{array}{c}\text { Density @ } \\
20^{\circ} \mathbf{C}[\mathrm{kg} / \mathrm{m} 3]\end{array}$ & $\begin{array}{c}\text { Density function } \\
{[\mathrm{kg} / \mathrm{m3}]}\end{array}$ & $\begin{array}{c}\text { Viscosity @20 } \\
{[\mathrm{cP}]}\end{array}$ & $\begin{array}{c}\text { Diffusivity } \\
{[\mathrm{m} 2 / \mathbf{s}]}\end{array}$ \\
\hline 104.15 & 0.906 & $\rho=\frac{1000}{(0.8075+0.001 T)}$ & 0.76 & About $2^{*} 10^{-9}$ \\
\hline
\end{tabular}

Source: Brandrup and Immergut (1989); Stevens (1988, apud Fontoura et al., 2002)

Table 3 - Toluene properties

\begin{tabular}{cccc}
\hline MW [g/mol] & Density @20 ${ }^{\circ} \mathrm{C}[\mathrm{kg} / \mathrm{m3}]$ & $\begin{array}{c}\text { Density function } \\
{[\mathrm{kg} / \mathrm{m3}]}\end{array}$ & Viscosity @20 \\
\hline 92.14 & 0.867 & $\rho=\frac{1000}{(1.047+0.00049 T)}$ & 0.59 \\
\hline
\end{tabular}

Source: Brandrup and Immergut (1989); Stevens (1988, apud Fontoura et al., 2002)

Table 4 - Polystyrene properties

\begin{tabular}{cc}
\hline Density $[\mathrm{kg} / \mathrm{m} 3]$ & Diffusivity [m2/s] \\
\hline $1.04-1.65$ & About $10^{-9}$ \\
\hline
\end{tabular}

Source: Brandrup and Immergut (1989)

\subsection{A general view on micro or millireactors}

Teuschel (2001, p.87) defines the principles of microsystem technology as those "[...] based on the optimization of processes in order to gain maximum outcome with a minimum of invested expenditure".

Jänisch et al. (2004) make a description of microstructured reactors as devices with three-dimensional structures, whose inner dimensions are under a millimeter in size, and more specifically between ten and a hundred micrometers.

Since the reactor used for the present work has an internal diameter of 500 micrometers, it could be more appropriate to introduce a new category in which to ideally classify the Syrris Asia reactor: mesoreactors or millireactors. Werner; Ceylan and Kirschning (2011) thereby define reactors presenting internal diameters between $500 \mu \mathrm{m}$ and a few $\mathrm{mm}$. Millireactors have smaller surface to volume ratios $(S / V=100$ -

\footnotetext{
${ }^{2}$ STEVENS, C. J. Mathematical Modeling of Bulk and Solution Free-Radical Polymerization in Tabular Reactors; Ph.D. Thesis; University of Wisconsin, Madison, 1988.
} 
$10,000 \mathrm{~m}^{2} / \mathrm{m}^{3}$ ) but can present advantages compared to microfluidic ones. In fact, although providing lower heat transfer surface and poorer heat transfer capabilities, they show improved flow capacities (which means higher productivity), lower pressure drops, lower tendency to block and allow working with packed bed reactors.

\subsubsection{Advantages of micro and millireactors}

Thanks to their special geometry, microreactors have interesting features:

- Reactor volume

Process parameters such as pressure, temperature, residence time and flow rate are more easily controlled in reactions that take place in small volumes (JÄNISCH et al., 2004). With these small volumes (JENSEN, 2001), a microreactor failure would not be so dangerous, because the small quantity of chemicals released accidentally is easily containable.

\section{- Specific surface area}

For the reactor volumes mentioned above, Jänisch et al. (2004) calculated that microstructured reactors have very high inner surface to volume ratios $(5,000-50,000$ $\mathrm{m}^{2} / \mathrm{m}^{3}$ ), whilst larger reactors typically only have a surface area of approximately 100 $\mathrm{m}^{2} / \mathrm{m}^{3}$.

\section{- Specific phase interface}

Depending on the dimensions, flow type and process parameters, multiphase flows in microchannels exhibit specific interfaces from approximately 5,000 to 50,000 $\mathrm{m}^{2} / \mathrm{m}^{3}$ for liquid-liquid mixtures. Their respective values for gas-liquid mixtures are slightly lower (maximum values of over $20,000 \mathrm{~m}^{2} / \mathrm{m}^{3}$ have been determined for a falling-film microreactor). Many conventional apparatus for corresponding applications achieve only limited interfaces, approximately $100 \mathrm{~m}^{2} / \mathrm{m}^{3}$, while conventional special apparatus (impinging jet reactors for gas-liquid contacting) achieve approximately $2,000 \mathrm{~m}^{2} / \mathrm{m}^{3}$ (JÄNISCH et al., 2004).

- Film thickness

Film thicknesses of $\approx 25 \mu \mathrm{m}$ have been measured in falling films running through microchannels. These are approximately by a factor of ten smaller than for macroscopic falling-film reactors. Even thinner films can exist between Taylor 
bubbles and channel walls in gas-liquid slug flow, as in the case of annular flows with same-fluid mixtures (JÄNISCH et al., 2004).

\section{- Mixing time}

In optimized mixers, typical mixing times for liquid mixtures amount to less than 1 second. In some cases, millisecond mixing times have also been proved. This is faster than most conventional stirrers, which have mixing times from one up to several tens of seconds (JÄNISCH et al., 2004).

In microreactors, small Reynolds numbers and laminar flows lead to a mixing which occurs by diffusion. In many micromixers, which are important parts of microreactors, the reactant flow is split into many lamination segments to increase the contact area and to reduce diffusion lengths, thus the influence of mass transport on the speed of a reaction can be considerably reduced, enabling the extraction of chemical kinetic parameters from sensor data (JENSEN, 2001).

\section{- Laminar flow}

In most cases, microreactors present laminar flow and thus back mixing is suppressed, which helps to avoid side reactions. Illg; Löb and Hessel (2010) pointed out how regular flow patterns for multiphase flow can be generated in such channel dimensions. In segmented flow, each segment behaves as a single reactor and, due to internal circulations, an enhancement in mass transfer can be achieved.

Table 5 - Differences between processes in microreactors and conventional reactors

\begin{tabular}{|c|c|c|c|}
\hline & Microreactors & $\begin{array}{l}\text { Conventional } \\
\text { reactors }\end{array}$ & $\begin{array}{l}\text { Consequence/benefits } \\
\text { of the microreactor }\end{array}$ \\
\hline Flow regimes & Laminar & Turbulent & Different hydrodynamic effects \\
\hline Diffusion paths & Very short & $\begin{array}{l}\text { Longer as in the } \\
\text { microreactors }\end{array}$ & $\begin{array}{l}\text { Ideal for heat transfer- or mass } \\
\text { transfer-limited reactions }\end{array}$ \\
\hline $\begin{array}{l}\text { Surface area-to- } \\
\text { volume ratio }\end{array}$ & Very high & $\begin{array}{l}\text { Lower as in } \\
\text { microreactors }\end{array}$ & $\begin{array}{l}\text { Surface effects dominate over the } \\
\text { volumetric effects }\end{array}$ \\
\hline Mixing & $\begin{array}{l}\text { Proceeds in } \\
\text { milliseconds }\end{array}$ & $\begin{array}{l}\text { Much slower than } \\
\text { in microreactors }\end{array}$ & Higher mass transfer coefficient \\
\hline $\begin{array}{l}\text { Part of solid wall } \\
\text { material }\end{array}$ & Very high & $\begin{array}{l}\text { Lower as in } \\
\text { microreactors }\end{array}$ & Higher heat transfer coefficient \\
\hline
\end{tabular}

Source: Reschetilowski (2013)

Microreactors small dimensions have strong consequences on heat transfer, mass transfer and fluid dynamic inside the reactor:

- Jänisch et al. (2004) stated that very high heat-transfer coefficients of up to $25,000 \mathrm{~W} / \mathrm{m}^{2} \mathrm{~K}$ were measured in micro heat-exchangers for liquid flows, that 
means 10-100 times that of macroreactors; the same is true for gas heat exchange (several hundreds of $\mathrm{W} / \mathrm{m}^{2} \mathrm{~K}$ for microchannels). This implies that reactions can be performed under more uniform temperature conditions, guaranteeing isothermal conditions, too.

- You-qi (2008) calculated that volumetric mass transfer coefficients are enhanced ( $K_{c} a$, with $K_{c}$ film coefficient and $a$ surface to volume ratio), being 10 100 times those of macroreactors. Without turbulence, the massive flux is ruled by Fick's law.

- Small dimensions imply laminar flow, with parabolic velocity profiles. Pressure drops turn linearly proportional to velocity, but increase with the decrease of diameter. Against these increases, flow may be split into multiple channels, so that the effective cross-sectional area is large, but pressure drops reduce while maintaining high surface to volume ratios.

$\mathrm{Ni}$ (2006) observed that the parabolic velocity profile typical of laminar flow would mean the presence of a velocity gradient along the radial direction, causing different residence times in the tube and thus affecting conversions, too. A tubular reactor that can achieve plug flow under laminar flow conditions (thanks to good radial mixing) would match all the advantages that these two hydraulic conditions have: lower pressure drops, mixing by diffusion, no backmixing and uniform residence time.

Figure 5 - Influence of the microfluidic reactor geometry on hydrodynamics, thermal and mass transfer

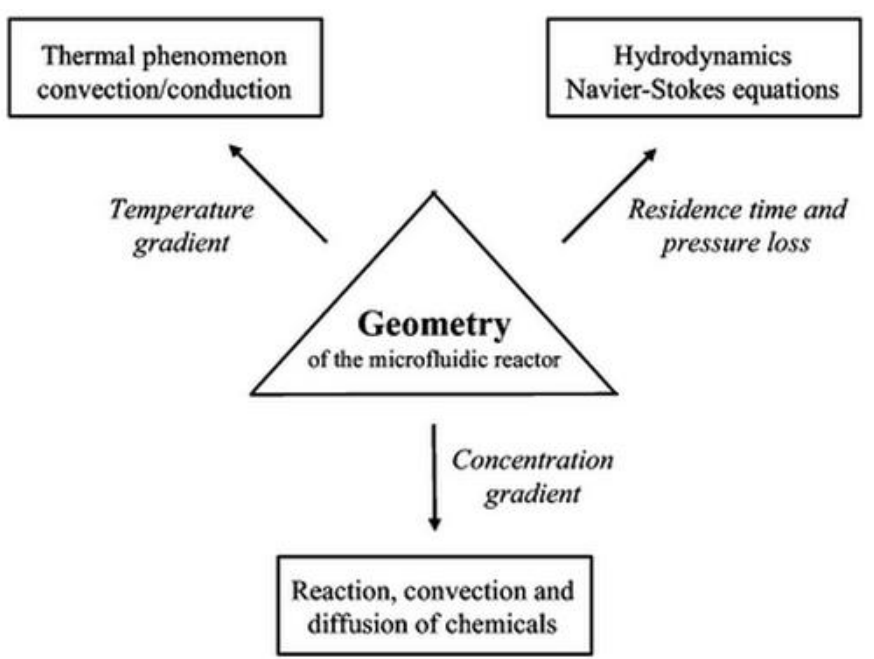

Source: Serra et al. (2005) 


\subsubsection{Dimensionless numbers in microspace}

Two dimensionless parameters, the Reynolds number $(R e)$ and the Péclet number $(P e)$, are commonly used to characterize mixing in microfluidic systems. Other two useful dimensionless numbers are the Fourier number $(F o)$ and the Bodenstein number $(B o)$. When analyzing the physical properties of microsystems, it is helpful to introduce the concept of scaling law, which expresses the variation of these quantities with the size $l$ of the system in object (BRUUS, 2008). If $l$ is at numerator, the smaller the characteristic length, the greater the reduction of the dimensionless quantity is, and vice versa.

- Reynolds number

The Reynolds number represents the ratio of convective to viscous forces:

$$
R e=\frac{\rho v l}{\mu}
$$

where $\rho$ is the fluid density, $v$ its mean velocity, $l$ the tube diameter and $\mu$ the dynamic viscosity.

- Péclet number

The Péclet number represents the ratio of mass transport due to convection and that due to diffusion:

$$
P e=\frac{l v}{\mathcal{D}}
$$

$l$ is the tube diameter, $v$ the fluid mean velocity and $\mathcal{D}$ the diffusivity coefficient.

Convective transport dominates in larger scale systems, which reduces mixing when flow remains laminar. In microscale, it is fundamental to work with low $P e$, that is high diffusion coefficients; in these conditions, the PDI goes near the minimum theoretical value of 1.5 (if only termination by combination occurs).

For laminar uniaxial flows, the mixing length $l_{m i x}$ is found to be proportional to $P e$ times the channel width (HESSEL et al., 2005).

- Fourier number

The Fourier number is the ratio between the average residence time and the diffusive mixing time: 


$$
F o=\frac{L / v}{l^{2} / \mathcal{D}}
$$

High Fo numbers mean good mixing in the reactor, that is, short diffusion times (HESSEL et al, 2005).

- Bodenstein number

Concerning back mixing, the introduction of a dimensionless number can be useful in order to represent the ratio between the axial dispersion time and the mean residence time, called the Bodenstein number:

$$
B o=\frac{t_{a x}}{\tau}=\frac{L^{2} / \mathcal{D}_{a x}}{\tau}
$$

with $\mathcal{D}_{a x}$ axial dispersion (correlated to molecular diffusion, as eq.(66) will show) and $\tau$ mean residence time. For $B 0>100$, axial dispersion can be neglected and plug flow can be assumed (KOCKMANN, 2007).

\subsubsection{Microreactors and deviations from the ideal plug flow model}

Starting from the plug flow model, there are different more complex models that can be applied to a tubular reactor, depending on the regime in which the reactor works. A first consideration to be made is that microreactors are expected to have low $R e$ numbers. Taylor $^{3}$ (1953, apud BISCHOFF; LEVENSPIEL, 1962) was the first to relate laminar flow in empty tubes, with dispersion due to molecular diffusion and radial velocity variations, to a flow with a flat velocity profile equal to the mean velocity and with an effective axial coefficient. Aris ${ }^{4}$ (1956, apud BISCHOFF; LEVENSPIEL, 1962), later on, showed that axial molecular diffusion is an additive effect to this coefficient; he also generalized this treatment by including all type of velocity distributions and any vessel geometry. This dependence is expressed by the numerical constant present in the axial dispersion formula, as shown later in eq.(66). Figure 6 is a model chart reported by Levenspiel (1999), which is a precious reference for the choice of the model of a tubular reactor in laminar flow regime.

\footnotetext{
${ }^{3}$ TAYLOR, G.I. Dispersion of Soluble Matter in Solvent Flowing Slowly through a Tube. Proc. R. Soc. Lond. A, v. 219, n. 1137, p. 186-203, 1953.

${ }^{4}$ ARIS, R. On the Dispersion of Soluble Matter in Solvent Flowing Slowly through a Tube. Proc. R. Soc. Lond. A, v. 235, p. 67-77, 1956.
} 
However, as Levenspiel says, "the sharpest way of experimentally distinguishing between models comes by noting how a pulse or sloppy input pulse of tracer spreads as it moves downstream in a flow channel" (LEVENSPIEL, 1999, p. 341). In effect, the more accurate estimation of the dispersion coefficient inside a tubular reactor is done by tracer injection.

Figure 6 - Map showing which flow models should be used in any situation

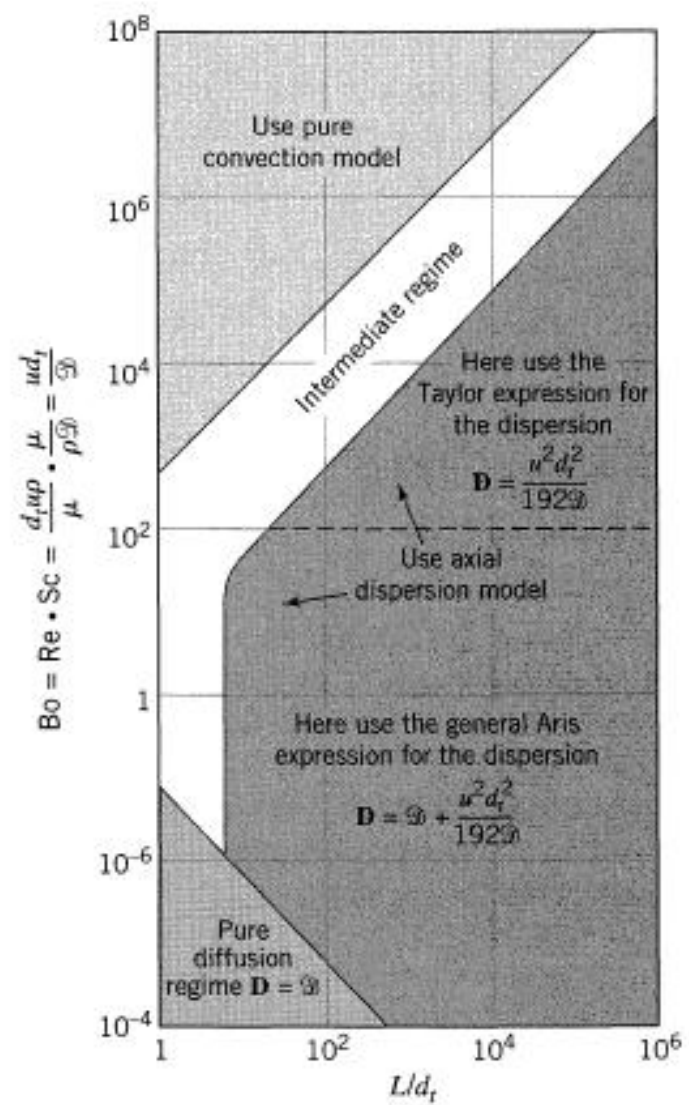

Source: Levenspiel, 1999

According to the author, for laminar flow in short tubes or laminar flow of viscous materials, the dispersion model may not apply, and it may be that the parabolic velocity profile is the main cause of deviation from plug flow. This situation is called the pure convection model and it represents, in effect, the behavior of high viscous fluids, with parabolic velocity profiles. 
Figure 7 - Comparison of the RTD of the pure diffusion model, the pure convection model and the dispersion model

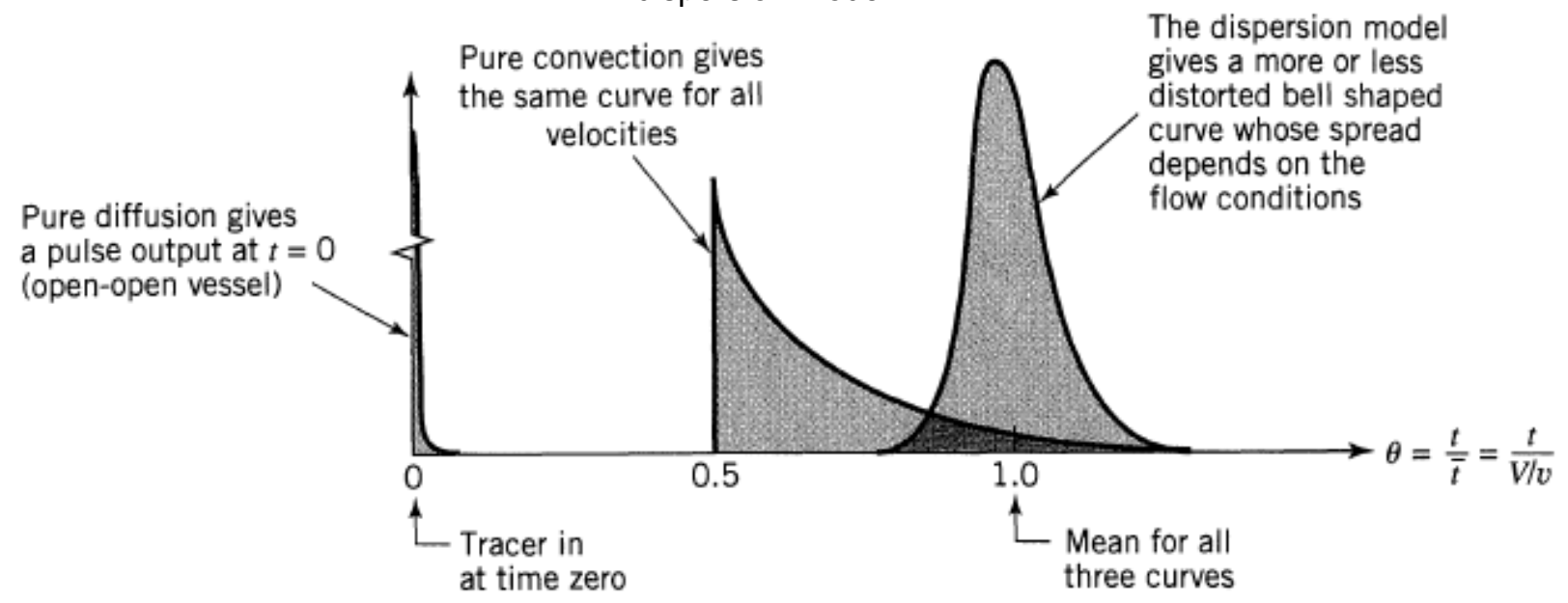

Source: Lievenspiel (1999)

In the pure convection regime (negligible molecular diffusion) each element of fluid follows its own streamline with no intermixing with neighboring elements, giving macrofluid behavior.

Convective flow lowers conversion compared to plug flow, as shown in Figure 8.

Figure 8 - Comparison between convection model and plug flow model

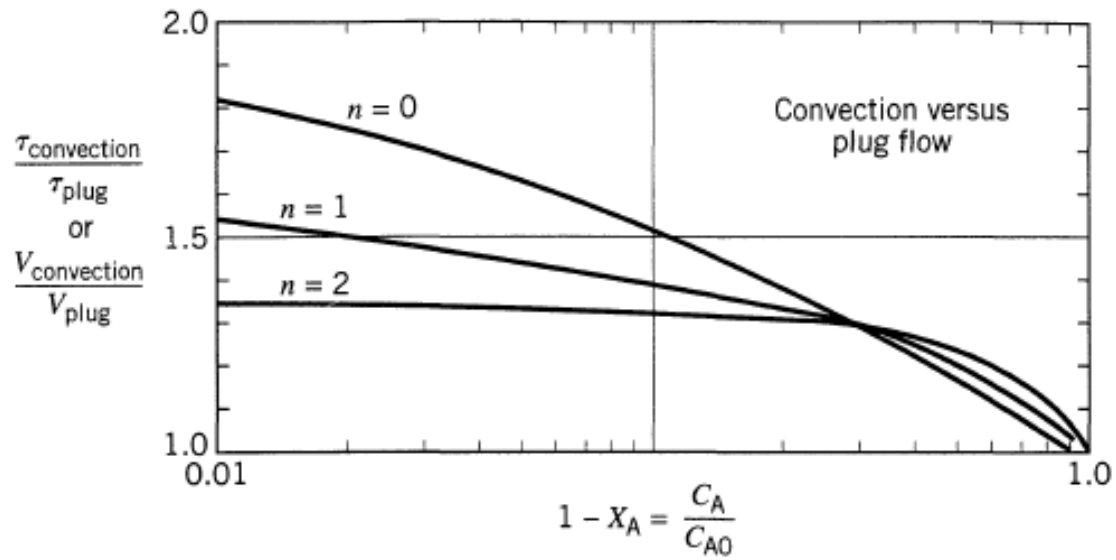

Source: Levenspiel (1999), p.347

Aris $^{5}$ (1965, apud LEVIEN; LEVENSPIEL, 1999) presented a plot of the ratio of conversion from a Newtonian laminar flow reactor (NFR) to that from a PFR, as a function of the Damköhler number. He aimed to evaluate the effect of nonuniform residence times with respect to a plug flow reactor, for first- and second-order reactions. His conclusion was that, since this ratio was always greater than 0.88 , the loss of conversion due to nonuniform residence times was at most $12 \%$ of what could

\footnotetext{
${ }^{5}$ ARIS, R. Introduction to the analysis of chemical reactors. Englewood Cliffs, NJ: Prentice-Hall., 1965. $337 \mathrm{p}$.
} 
be achieved if the fluid was in plug flow. That is, if the convective model was representative of the fluid dynamics of the millireactor in study, it may justify conversions that are at most $12 \%$ lower than the plug flow model would give.

Going back to Figure 6, the chart indicates what regime the reactor is working in and which model to use, given the fluid characteristics (Schmidt number), the flow conditions (Reynolds number), and vessel geometry $\left(L / d_{t}\right)$.

Considering the concept of scaling law of section 2.2.2, millireactors are supposed to work with low $R e$, high $B o$ and high $L / d_{t}$ ratio (given a small tube diameter); thus their operation appears to be located in the axial dispersion regime for most of the cases (see Figure 6); for the greatest Bodenstein numbers, these devices may enter the "intermediate regime", or the pure convective model.

The axial dispersion model, however, seems to be the more suitable choice for a millireactor: Nagy et al. (2012) verified that systems with a Bo>100 have small deviations from plug flow; if $B 0>1000$, they can be approximated as having plug flow behavior. In their work with $500 \mu \mathrm{m}$ diameter capillary tubes, they observed a plug flow behavior at residence times $>20$ min.

In a similar way, Hornung and Mackley (2009) state that in slowly flowing systems with small channel diameters, molecular diffusion effects occur, giving a beneficial influence on the RTD, as it results in a narrower distribution than expected from the parabolic velocity profile associated with laminar flow. RTD experiments on their capillary reactor of $230 \mu \mathrm{m}$ confirmed a behavior close to plug flow.

To take into account these effects of both axial and radial diffusion occurring, Taylor in 1953 introduced an effective diffusion coefficient, defined as:

$$
D_{a x}=D_{m o l}+\frac{d_{t}^{2} v_{z}^{2}}{192 D_{m o l}}
$$

Where $D_{m o l}$ is the molecular diffusion coefficient, $v_{z}$ the medium axial velocity, and $d_{t}$ the reactor diameter.

Considering:

$$
v_{z}=\frac{4 Q}{\pi d_{t}^{2}}
$$

where $Q$ is the volumetric flow imposed to the reactor; using the Levenspiel's notation for other two adimensional numbers: 


$$
\begin{aligned}
& \frac{D_{a x}}{v_{z} d_{t}}=\text { intensity of axial dispersion } \\
& \frac{D_{a x}}{v_{z} L}=\text { vessel dispersion number }
\end{aligned}
$$

that indicate the ratio between movement by longitudinal dispersion and movement by bulk flow, it is possible to evaluate the degree of dispersion inside a tubular reactor. These calculations will be necessary to verify the hypothesis made on the reactor fluid dynamics.

\subsubsection{Considerations about other tubular reactors models}

Lynn and Huff (1971) modeled a tubular polymerization reactor by considering the following fluid dynamic evolving along the tube: in a first moment, the homogeneous solution of monomer, initiator and solvent develops a radial concentration gradient because the material in the center moves faster than the material near the wall, reacting for less time. Thus, the most of polymer forms near the walls, causing an even slower flow in this region and a velocity profile that departs even more from the parabolic type. When the monomer content finishes in this layer, while reaction proceeds in the center, the viscosity gradient decreases and the velocity profile turns to be parabolic again. The authors simulated this behavior for four tubular reactors, with an i.d. ranging from 0.742 in up to 18 in. However, experiments were not performed in order to validate the model. Surely, a parabolic or distorted velocity profile would justify the fact of obtaining lower conversions than those predicted from a plug flow model. In fact, the quantity of fluid exiting the reactor in less time than the average residence time would not compensate the fluid that remains longer in the reactor. Moreover this type of profile, creating a radial concentration gradient, would make polymer chains grow with different lengths, thus raising the polydispersity index.

Chen and Nauman (1989) modeled a tubular polymerization reactor with the hypotheses of steady state laminar flow, with viscosity and velocity varying both radially and axially. The simulated reactor had a $0.011 \mathrm{~m}$ diameter and showed (for a bulk polymerization) a behavior analogous to Lynn and Huff's (1971) model. The axial velocity profile and its deviation from the initial parabolic distribution had a substantial effect on the residence time distribution. RTD experiments were 
performed by the authors in a $0.011 \mathrm{~m}$ i.d. tube reactor, with reactive styrene as the process fluid; the measured washout function confirmed the presence of velocity profile elongation for that type of reactor.

However, the aforementioned examples, even if referred to tubular reactors, may not suit to the Asia millireactor; the change of fluid dynamic behavior from macroscale to microscale, as well as its degree of mixing, might lie exactly in this length region.

\subsubsection{Considerations about micromixing and the dispersion model}

The fact of tubular reactors giving molecular weight distributions broader than would be expected for perfect radial mixing (like an ideal plug flow regime) can be attributed to the gel effect, as well as to segregation (NAUMAN, 1976). Segregation is one of the two opposite conditions of micromixing inside a reactor. Nauman (1976) explains the difference between macromixing and micromixing as the former referring to those gross flow processes which cause different fluid elements to have different residence times; the latter is molecular scale mixing. If there is no molecular scale mixing, the reactor is completely segregated and it can be modeled as a PFR with multiple exits; the opposite condition of maximum mixedness can be seen as a PFR with multiple side entrances. There are various ways to composite macro/micromixing model: treating the system as two reactors in parallel, or in series, supposing reactants entering well mixed and then becoming segregated as viscosities increase. For polymerization reactors, it seems that micromixing would have no influence in conversion, but it has on molecular weight distribution, in which segregation would increase PDI with respect to ideal plug flow (NAUMAN, 1976).

However, the fact of having laminar flow conditions does not prevent using the plug flow model, or a more complex one such as the axial dispersion model, as suggested in Figure 6. In fact, as explained by Wissler (1969), in a tubular reactor there are two different times characterizing transport of material: the time required for diffusion to materially reduce radial concentration gradients $\left(\sim d_{t}^{2} / D\right)$ and that required to transport material along distance $L$ at the mean velocity of the stream $(\sim L / v)$. A third characteristic time can be recognized for the reacting system, that is typical 
polymerization time. As $\operatorname{Taylor}^{6}$ (1953, apud AL-HENGARI, 2011) pointed out, if the ratio between the diffusional time and the convective time is relatively small, radial diffusion is rapid enough to overcome axial dispersion due to the parabolic velocity profile. Thus, this model also justifies a non-turbulent fluid dynamic. Besides, the dispersion model can somehow include micromixing effects in its coefficient; it is directly related to molecular diffusion, responsible for eliminating the regions of segregation of the fluid more or less efficiently (AL-HENGARI, 2011).

As Kiparissides (1996) states, the molecular properties of the polymer produced in continuous polymerization reactors are strongly dependent on both the macroscopic mixing of different volume elements (e.g. residence time distribution) and microscopic molecular scale mixing (e.g. the state of fluid aggregation). Biesenberger and Sebastian (1983) calculated the effects of macro- and micromixing on the polydispersity index of polymer produced by free-radical polymerization, shown in Figure 9.

Figure 9 - Polydispersity index as a function of monomer conversion for a free-radical polymerization

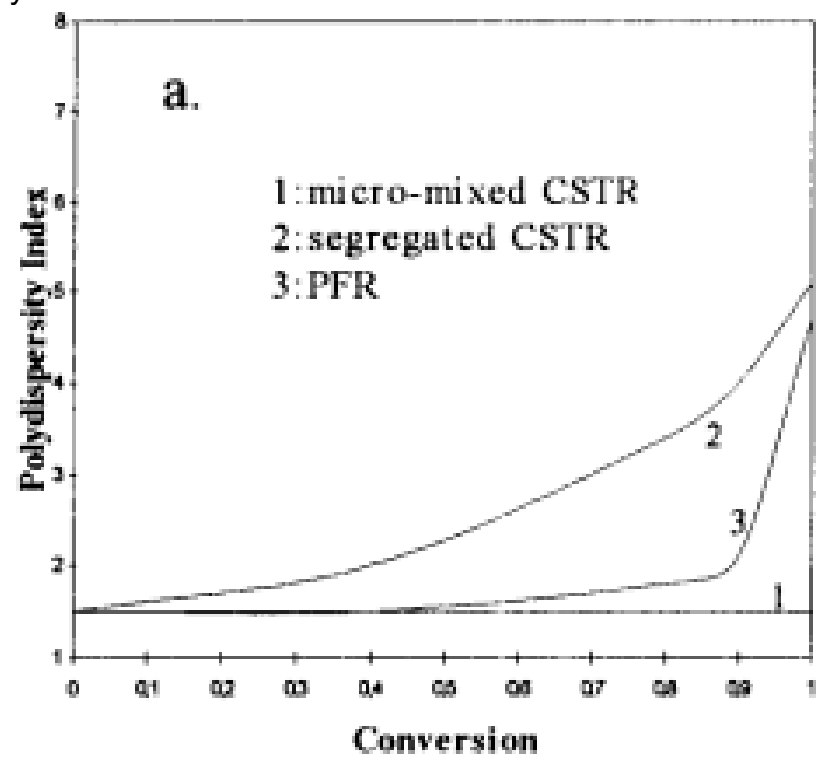

Source: Biesenberger and Sebastian (1983, apud Kiparessides, 2009)

As can be seen from Figure 9, the PDI rises with conversion and when the reactor behavior departs from the ideal plug flow; this means that molecular weights are sensitive to the degree of mixedness, which lowers when there are a lot of polymer chains.

\footnotetext{
${ }^{6}$ TAYLOR, G.I. Dispersion of Soluble Matter in Solvent Flowing Slowly through a Tube. Proc. R. Soc. Lond. A, v. 219, n. 1137, p. 186-203, 1953.
} 


\subsubsection{Considering the micromixing degree by an effective axial dispersion coefficient}

As discussed in section 2.2.3, the most recent works about fluid dynamic in microreactors agreed in adopting the axial dispersion model for these devices (HORNUNG; MACKLEY, 2009; NAGY et al., 2012). However, the model may result inefficient due to the dispersion coefficient evaluation as shown in eq.(66). One reason could be the fact of considering the fluid as Newtonian. As reported by Fan and Hwang (1965), in case of an Ostwald-de Waele fluid (or power low fluid), the axial dispersion coefficient is correctly expressed by eq.(70):

$$
D_{a x}=\frac{1}{8(n+3)(n+5)} \frac{\left(d_{t} v_{z}\right)^{2}}{D_{m o l}}
$$

However, changes in the value of the dispersion coefficient could be also due to different mixing efficiency at molecular scale (AL-HENGARI, 2011). An "effective dispersion coefficient" can thus be introduced, which depends on the efficiency of micromixing polymer chains and monomer units. This parameter, which should better represent the experimental values of conversion and molecular weights, can also be associated to the "millireactor mixing time". This time value will thus depend either on the geometric characteristics of the specific millireactor, in which the reaction is occurring, and on the particular polymerization conditions inside it. The lower the time, the better the micromixing is inside the reactor. 


\section{Chapter 3 LITERATURE REVIEW}

\subsection{Solution styrene polymerization in tubular reactors}

Enright and Cunningham (2005) performed the polystyrene reaction both in a batch and a tubular reactor, in order to compare the two systems. It resulted that the reaction rate was almost identical for the batch and continuous reactors throughout most of the reaction; this confirmed the analogy existing between the two reactors (associating time and residence time). Conversion was slightly lower in the continuous reactor at the end of the reaction: this was probably caused by axial mixing within the tube during the experiment. Under perfect plug flow conditions, in fact, a tubular reactor should give the same conversion as a batch reactor within the same reaction time conditions.

\subsubsection{Solution polymerization}

Examples of using tubular reactors in polymerizations can be found in solution polymerizations: the presence of solvent, in fact, reduces the probability for tubes to be plugged. Depending on the conversion level desired, the solvent content could influence the kinetics of the reaction (because of the interaction between active radicals and common organic solvents), restricting the yield of the product; the transfer-to-solvent effect can also decrease the polymer final molecular weight.

Portillo (2011) remarks that other factors must be taken into account in this type of reaction, such as the solubility of the polymer in solvent, the facility of separation of the final product, the purity of the products and the toxic effect of residuals.

Fontoura et al. (2003) state that solution polymerization is widely used for the production of polymer resins. In this case the catalyst, the monomer, and the polymer are all soluble in the reaction medium, leading to the formation of a homogeneous reacting mixture. The main disadvantages of solution processes are the low rate of heat removal, but the operation is much simpler than in heterogeneous processes. For this reason, reactions can be performed in batch, semicontinuous and continuous operation modes, providing a wider choice of reactor configurations. On the other hand, the reaction rates are lower (because of the dilution) and the average molecular weights obtained are smaller than those from bulk and emulsion 
polymerizations. The author concludes that the main challenges in controlling solution polymerization processes are the control of the average molecular weight, of the molecular weight distribution curve, of the monomer conversion and of the copolymer composition in case of copolymerizations.

\subsection{Examples of tubular millireactors for styrene polymerization}

All the characteristics of microreactors already discussed turn these devices suitable for polymerization processes. However, microreaction technology became an area of interest for polymer chemistry only in the late nineties, due to the challenges arising from high viscosities of polymer solutions and melts (HESSEL et al. ${ }^{7}, 2005$, apud WILMS; KLOS; FREY, 2008).

The first investigation to report the advantages of microreaction technology in polymer reaction engineering applications was made by Bayer, Pysall and Wachsen ${ }^{8}$ (2000, apud PORTILLO, 2011). They noticed a reduction in the distribution of molecular weights during the solution polymerization of acrylates such as polymethyl methacrylate (PMMA) and polyacrylic acid (PAA), without fouling of the tubular reactor.

However, polymerization in continuous flow-type processes dates back to the early 1960s and, since then, various experiments have been made in tubular reactors of small diameters. The works that will be presented in the next sections are directly related to styrene polymerizations performed in reactors of such characteristics.

\subsubsection{Wallis, Ritter and Andre's work, 1975}

These authors made an experimental analysis of the tubular reactor for mass polystyrene production. The process was made up of a tank reactor for prepolymerization, followed by a tube to complete the reaction $(6 \mathrm{~m}$ length, 1 in diameter). They obtained up to $32.1 \%$ conversion and weight average molecular weights in the range of 80,000 to $140,000 \mathrm{~g} / \mathrm{mol}$. Their conclusions were that such a configuration could produce polystyrene with industrial quality.

\footnotetext{
${ }^{7}$ HESSEL,V.; SERRA, C.; LÖWE, H., HADZIIOANNOU, G. Chem. Ing. Tech., v. 77, p. 1693, 2005.

${ }^{8}$ BAYER, T.; PYSALL, D.; WACHSEN, O. Micro mixing effects in continuous radical polymerization. Paper presented at the 3rd International Conference on Microreaction Technology IMRET 3, Berlin, 2000.
} 


\subsubsection{Mass and Tomkinsn's work, 1977}

The work by Mass and Tomkinsn (1977) started from considering that in many instances, in the preparation of thermoplastic polymers, it is desired to carry out the polymerization at a temperature below the melting temperature of the polymer. This condition causes a gradual growth of polymer on the inner walls (reducing the heat transfer and the effective volume of the reactor), a decrease in conversion and an increase in pressure drop, eventually leading to the reactor clogging.

The benefits of tubular reactors were reached by using a method for performing a solution polymerization, helping the fact that in certain instances the polymerization was carried out at a temperature below the melting one. The monomer was fed intermittently, while back mixing could be increased by the use of flow invertors.

Their reactor consisted of four sections of stainless steel tubing 7 feet long. The tubing had an inside diameter of 0.315 in; each section of the tubing had an oilheated jacket maintained at temperatures of $140-145{ }^{\circ} \mathrm{C}$. The four sections were connected in series and were preceded by a similar stainless steel tubing which was unheated, where the reactants could mix by diffusion.

The reactor was immediately filled with benzene and the styrene-benzene mixture was intermittently pumped to the mixing zone with n-butyl lithium as initiator, alternating periods of flow and no flow.

With this method, polystyrenes with molecular weights of about $10^{5}-6^{*} 10^{5}$ Da were prepared without plugging or fouling.

\subsubsection{Serra et al.'s work, 2005}

Serra et al. (2005) studied by means of CFD the free-radical polymerization of styrene in two multilaminated microreactors and in a conventional T-junction microreactor. They obtained almost isothermal conditions in their simulations and found that a low PDI (i.e. <2.5) can be maintained for a larger range of diffusion coefficients of the chemical species $\left(10^{-11}-10^{-8} \mathrm{~m}^{2} / \mathrm{s}\right)$ when the microreactor radius is lower than $\sim 0.25 \mathrm{~mm}$. They verified that the smaller the characteristic width of the microreactor, the lower is the diffusion coefficient for which the sharp increase in PDI is observed. This practically means that by using microreactors with characteristic width in the range of hundreds of micrometers rather than laboratory or industrial 
scale reactors, one can get a better control all over the polymerization despite the continuous increase in medium viscosity resulting from the monomer conversion.

\subsubsection{Iwasaki and Yoshida's work, 2005: no great advantages}

Iwasaki and Yoshida (2005) carried out different free radical polymerizations in microreactors of $0.5 \mathrm{~mm}$ of internal diameter and discussed the following results.

They used the reactor to polymerize styrene, comparing the data with other more exothermic polymerizations. The polymerization of styrene was much slower than the other ones, therefore it was considered to be the least exothermic. The PDI of the polymer obtained in the microreactor was similar to that obtained in the macroscale batch reactor, indicating that the heat removal ability of the reactor was not so important in this case. As a matter of fact, the effect of the microreactor on the molecular weight distribution control was found to be unappreciable.

Figure 10 - Microreactor system for polymerization; M1: T-shape micromixer, R1, R2, R3 microtube reactors

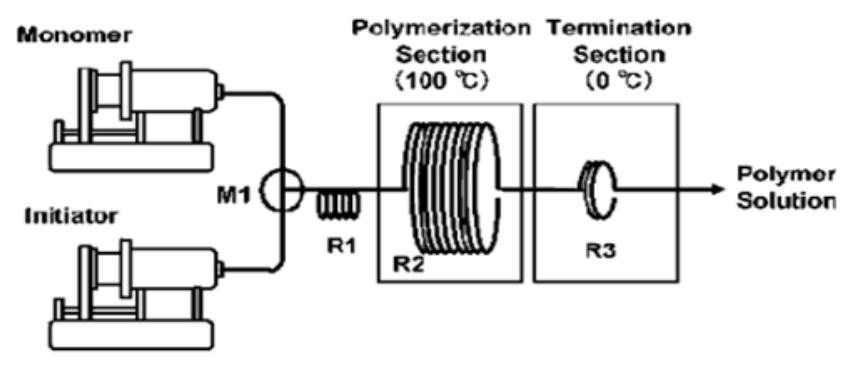

Source: Iwasaki and Yoshida (2005)

\subsubsection{Rosenfeld et al.'s work, 2007: good improvements}

Rosenfeld et al. (2007) carried out continuous TIPNO-mediated polymerizations (a type of living radical polymerizations) in toluene solution ( $25 \%$ volume) with $6.5 \mathrm{~mol} / \mathrm{l}$ of styrene; the reactor was a $900 \mu \mathrm{m}$ i.d. stainless steel tube reactor of $2.9 \mathrm{~m}$ length. The system was mantained under a minimum pressure of 20 bars, in order to keep all components liquid. The polymerization solution was injected into the microtube reactor with a piston pump at a variable flow rate. The microtube reactor was coiled around a stainless steel core and heated at $140^{\circ} \mathrm{C}$ with a heater collar.

It was observed that the kinetics of the polymerization were identical in batch and in the microtube reactors. Moreover, a linear increase of the molecular weights $(\mathrm{Mn})$ 
with conversion and a very good agreement with the theoretical predictions also occurred.

PDIs were the same in batch and in microtube reactors and were lower than 1.5 (this being possible for living radical polymerizations), which strongly suggested the controlled nature of the polymerization. There was a sharp increase in the PDI for the highest residence times: this little loss of control could result from an increasing percentage of dead chains from termination, and this assumption was confirmed since a bimodal distribution had been observed in the GPC. The discrepancy between the microreactor and the batch configuration increased as the exothermicity of the monomer increased. Indeed, in the case of styrene polymerization, it was observed no difference between batch and microtube reactors.

Figure 11 - Representation of the reactor configuration

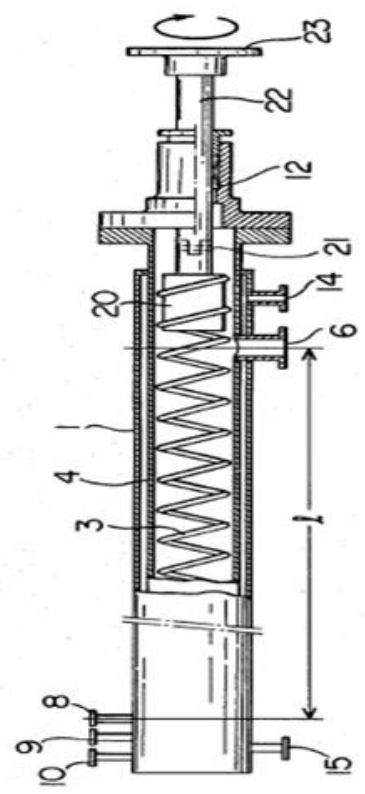

Source: Rosenfeld et al. (2007)

\subsubsection{Vianna's work, 2011: three different configurations}

Another example of exploration in the "millimetric range" was made by Vianna (2011), who studied three different tubular reactor configurations for free radical polymerization of styrene. He used tubes of $12 \mathrm{~m}$ length and 0.25 in of external diameter; the polymerization temperature varied between 70 and $85^{\circ} \mathrm{C}$.

As long as physical properties changed during the reaction, it was necessary to implement a model that took into account this fact. The first type of reactor used was 
an empty tube, already employed by Vega; Lima and Pinto (1997) and by Cabral ${ }^{9}$ (1998, apud VIANNA, 2011): experiments performed by Lynn (1977) had already shown that a layer of polymer would form near the wall, modifying its fluid dynamic (distorted velocity profiles) and heat transfer capacity. This is why the author analyzed other two configurations: one with a coiled steel component inside $(3 \mathrm{~mm}$ width), the other with an element of static mixing of $10 \mathrm{~cm}$ every meter of the reactor (discontinuous mixing). The idea of the last type of reactor was to simulate an intermittent mixing of the reacting fluid, reducing deformations of the velocity profiles and thus approximating the plug flow type.

The results obtained were very similar among the three reactors and can be summed up in Table 6.

Table 6 - Vianna's work results

\begin{tabular}{ccccc}
\hline $\mathbf{T}\left[{ }^{\circ} \mathbf{C}\right]$ & $\mathrm{Re}$ & Conversion & $\mathbf{M}_{\mathbf{n}}[\mathrm{Da}]$ & $\mathbf{M}_{\mathbf{w}}[\mathrm{Da}]$ \\
\hline 70 & 20 & $0.2-0.22$ & $15,000-20,000$ & 30,000 \\
85 & 20 & $0.35-0.4$ & $8,000-12,000$ & $14,000-20,000$ \\
\hline
\end{tabular}

Source: Vianna (2003)

The PDI always gave a value of 1.5: it seemed that the fluid dynamic profiles did not exercise a strong influence on polymerization, or, that the configuration changes were not sufficiently efficient to improve conversions.

Even a coiled reactor was studied and also in this case there were not significant differences.

\subsubsection{Mandal et al.'s work, 2010: coiled reactor}

The coiled tube was also investigated by another work by Mandal et al. (2011), who applied this configuration in a millireactor having a tube diameter of $2 \mathrm{~mm}$ and length of $3 \mathrm{~m}$. The performance of the coiled tube reactor lied between a plug flow and a laminar flow reactor. Thus, the authors deduced that a tube of alternating curvature could be an efficient mean for mixing of fluid with low mass transfer, because of the presence of secondary flows. In fact, monomer conversion in coiled tube reactor was

\footnotetext{
${ }^{9}$ CABRAL, P., M.Sc. Thesis, UFRJ/COPPE/PEQ (1998)
} 
found to be nearly $17-29 \%$ higher than in the straight tube reactor, while the PDI did not change significantly and was approximately 1.5 .

\subsection{Polymerizing in microreactors: many potential improvements}

The previous examples of polymerization in micro or millireactors showed both positive and negative results about the advantages of this technology with respect to the polymers field, in particular for polystyrene production.

Portillo (2011) points out that there is still skepticism about microreactors potential application for industrial production. In fact, the bigger concerns among the chemical engineering community are about:

- possible fouling problems during reaction, as molecular weight increases;

- the real possibility of scale-up, since it is difficult to uniformly splitting one main stream into a multitude of substreams;

- cleaning procedures after shutdown of the system, that are common for laboratory equipment but quite inapplicable for industrial production plants (if composed of thousands of microchannels), as discussed by Hessel; Hardt and Löwe (2004).

However, microreactors are considered a very promising field of study, because:

- They solve thermal instability:

In free radical polymerization, the precise temperature control is essential for carrying out the reaction in a highly controlled manner, because of its high exothermality. Thanks to a very high surface to volume ratio, microreactors can be seen as an important solution for these polymerizations (IWASAKI; YOSHIDA, 2005).

- They reduce polydispersity:

As reported by Wu et al. (2004), varying either the flow rate or the relative concentrations of reactants (i.e. stoichiometry) or polymerization time, the molecular properties of the products can be controlled.

- The scale-out is simple:

The real interest in microreactors could be achieved only by managing to produce more relevant quantities of product. 
According to Iwasaki; Kawano and Yoshida (2006), microchemical plants are expected to solve the problem of scaling-up a bench process performed in a macroscale reactor. In fact, the increase of the production scale can be achieved by numbering up of the microreactors, without changing the size of each of them. Large scale production would then be possible just combining reactors in parallel. Meyer and Keurentjes (2005) list several scale-up possibilities:

- Adding identical reactors in parallel, guaranteeing a uniform distribution of feed. In the polymer industry, 1000-tube heat exchangers are commonly used as post-reactors and devolatilization pre-heater for polystyrene;

- Making the reactor longer or adding reactors in series; adding stirred-tank or stirred-tube reactors in series is sometimes used to scale up polystyrene processes, but scaling in series is sometimes limited by pressure drops;

- Simultaneously increasing two or more characteristic dimensions (for tank reactors), keeping the same $L / d_{t}$ ratio (for tube reactors) or maintaining the same pressure drops.

\subsubsection{Scale-up considerations}

Scaling tubes in parallel presents the problem of distributing the feeds, as mentioned above, but this becomes a concern when the viscosity of the feed is much less than that of the product: the material entering the tube, with low viscosity, cannot displace the polymerized material inside and the tubes plug.

A solution to this issue can be limiting per pass conversion, so that the outlet viscosity is within an order of magnitude of the inlet one: polystyrene post-reactors function satisfactorily when the entering feed is $70 \%$ polymer (MEYER et al., 2005).

Therefore the most important technical point for commercialization of microreactor polymerization is guaranteeing stable continuous operation without any troubles such as clogging. However, it has been already proved by Iwasaki; Kawano and Yoshida (2006) that a pilot plant made of microreactors can attain a continuous operation of polymerization. Their plant worked with eight microreactor blocks in parallel, each consisting of three microtube reactors in series of $2 \mathrm{~m}$ length and $500 \mu \mathrm{m}$ diameter width. The authors successfully performed for one week a continuous operation of MMA polymerization, without pressure increase or reactor temperature rise (IWASAKI; KAWANO; YOSHIDA, 2006). 


\section{Chapter 4 MATERIALS AND METHODS}

\subsection{Experimental section}

\subsubsection{The Syrris microreactor "ASIA 120"}

The Syrris microreactor used is composed of various moduli:
a) Bottles pressurizing modulus
b) Climate controller
c) System pressurizing modulus
d) Heater
e) Pumps
f) Chip reactor or tubular reactor; for this work, the tubular reactor was chosen

Figure 12 - The Syrris complete microreactor

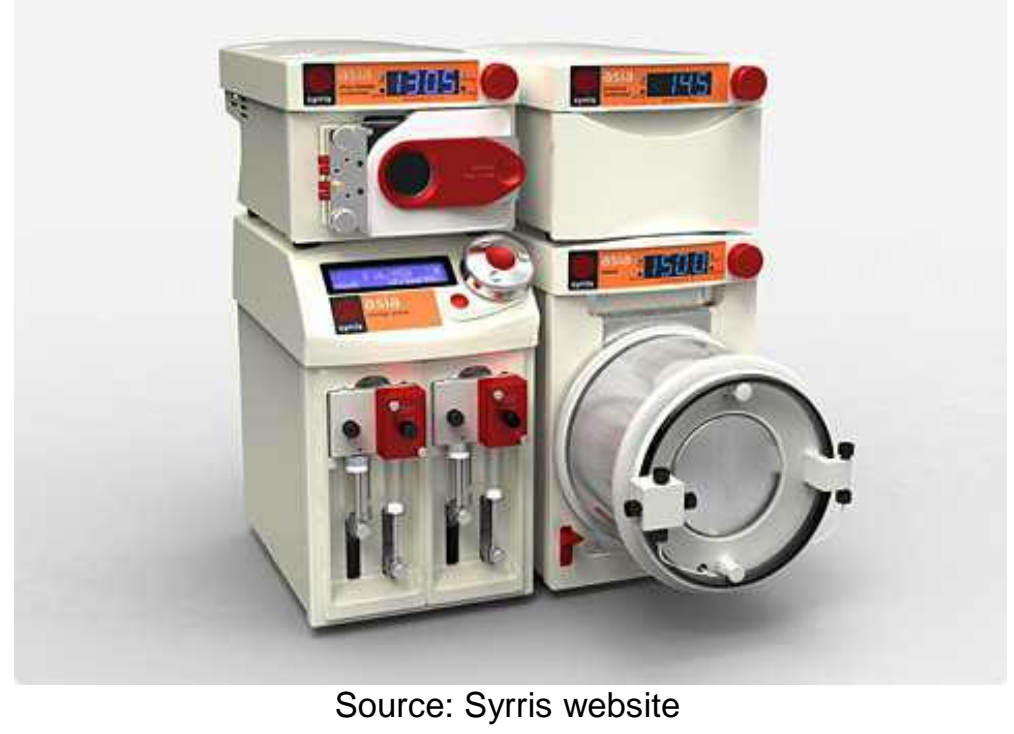

- The tubular millireactor

This reactor has a total volume of $4 \mathrm{~mL}$ and it is formed by a Teflon tube rolled on a cylinder of about $14 \mathrm{~cm}$ diameter. Its major volume (compared with the chip reactor) allows a bigger production and larger residence times for the reactions. Considering an internal diameter of $0.5 \mathrm{~mm}$, its total length is $20.37 \mathrm{~m}$. 
Figure 13 - The tubular millireactor

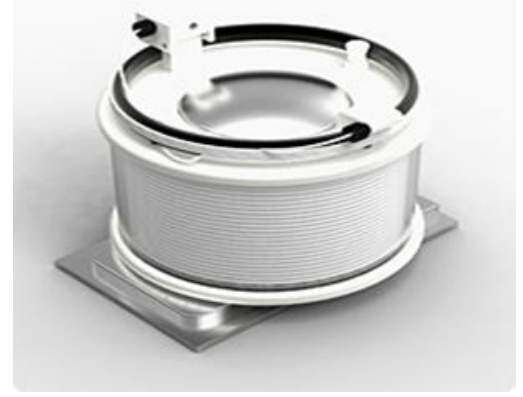

Source: Syrris website

- The chip reactor

The chip reactor is a microreactor of $250 \mu \mathrm{L}$ volume. It was the first reactor type to be tested for styrene polymerization, but all the experiments that will be reported in this text were performed in the tubular one.

- The bottles pressurizing modulus:

In this modulus, nitrogen is used to pressurize the bottles with reagents inside: this helps solvents and reagents to enter the syringes and to fill them; this pressurizing part is not related to the system pressurizer.

Figure 14 - The bottles pressurizing modulus

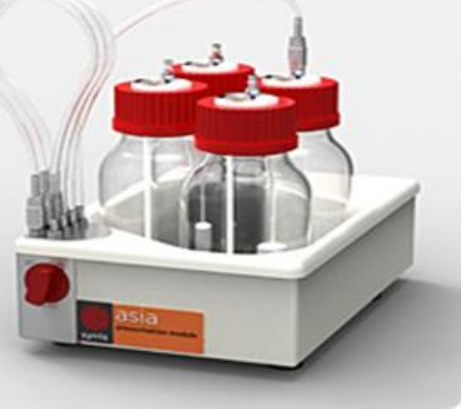

Source: Syrris website

- The climate controller

The reactor chip must be located in the climate controller modulus, in which temperatures from $-15{ }^{\circ} \mathrm{C}$ up to $150{ }^{\circ} \mathrm{C}$ can be set. This section is designed just for the chip reactor. 
- The system pressurizer

The system pressure can be set between atmospheric and 20 bar, in order to permit stronger conditions and faster reactions.

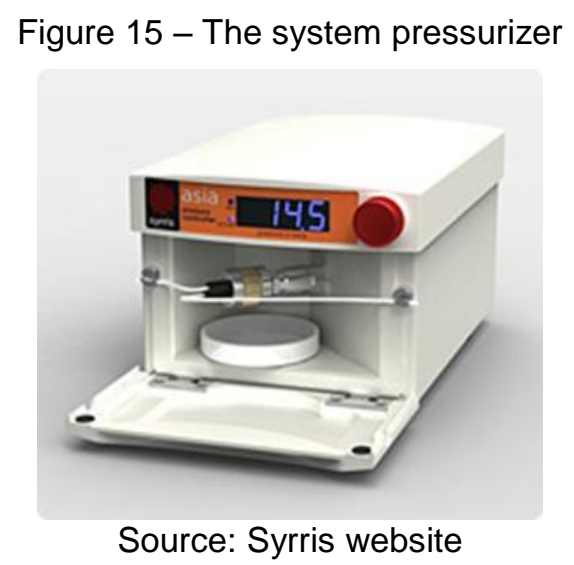

- The heater

This second climate controller just heats from ambient temperature up to $250{ }^{\circ} \mathrm{C}$. It can be used both for the chip reactor (reaching higher temperatures than the first climate controller) and the tubular reactor, but for the last one the maximum available temperature is $125^{\circ} \mathrm{C}$.

\subsubsection{Adopted chemical materials}

In industrial processes, monomers are usually used as received, as it is not economically advantageous to purify them any further. Since the study of the Syrris millireactor is made with the intention of evaluating its possible employment in industry, the experiments were done without any sort of additional purification. The employed reagents were:

a) Styrene, used as monomer in the solution polymerization, liquid. BASF, industrial purity;

a) Toluene, used as solvent, liquid. Vetec, $99.5 \%$;

b) Benzoyl peroxide, used as initiator, white solid powder. Arkema, $75 \%$;

c) Methanol, used to precipitate the polystyrene formed, liquid. Vetec, $99.8 \%$;

d) Tetrahydrofuran, used as mobile phase in the SEC analysis, liquid. J. T, Baker, 99.997\%; 
e) Nitrogen, used to remove oxygen from the bottle with reagents, gaseous. White Martins, Industrial purity;

f) Acetone, used to clean laboratory glassware, liquid. Synth, 99.5\%.

\subsubsection{Set of experiments}

The starting point was choosing reactants quantities similar to the experiments already performed by Vianna (2003). Then, the planning of the experiments was organized in order to change just one input variable from the previous to the following experimental condition.

Three groups of experiments can be recognized, by assembling the ones that presented the same temperature and monomer to solvent ratio.

Here are listed all the experiments carried out in the millireactor.

Table 7 - List of the experiments performed.

\begin{tabular}{|c|c|c|c|c|c|c|}
\hline Experiment & $\mathrm{T}\left({ }^{\circ} \mathrm{C}\right)$ & $\begin{array}{c}\text { Inlet } \\
\text { volumetric } \\
\text { flow }(\mu \mathrm{l} / \mathrm{min})\end{array}$ & $\begin{array}{l}\text { Residence } \\
\text { time (min) }\end{array}$ & $\begin{array}{l}\text { Initial mass } \\
\text { of initiator } \\
\text { (g) }\end{array}$ & $\begin{array}{l}\text { Initial mass } \\
\text { of styrene } \\
\text { (g) }\end{array}$ & $\begin{array}{l}\text { Initial mass } \\
\text { of toluene } \\
\text { (g) }\end{array}$ \\
\hline 1 & \multirow{4}{*}{100} & 800 & 5 & 1 & 41 & 59 \\
\hline 2 & & 200 & 20 & 1 & 41 & 59 \\
\hline 3 & & 200 & 20 & 2 & 41 & 59 \\
\hline 4 & & 200 & 20 & 0.5 & 41 & 59 \\
\hline 5 & \multirow{4}{*}{100} & 100 & 40 & 1.5 & 61 & 39 \\
\hline 6 & & 100 & 40 & 1 & 61 & 39 \\
\hline 7 & & 50 & 80 & 1 & 61 & 39 \\
\hline 8 & & 50 & 80 & 0.2 & 61 & 39 \\
\hline 9 & \multirow{2}{*}{115} & 50 & 80 & 1 & 70.9 & 29.1 \\
\hline 10 & & 50 & 80 & 0.5 & 70.9 & 29.1 \\
\hline
\end{tabular}

In order to minimize the experimental error, each experiment was performed three, four or five times.

\subsubsection{Reactor assembly}

In each experiment, the tubular reactor was assembled to the heater. It was chosen to use just one injection pump of the two available, which meant the reagents mixture happened before the feed entered the system. 
Each unit was connected through Teflon tubes; the heater unit was set to a constant temperature of $100^{\circ} \mathrm{C}$ (for Experiment 1 to 8) or $115^{\circ} \mathrm{C}$ (for Experiment 9 and 10) before starting the experiment. Even if the pressure modulus allowed to set pressures up to $30 \mathrm{bar}$, for the first eight experiments pressure was set to $1 \mathrm{bar}$, giving this unit the function to close the circuit of the nitrogen passing through all the equipment. Only the last two experiments required a greater pressure, since the toluene boiling point at atmospheric pressure is $111^{\circ} \mathrm{C}$.

Before each experiment, toluene was run through the reactor in order to condition it and to remove all the possible residuals. This procedure was adopted also at the end of each experiment, to clean all the tubes: it is crucial to do it as soon as the reaction ends, in order not to let the polymer cool out, solidify and eventually clog the reactor.

Figure 16 - Reactor operation scheme

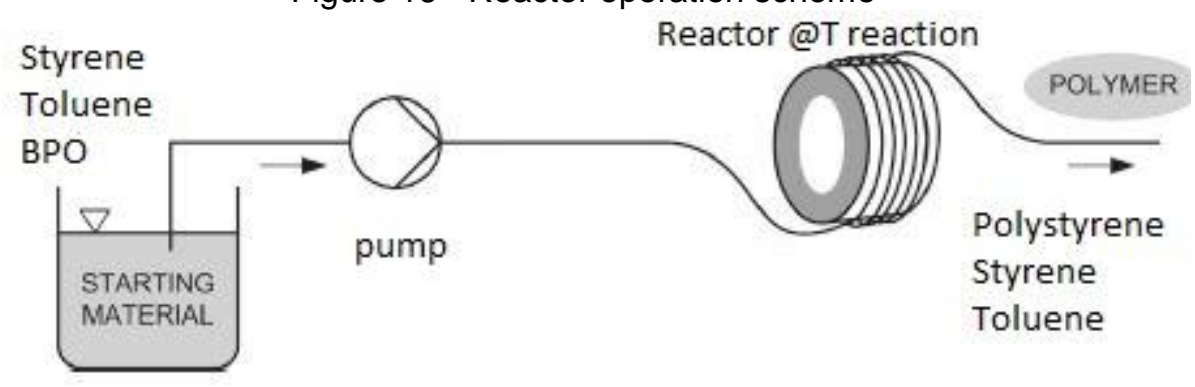

\subsubsection{Reagents preparation}

The reactive solution was prepared by weighing the masses of the monomer, solvent and initiator, in order to obtain $100 \mathrm{~g}$ of solution.

Since Cabral et al. (2003) correlated the density to reaction conversion for some specific volumetric ratios between styrene and toluene, it was decided to work at $60 / 40$ toluene to styrene, $40 / 60$ toluene to styrene and $30 / 70$ toluene to styrene (based on volumes). Considering at $20{ }^{\circ} \mathrm{C}$ the following density values: $\rho_{\text {tol }}=$ $0.867 \mathrm{~g} / \mathrm{cm}^{3}$ and $\rho_{\text {sty }}=0.906 \mathrm{~g} / \mathrm{cm}^{3}$, in the three situations the monomer and solvent masses are:

$$
\begin{array}{r}
\varphi=\frac{60}{40}=\frac{3}{2} \frac{V_{t o l}}{V_{s t y}} \rightarrow \quad 100=0.867 * \varphi * V_{\text {sty }}+0.906 V_{\text {sty }} \\
V_{\text {sty }}=45.3 \mathrm{~cm}^{3} \rightarrow m_{\text {sty }}=41 \mathrm{~g} \quad m_{\text {tol }}=59 \mathrm{~g}
\end{array}
$$




$$
\begin{gathered}
\varphi=\frac{40}{60}=\frac{2}{3} \frac{V_{\text {tol }}}{V_{\text {sty }}} \rightarrow \quad 100=0.867 * \varphi * V_{\text {sty }}+0.906 V_{\text {sty }} \\
V_{\text {sty }}=67.4 \mathrm{~cm}^{3} \rightarrow m_{\text {sty }}=61 \mathrm{~g} \quad m_{\text {tol }}=39 \mathrm{~g} \\
\varphi=\frac{30}{70}=\frac{3}{7} \frac{V_{\text {tol }}}{V_{\text {sty }}} \rightarrow 100=0.867 * \varphi * V_{\text {sty }}+0.906 V_{\text {sty }} \\
V_{\text {sty }}=78.27 \mathrm{~cm}^{3} \rightarrow m_{\text {sty }}=70.9 \mathrm{~g} \quad m_{\text {tol }}=29.1 \mathrm{~g}
\end{gathered}
$$

After weighing the solvent, the monomer and the initiator (about 1\% in mass), the initiator was dissolved in the only toluene using a magnetic agitator, in order to not activate it. Just before the feeding started, solvent and monomer were put altogether in the feeding bottle.

In each experiment, samples were collected and submitted to density and viscosity measures, with the help of a densimeter tool (Anton Paar); the measures were taken off-line, at $20^{\circ} \mathrm{C}$.

\subsubsection{Density measure}

The density measure of the solution is useful in order to estimate the reaction conversion, through empirical formulas obtained by Cabral et al. (2004), which also take into account the temperature influence; depending on the monomer to solvent ratio of the feed, the authors found different correlations related to different reference temperatures, as reported in Table 8.

Table 8 - Density-Temperature dependence correlation for various monomer/solvent feed volumetric ratios

\begin{tabular}{cccc}
\hline $\boldsymbol{\varphi}$ & $\rho[\mathrm{kg} / \mathrm{m} 3]$ & $\mathrm{T}_{\mathrm{r}}\left[{ }^{\circ} \mathrm{C}\right]$ & $\beta\left[\mathrm{m}^{3} /{ }^{\circ} \mathrm{C} / \mathrm{kg}\right]$ \\
\hline $\mathbf{4 0 / 6 0}$ & $\rho=877.33+58 \mathrm{X}$ & 26 & $1.270 \mathrm{E}-06$ \\
$\mathbf{5 0 / 5 0}$ & $\rho=882.77+75 x$ & 30 & $1.190 \mathrm{E}-06$ \\
$\mathbf{6 0 / 4 0}$ & $\rho=884.98+95 \mathrm{X}$ & 30 & $1.153 \mathrm{E}-06$ \\
$\mathbf{7 0 / 3 0}$ & $\rho=889.15+109 \mathrm{X}$ & 31 & $1.140 \mathrm{E}-06$ \\
\hline
\end{tabular}

Source: Cabral et al. (2004)

Densities of the samples at $T=20^{\circ} \mathrm{C}$ were measured by the densimeter tool; then, densities of the system at $T_{r}$ were calculated by the equation: 


$$
\beta\left(T-T_{r}\right)=\frac{1}{\rho(T)}-\frac{1}{\rho\left(T_{r}\right)}
$$

Finally, conversion values were obtained from the second column in Table 8.

\subsubsection{Method of samples collection}

The reagents were mixed and put in the bottle which feeds the syringe pump; the pump was set to different pumping velocities, varying the residence time $\tau$ of the reactive solution, too. After waiting one $\tau$, a first sample used to be collected and measured; after waiting for about three $\tau$, a reasonable time needed to reach steadystate, another sample was collected and analyzed, measuring density and viscosity. From this last sample, the polymer was separated from the solution with the addition of methanol; then, in a becker, the polymer was dried under agitation and under a flux of nitrogen which helped the evaporation of styrene, toluene and alcohol.

\subsubsection{GPC analysis}

The resulting powder was collected and a very small quantity of it analyzed through GPC, after dissolving it in THF. The equipment used is a multidetector ViscotekGPCmaxVE2001, with 3 columns of $8 \mathrm{~mm}$ diameter and pore diameter of $10^{3} \AA$. The instrument calibration was made by using the standard PS-105K.

The aforementioned GPC employs three detectors, giving high precise analysis of the samples:
I. RI detector
II. LALS and RARS detector
III. IV detector

\subsection{Modeling the polymerization reaction in the millireactor: the plug flow model}

Tubular reactors behavior is commonly modeled as a PFR, in the most simplified case. From this simple representation, improvements can be made by introducing more rigorous hypothesis, such as axial or radial dispersion and appropriate velocity profiles. 
Focusing on styrene polymerization, this reaction is dominated by termination by combination (MATYJASZEWSKI; DAVIS, 2003); as a consequence, the gel effect contribution should be considered in the reactor model. However, this effect is not so influent: first, because this polymerization is not the most affected by autoacceleration; second, because the presence of toluene prevents a too high viscosity growth. However, as a first attempt, both gel effect and contraction volume were considered in the reactor model.

In order to solve the mass balances written in section 2.1.10 (eq.(52-61)), they were implemented in the Matlab numerical environment. The resolution of the resulting system of stiff equations was performed by using the ODE15s solver, that turned to be more efficient than ODE23s (also indicated for stiff problems) in terms of computational time.

\subsubsection{Isothermality}

In the reactor model, no energy balance was included. This choice was made since its operation during reaction was supposed isothermal.

We have sufficient reasons to say that the Asia millireactor operates in isothermal conditions; in fact, sensitivity studies on reactor internal temperature varying the tube diameter have been already carried out with polymerization of undiluted styrene, giving the results reported by Meyer and Keurentjes (2005) in Figure 17. 
Figure 17 - Temperature profiles for the polymerization of undiluted styrene in a tubular reactor with good radial mixing. $\mathrm{T}_{\text {in }}=135^{\circ} \mathrm{C}, \mathrm{T}_{\mathrm{w}}=20^{\circ} \mathrm{C}$; the parameter in the plot is the tube diameter in meters

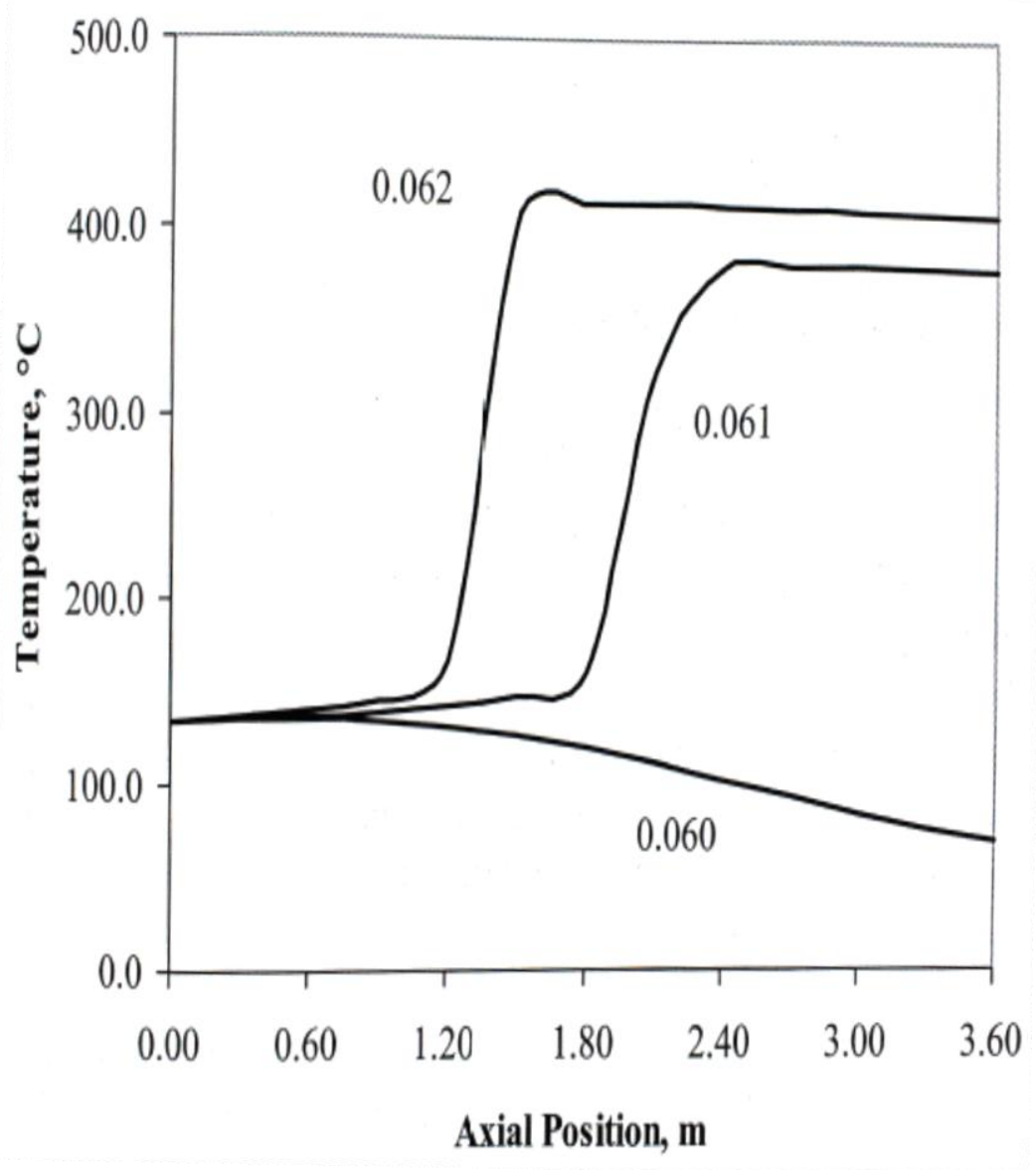

Source: Meyer and Keurentjes (2005), p 547

Considering the fact of the Syrris Asia reactor having a $0.5 \mathrm{~mm}$ diameter, it is realistic to say that the reaction happens in isothermal conditions. In support of this, Iwasaki and Yoshida (2005) proved isothermality in their microreactor of i.d. $0.5 \mathrm{~mm}$ introducing a solution of AIBN in toluene. The amount of unchanged AIBN in the outlet solution was plotted against the residence time and it fitted well to the calculated values based on the bath temperature. In this way, we are allowed to solve the mass balance independently from the energy balance.

Besides, it is possible to state that the thermal entrance length, that is the tube section in which the fluid passes from its feed temperature to the reactor temperature, is negligible. An estimation of the thermal Péclet number from the physical data of Yoon (1996) gives the following result:

$$
P e=\frac{\rho c_{p} d_{t} \bar{v}}{k} \approx 7166 \bar{v}
$$


Considering the maximum velocity value among the experiments, that is $0.068 \mathrm{~m} / \mathrm{s}$, the biggest thermal $P e$ number is about 487. Since the thermal entrance length is given by eq.(74) (JIJI, 2006):

$$
\frac{L_{T}}{d_{t}}=0.033 P e \rightarrow L_{T} \approx 0.0134 \mathrm{~m}
$$

it is clear that its value does not affect considerably the polymerization results.

\subsubsection{Deviation from the ideal plug flow model}

The real difficulty of making the right choice to model the millireactor is the fact of not having the possibility to make a previous RTD study. The configuration of the reactor and its small size, besides the lack of specific instruments, prevented to do it. This made it difficult to deeply understand the reactor fluid dynamic.

In order to verify the choice of the model used to simulate the millireactor Asia, dimensionless numbers such as the Schmidt number, the Reynolds number, the Bodenstein number and the vessel geometry must be calculated, as seen in section 2.2.3., for each experimental condition. These parameters will permit to use the chart reported by Levenspiel (1999) and already shown in Figure 6.

In the specific case of the experiments performed, solution viscosities varied from 0.8 $\mathrm{CP}$ up to $400 \mathrm{cP}$ at $20^{\circ} \mathrm{C}$ (as measured off-line by the densimeter-viscosimeter Anton-Paar); an estimation of viscosities at different temperatures can be made by using two formulas: the first one, for diluted conditions (i.e. for the first and part of the second group of experiments), can be found in the work by Chen ${ }^{10}$ (1994, apud VIANNA, 2003); the second one, for more concentrated solution, can be found from Hui and Hamielec (1968). The viscosity values at $100^{\circ} \mathrm{C}$ calculated using these two formulas (not reported in the text) approximately varied between $0.5 \mathrm{cP}$ up to $60 \mathrm{cP}$. Densities at $100{ }^{\circ} \mathrm{C}$ varied from 815 and $900 \mathrm{~kg} / \mathrm{m} 3$. The knowledge of these quantities and the velocity in the reactor permits the estimation of the required dimensionless numbers (eq.(77-80)). $D_{m o l}=10^{-9} \mathrm{~m}^{2} / \mathrm{s}$ was the value assumed for molecular diffusion of all the reactive species.

$$
S c=\frac{\mu}{\rho D_{m o l}}=\frac{(0.5 \sim 60) * 10^{-3}}{(815 \sim 900) * 1 * 10^{-9}}=550 \sim 73600
$$

\footnotetext{
${ }^{10}$ CHEN, C.C. A continuous bulk polymerization process for crystal polystyrene, Polym.Plast.Technol., v. 33, p.55-61, 1994.
} 


$$
\begin{gathered}
R e=0.03 \sim 50 \\
B o=S c * R e=2100 \sim 34000 \\
\frac{L}{d_{t}}=\frac{20.37}{0.0005}=4 * 10^{4}
\end{gathered}
$$

Comparing eq.(77-80) with Figure 6 , the millireactor appears to effectively operate in the axial dispersion regime.

Moreover, recalling the definitions of intensity of axial dispersion (eq.(68)) and vessel dispersion number (eq.(69)), it is also possible to calculate these two adimensional quantities for each experimental condition, as reported in Table 9:

\begin{tabular}{cccccc}
\hline Table 9 - Diffusional values in the millireactor under the experimental conditions perform \\
\hline Experiment & $\begin{array}{c}\text { Velocity } \\
{[\mathrm{m} / \mathrm{s}]}\end{array}$ & $\mathbf{R e}$ & Dax [m2/s] & $\frac{\boldsymbol{D}_{\boldsymbol{a x}}}{\boldsymbol{v}_{\mathbf{z}} \boldsymbol{d}_{\boldsymbol{t}}}$ & $\frac{\boldsymbol{D}_{\boldsymbol{a x}}}{\boldsymbol{v}_{\mathbf{z}} \boldsymbol{L}}$ \\
\hline $\mathbf{1}$ & 0.06792 & $\sim 50$ & 0.006 & 176.6784 & 0.004337 \\
$\mathbf{2}$ & 0.01698 & $\sim 12.5$ & $3.754 \mathrm{E}-04$ & 44.21673 & 0.001085 \\
$\mathbf{3}$ & 0.01698 & $\sim 13$ & $3.754 \mathrm{E}-04$ & 44.21673 & 0.001085 \\
$\mathbf{4}$ & 0.01698 & $\sim 12.5$ & $3.754 \mathrm{E}-04$ & 44.21673 & 0.001085 \\
$\mathbf{5}$ & 0.00849 & $\sim 0.6$ & $9.386 \mathrm{E}-05$ & 22.11072 & 0.000543 \\
$\mathbf{6}$ & 0.00849 & $\sim 0.6$ & $9.386 \mathrm{E}-05$ & 22.11072 & 0.000543 \\
$\mathbf{7}$ & 0.004245 & $\sim 0.05$ & $2.347 \mathrm{E}-05$ & 11.05771 & 0.000271 \\
$\mathbf{8}$ & 0.004245 & $\sim 0.3$ & $2.347 \mathrm{E}-05$ & 11.05771 & 0.000271 \\
$\mathbf{9}$ & 0.004245 & $\sim 0.03$ & $2.347 \mathrm{E}-05$ & 11.05771 & 0.000271 \\
$\mathbf{1 0}$ & 0.004245 & $\sim 0.1$ & $2.347 \mathrm{E}-05$ & 11.05771 & 0.000271 \\
\hline
\end{tabular}

When the vessel dispersion number tends to zero, the reactor behavior tends to plug flow (LEVENSPIEL, 1999); thus, the millireactor seems to approach this behavior, even if the axial dispersion model would represent it more precisely.

In steady-state conditions, the axial dispersion model applied to the reactor leads to the following general equation:

$$
v_{z} \frac{d c_{i}}{d z}=D_{a x} \frac{d^{2} c_{i}}{d z^{2}}+R_{i}
$$

To be solved with Danckwerts' boundary conditions (1953):

$$
v_{z} c_{i, 0}=\left(v_{z} c_{i}-D_{a x} \frac{d c_{i}}{d z}\right)_{z=0}
$$




$$
\left(\frac{d c_{i}}{d z}\right)_{z=L}=0
$$

In order to solve this second model, the following hypotheses were adopted:

- QSSA for all radicals species, including the radicals moments;

- No volume contraction factor, but only gel effect contribution;

- The same axial dispersion coefficient for all the species in the system;

The resulting system is a boundary value problem, with second ordinary differential equations. The finite-difference method can replace the derivatives in the differential equations with finite difference approximations at each point in the interval of integration, thus converting the differential equations to a large set of simultaneous nonlinear algebraic equations. Then, the system of discretized equations can be solved using Newton's method for simultaneous nonlinear algebraic equations (CONSTANTINIDES; MOSTOUFI, 2000).

Applying the upwind finite difference scheme, for each grid point it is:

$$
0=-v_{z}\left[\frac{c_{j}\left(z_{k}\right)-c_{j}\left(z_{k-1}\right)}{\Delta z}\right]+D_{a x}\left[\frac{c_{j}\left(z_{k-1}\right)-2 c_{j}\left(z_{k}\right)+c_{j}\left(z_{k+1}\right)}{(\Delta z)^{2}}\right]+R_{j}\left[c_{m}\left(z_{k}\right)\right]
$$

The system of equations was solved by rearranging a Matlab code provided by Beers (2007), in which the analytical Jacobian was also codified in order to make the resolution more efficient. 


\section{Chapter 5 RESULTS AND DISCUSSION}

The goal of the present work is to study the performance of microreactors with respect to a free-radical polymerization. First, some tests were carried out in the microchip reactor; however, the monomer conversion was about $2 \%$ with a residence time of 1 minute. It should be pointed out that given a volume of $250 \mu \mathrm{L}$, only very slow flow feeds would permit higher conversion values. Since one of the focuses of the present study is to consider the process intensification in a non-conventional reactor, the tubular millireactor was considered to be more appropriate to reach higher conversions, molecular weights and productivities.

The first set of experiments performed had the aim to understand which reactor conditions were the best in order to obtain the best compromise between conversion and high molecular weights of polystyrene. Some parameters were varied: the monomer concentration, the initiator mass, the feed flows and the temperature.

The last step was to understand the fluid dynamics inside the millireactor; thus, the equipment was simulated by using two simple models: PFR and axial dispersion.

\subsection{Experimental results}

Tables 10-14 report a resume of the experimental results obtained for each experiment. In the last column of each, averages were calculated in order to more rapidly analyze the outputs of the experiments. In the case of molecular weights, only some of the available results from GPC were taken into account; some values were considered as outliers, probably due to the instrument instability.

- Conversions:

Table 10 shows the conversions for the more diluted conditions; the values were rather low, varying from $0.091(9.1 \%)$ to $0.391(39.1 \%)$. When the monomer concentration was increased, the conversion increased as well (see Table 11), ranging from $0.279(27.9 \%)$ to $0.638(63.8 \%)$. The greatest levels of monomer conversion (53.1\% and 66.8\%), though, were obtained with the highest styrene concentration $(70 \%)$ and temperature $\left(115^{\circ} \mathrm{C}\right)$, as shown in Table 12. 
Table 10 - Conversions for the first group of experiments

\begin{tabular}{|c|c|c|c|c|c|c|}
\hline \multirow{2}{*}{$\begin{array}{l}\text { Conversion } \\
\text { Comparison }\end{array}$} & \multicolumn{6}{|c|}{ Toluene/Styrene $60 / 40 \mathrm{v} / \mathrm{v} 100^{\circ} \mathrm{C}$} \\
\hline & $\mathrm{X}($ Run 1$)$ & $\mathrm{X}($ Run 2) & $\mathrm{X}($ Run 3$)$ & $\mathrm{X}($ Run 4$)$ & $\mathrm{X}($ Run 5$)$ & $\mathrm{X}_{\text {average }}$ \\
\hline $\begin{array}{c}\operatorname{Exp~1~} \\
\tau=5 \text { min } \\
\% \text { init } \cong 1\end{array}$ & 0.0896 & 0.093 & 0.083 & 0.098 & & 0.091 \\
\hline $\begin{array}{c}\operatorname{Exp}_{2} \\
\tau=20 \mathrm{~min} \\
\% \mathrm{w} \text { init } \cong 1\end{array}$ & 0.241 & 0.266 & 0.312 & 0.268 & 0.275 & 0.272 \\
\hline $\begin{array}{c}\operatorname{Exp} 3 \\
\tau=20 \text { min } \\
\% \mathrm{w} \text { init } \cong 2\end{array}$ & 0.372 & 0.408 & 0.37 & 0.413 & & 0.391 \\
\hline $\begin{array}{c}\operatorname{Exp} 4 \\
\tau=20 \text { min } \\
\% \text { w init } \cong 0.5\end{array}$ & 0.158 & 0.18 & 0.187 & 0.198 & & 0.181 \\
\hline
\end{tabular}

Table 11 - Conversions for the second group of experiments

\begin{tabular}{|c|c|c|c|c|c|}
\hline \multirow{2}{*}{$\begin{array}{l}\text { Conversion } \\
\text { Comparison }\end{array}$} & \multicolumn{5}{|c|}{ Toluene/Styrene $40 / 60 \mathrm{v} / \mathrm{v} 100^{\circ} \mathrm{C}$} \\
\hline & $\mathrm{X}($ Run 1$)$ & $\mathrm{X}(\operatorname{Run} 2)$ & $X(\operatorname{Run} 3)$ & $\mathrm{X}($ Run 4$)$ & $\mathrm{X}_{\text {average }}$ \\
\hline $\begin{array}{c}\operatorname{Exp} 5 \\
\tau=40 \text { min } \\
\% \text { w init } \cong 1.5\end{array}$ & 0.462 & 0.473 & 0.5 & & 0.478 \\
\hline $\begin{array}{c}\operatorname{Exp} 6 \\
\tau=40 \mathrm{~min} \\
\% \mathrm{w} \text { init } \cong 1\end{array}$ & 0.397 & 0.411 & 0.433 & & 0.414 \\
\hline $\begin{array}{c}\operatorname{Exp} 7 \\
\tau=80 \text { min } \\
\% \text { w init } \cong 1\end{array}$ & 0.56 & 0.658 & 0.722 & 0.61 & 0.638 \\
\hline $\begin{array}{c}\operatorname{Exp~8} \\
\tau=80 \mathrm{~min} \\
\% \mathrm{w} \text { init } \cong 0.2\end{array}$ & 0.233 & 0.234 & 0.361 & 0.289 & 0.279 \\
\hline
\end{tabular}

\footnotetext{
${ }^{11}$ Mass fraction with respect to the total mass (styrene plus toluene).
} 
Table 12 - Conversions for the third group of experiments

\begin{tabular}{|c|c|c|c|c|}
\hline \multirow{2}{*}{$\begin{array}{l}\text { Conversion } \\
\text { Comparison }\end{array}$} & \multicolumn{4}{|c|}{ Toluene/Styrene $30 / 70 \mathrm{v} / \mathrm{v} 115^{\circ} \mathrm{C}$} \\
\hline & $\mathrm{X}(\operatorname{Run} 1)$ & $\mathrm{X}(\operatorname{Run} 2)$ & $\mathrm{X}(\operatorname{Run} 3)$ & $\mathrm{X}_{\text {average }}$ \\
\hline $\begin{array}{c}\text { Exp } 9 \\
\tau=80 \text { min } \\
\% \mathrm{w} \text { init } \cong 1\end{array}$ & 0.653 & 0.689 & 0.663 & 0.668 \\
\hline $\begin{array}{c}\text { Exp 10 } \\
\tau=80 \mathrm{~min} \\
\% \mathrm{w} \text { init } \cong 0.5\end{array}$ & 0.528 & 0.524 & 0.541 & 0.531 \\
\hline
\end{tabular}

- Molecular weights:

In the first group of experiments shown in Table 13, Mn values ranged from 5,600 to 11,500 , with polydispersities always lower than 1.85. In Table 14, the molecular weights increased due to the higher monomer content in the reactive solution; generally, PDIs raised with respect to the more diluted conditions; Mw values almost reached 60,000 Da (experiment 8). Finally, Table 15 reports the results of the two experiments performed under the most aggressive conditions; the last one was considered rather good: conversions were above 60\% (see Table 12), Mn was approximately 21,000 Da and Mw $46,000 \mathrm{Da}$, thus giving a polymer with a PDI of about 2. So, experiment 10 was considered to be the best outcome of the millireactor. 
Table 13 - Molecular weights for the first group of experiments

\begin{tabular}{|c|c|c|c|c|}
\hline \multirow{4}{*}{$\begin{array}{c}\text { MW } \\
\text { Comparison }\end{array}$} & \multicolumn{4}{|c|}{ Toluene/Styrene $60 / 40 \mathrm{v} / \mathrm{v} 100^{\circ} \mathrm{C}$} \\
\hline & $\mathrm{Mn}$ & $\mathrm{Mn}$ & $\mathrm{Mn}$ & $\mathrm{Mn}_{\text {average }}$ \\
\hline & Mw & Mw & Mw & Mw average \\
\hline & $\begin{array}{c}\text { PD } \\
\text { st } \\
(1 \quad \text { Analysis })\end{array}$ & $\begin{array}{c}\text { PD } \\
\left(\begin{array}{l}\text { nd } \\
2\end{array} \text { Analysis }\right)\end{array}$ & $\begin{array}{c}\text { PD } \\
\left(3^{\text {rd }} \text { Analysis }\right)\end{array}$ & $\mathrm{PD}_{\text {average }}$ \\
\hline \multirow{3}{*}{$\begin{array}{c}\underset{\operatorname{Exp} 1}{\tau=5 \text { min }} \\
\% \text { w init } \cong 1\end{array}$} & 6919 & 6616 & & 6768 \\
\hline & 11247 & 9967 & & 10607 \\
\hline & 1.63 & 1.51 & & 1.57 \\
\hline \multirow{3}{*}{$\begin{array}{c}\operatorname{Exp~2} \\
\tau=20 \text { min } \\
\% \text { w init } \cong 1\end{array}$} & 5892 & 6463 & 7408 & 6587 \\
\hline & 11043 & 10990 & 13595 & 11876 \\
\hline & 1.874 & 1.7 & 1.84 & 1.8 \\
\hline \multirow{3}{*}{$\begin{array}{c}\operatorname{Exp} 3 \\
\tau=20 \mathrm{~min} \\
\% \mathrm{w} \text { init } \cong 2\end{array}$} & 5210 & 6069 & & 5640 \\
\hline & 7656 & 8790 & & 8223 \\
\hline & 1.47 & 1.45 & & $1.46^{12}$ \\
\hline \multirow{3}{*}{$\begin{array}{c}\operatorname{Exp~} 4 \\
\tau=20 \mathrm{~min} \\
\% \mathrm{w} \text { init } \cong 0.5\end{array}$} & 10334 & 11905 & 12354 & 11531 \\
\hline & 17274 & 22062 & 18655 & 19330 \\
\hline & 1.67 & 1.85 & 1.51 & 1.68 \\
\hline
\end{tabular}

${ }^{12}$ This value is below the minimum theoretical PDI value, but it should be accepted considering the GPC error tolerance. 
Table 14 - Molecular weights for the second group of experiments

\begin{tabular}{|c|c|c|c|c|}
\hline \multirow{4}{*}{$\begin{array}{c}\text { MW } \\
\text { Comparison }\end{array}$} & \multicolumn{4}{|c|}{ Toluene/Styrene $40 / 60 \mathrm{v} / \mathrm{v} 100^{\circ} \mathrm{C}$} \\
\hline & Mn & Mn & $\mathrm{Mn}$ & $\mathrm{Mn}_{\text {average }}$ \\
\hline & Mw & Mw & Mw & Mw average \\
\hline & $\begin{array}{c}\text { PD } \\
\text { st } \\
(1 \quad \text { Analysis })\end{array}$ & $\begin{array}{c}{ }_{\text {nd }} \text { PD } \\
\left(2^{2} \text { Analysis }\right)\end{array}$ & $\begin{array}{c}\text { PD } \\
\left({ }^{\text {rd }} \quad \text { Analysis }\right)\end{array}$ & $\mathrm{PD}_{\text {average }}$ \\
\hline \multirow{3}{*}{$\begin{array}{c}\operatorname{Exp~5} \\
\tau=40 \text { min } \\
\% \text { w init } \cong 1.5\end{array}$} & 10280 & 8770 & 7670 & 8907 \\
\hline & 15982 & 16839 & 17419 & 16747 \\
\hline & 1.56 & 1.92 & 2.27 & 1.88 \\
\hline \multirow{3}{*}{$\begin{array}{c}\operatorname{Exp} 6 \\
\tau=40 \mathrm{~min} \\
\% \mathrm{w} \text { init } \cong 1\end{array}$} & 8615 & 10264 & 8886 & 9255 \\
\hline & 23864 & 16313 & 21315 & 20497 \\
\hline & 2.77 & 1.59 & 2.4 & 2.22 \\
\hline \multirow{3}{*}{$\begin{array}{c}\operatorname{Exp} 7 \\
\tau=80 \text { min } \\
\% \text { w init } \cong 1\end{array}$} & 13388 & 13802 & 14169 & 13786 \\
\hline & 23214 & 30161 & 23337 & 25571 \\
\hline & 1.73 & 2.19 & 1.65 & 1.86 \\
\hline \multirow{3}{*}{$\begin{array}{c}\operatorname{Exp~} 8 \\
\tau=80 \text { min } \\
\% \text { w init } \cong 0.2\end{array}$} & 35385 & 24375 & 33472 & 31077 \\
\hline & 57106 & 43259 & 68740 & 56368 \\
\hline & 1.61 & 1.78 & 2.05 & 1.81 \\
\hline
\end{tabular}

Table 15 - Molecular weights for the third group of experiments

\begin{tabular}{|c|c|c|c|c|}
\hline \multirow{5}{*}{$\begin{array}{c}\text { MW } \\
\text { Comparison }\end{array}$} & \multicolumn{4}{|c|}{ Toluene/Styrene $30 / 70 \mathrm{v} / \mathrm{v} 115^{\circ} \mathrm{C}$} \\
\hline & $\mathrm{Mn}$ & $\mathrm{Mn}$ & $\mathrm{Mn}$ & $\mathrm{Mn}_{\text {average }}$ \\
\hline & Mw & Mw & Mw & Mw $_{\text {average }}$ \\
\hline & PD & PD & PD & $\mathrm{PD}_{\text {average }}$ \\
\hline & (1 Analysis) & (2 $2^{\text {nd }}$ Analysis) & ( $3^{\text {rd }}$ Analysis) & \\
\hline & 17676 & 11793 & & 14735 \\
\hline$\tau=80 \mathrm{~min}$ & 32787 & 28674 & & 30731 \\
\hline & 1.86 & 2.43 & & 2.09 \\
\hline & 26088 & 19721 & 18436 & 21415 \\
\hline$\tau=80 \mathrm{~min}$ & 50576 & 41920 & 44867 & 45788 \\
\hline & 1.94 & 2.13 & 2.43 & 2.14 \\
\hline
\end{tabular}


In order to have an idea of the change of viscosity of the reactive solution from the inlet to the outlet, viscosity measures were taken with the densimeter-viscosimeter instrument at $20^{\circ} \mathrm{C}$; here, average values are reported:

Table 16 - Viscosity changes for the Experiments

\begin{tabular}{|c|c|c|c|c|c|c|c|c|c|c|}
\hline & Exp 1 & Exp2 & Exp3 & Exp4 & Exp5 & Exp6 & Exp7 & Exp8 & Exp9 & Exp10 \\
\hline$\frac{2}{\frac{\pi}{\pi}} \overline{0}$ & 0.65 & 0.65 & 0.65 & 0.65 & 0.7 & 0.7 & 0.7 & 0.71 & 0.71 & 0.71 \\
\hline$\stackrel{\frac{2}{\pi}}{\stackrel{\frac{\pi}{2}}{\frac{0}{2}}}$ & 0.835 & 1.63 & 1.735 & 1.37 & 16.3 & 12.7 & $\sim 55$ & 11.5 & 320 & 135 \\
\hline
\end{tabular}

In Experiments 7, 9 and 10, the values should be considered approximated, because the instrument oscillated considerably from run to run, due to the high solution viscosity. These are also the experimental conditions were the fluid dynamic inside the reactor most changed along the reactor length. The effective viscosity present inside the reactor, since the reaction temperature was $100{ }^{\circ} \mathrm{C}$ and $115^{\circ} \mathrm{C}$, reduced its value in a range of $0.5 \mathrm{cP}$ and $60 \mathrm{cP}$.

\subsubsection{Reactor steady state behavior}

In order to evaluate the reactor stability for longer reaction times, the conditions of experiment 8 were performed for 24 hours. From the product solution, different samples densities were measured, thus giving the conversion result. Its value was consistent with those estimated in the other runs of the same experiment: the reactor managed to work in steady state conditions and at constant temperature the whole reaction time.

\subsubsection{Statistical analysis on conversion data}

In order to better compare model results with experimental ones, a simple statistical analysis was carried out.

From the different runs of each experiment, the mean values of conversion and molecular weight can be calculated. This mean value $\bar{y}$ is an estimation of the mean 
of the true conversion value result, $\eta$, that is always unknown. If a random sampling of $n$ observations (in our case the number of experimental runs) is drawn from a normal distribution, the sample variance $s^{2}$ is a good estimation of the true variance of the distribution, $\sigma^{2}$. The quantity $(\bar{y}-\eta) /\left(\frac{s}{\sqrt{n}}\right)$ is distributed in a $t$ distribution with $\mathrm{n}$ 1 degrees of freedom; $\frac{s}{\sqrt{n}}$ is an estimation of the standard error (BOX; HUNTER; HUNTER, 2005).

Given $\mathrm{n}, \bar{y}$ and $\mathrm{s}$, it is possible to calculate the width of the "confidence interval", which is smaller or bigger depending on the probability required to find a value in that interval.

In Figure 18, mean values and confidence intervals were represented (considering a probability of $95 \%$ ) for each experiment:

Figure 18 - Mean conversion values with confidence intervals

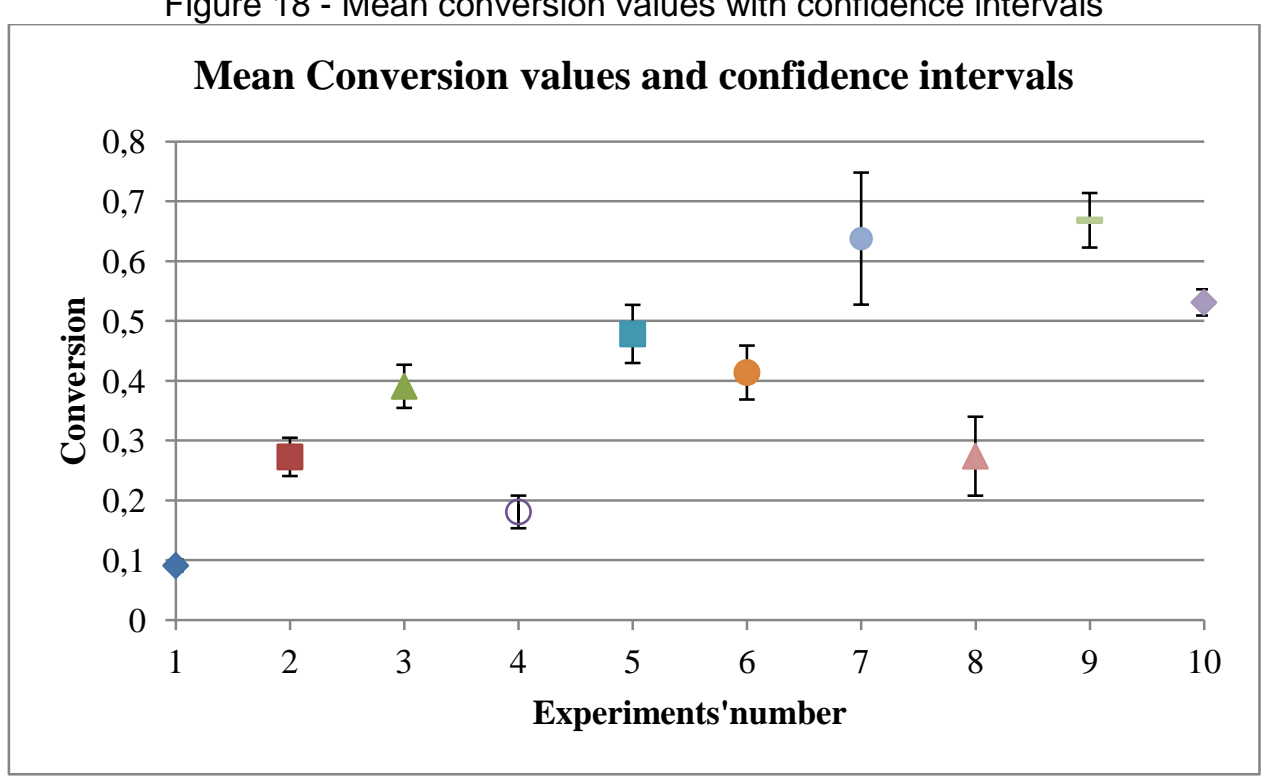

In terms of residence time, the previous intervals are represented in Figure 19: conversions generally increase with $\tau$; for the same residence time, their values vary with respect to the initiator mass. 
Figure 19 - Mean conversion values varying residence time

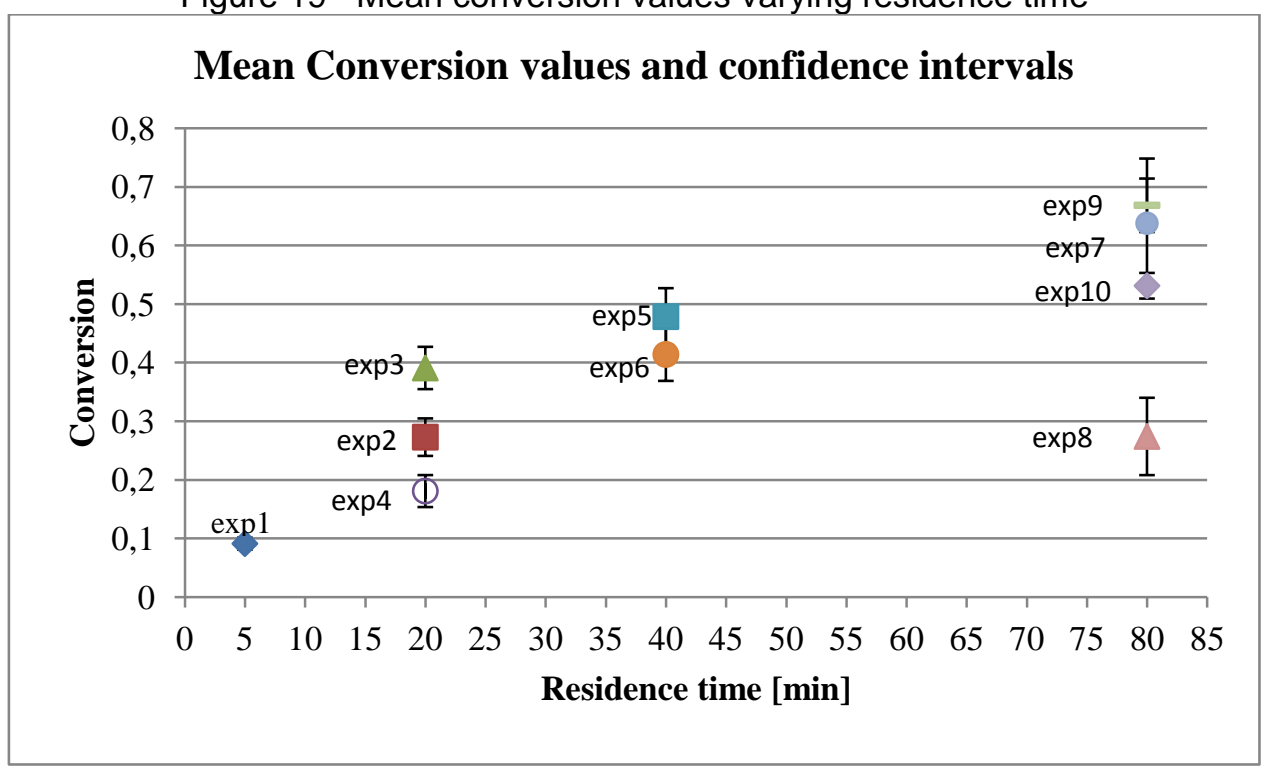

Uncertainties laid between 4 and $12 \%$ of the mean values, except for the Experiments 7 and 8, in which this percentage raised to 17 and $24 \%$.

An analogous statistical analysis could be also developed for the measured molecular weights. However, it would be less meaningful, since the percentage of associated error would be very high. In fact, samples measured in different times, with different stabilized conditions of the GPC instrument, gave quite different results. The fact of considering the uncertainties due to different runs of the same experiment, plus the average 10\% error related to the GPC instrument (as shown later in section 5.1.4), would give very large confidence intervals. This is why the comparison between model and experiments will not be statistically-based.

\subsubsection{Effects of reaction parameters}

The initiator content, the monomer to solvent ratio and the residence time were the variables that influenced the polymer quantity and properties at the end of the reactor. The comparison between experiments with the same residence time and monomer content, but different initiator concentration, shows the behavior presented in Figure 20. 
Figure 20 - Initiator effects on conversion and Mn

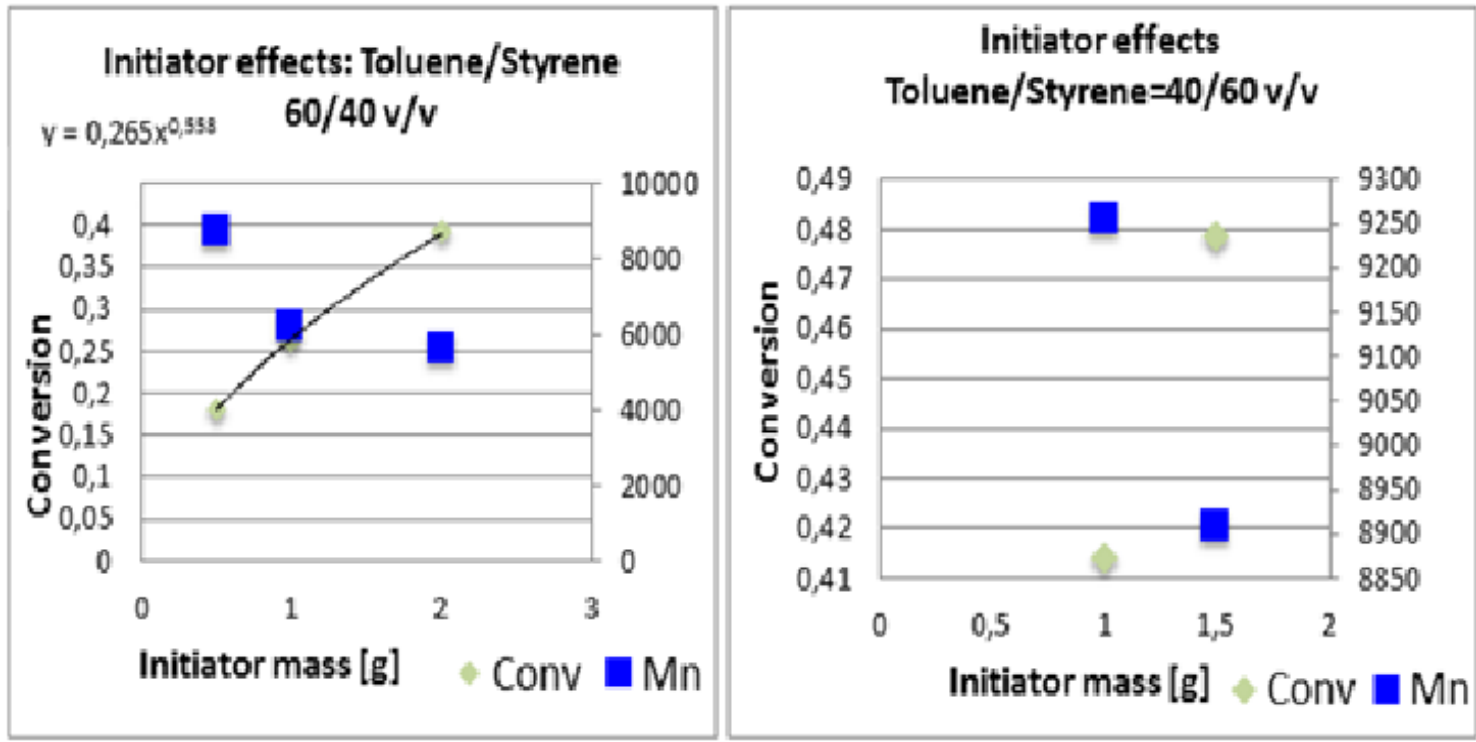

As expected, the conversion increased and molecular weight lowered when the initiator mass raised. This happened because the propagation reaction was favored. On the left side of Figure 20, a power-law regression of the three conversion points gave an exponent close to 0.5 , as was showed at the end of section 2.1.4. For the sake of greater precision, it is the polymerization rate - which corresponds to the conversion derivative - to be proportional to the initiator concentration raised to the half power. Thus, for an isothermal PFR, the integration of the expression for conversion results in eq.(85) as:

$$
\ln \left(\frac{1}{1-\chi}\right)=k_{p}\left(\frac{8 f}{k_{d} k_{t}}\right)^{0.5}\left(I_{0}\right)^{0.5}\left[1-\exp \left(\frac{-k_{d} \tau}{2}\right)\right]
$$

In this way, $\ln \left(\frac{1}{1-\chi}\right)$ and not $\chi$ has the power law dependence shown before.

At the same time, however, the presence of more radicals favored the termination reaction and the mean chain length suffered a reduction.

When initiator concentration was kept constant, while the residence time was varied, the following behavior on conversion was observed (Figure 21): 
Figure 21 - Residence time effects on conversion

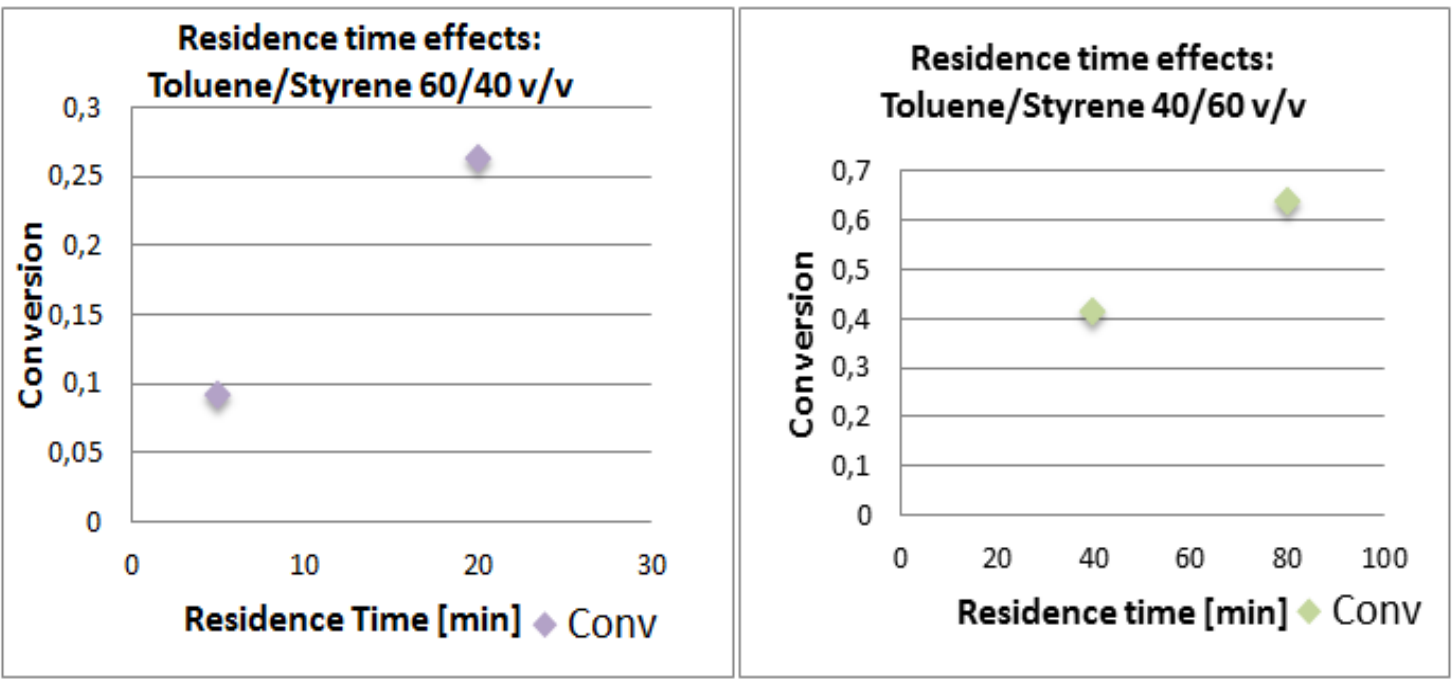

This effect can be justified by the analytical expression for the conversion, that can be obtained from eq.(85), considering $R_{i}$ constant (MORBIDELLI, 2012):

$$
\chi=1-\exp \left(-k_{p}\left(\frac{R_{i}}{2\left(k_{t c}+k_{t d}\right)}\right)^{1 / 2} \tau\right)
$$

Thus, increasing $\tau$ causes the increase of conversion, too.

A last analysis can be carried out on the behavior of $M_{w}$ with respect to the initiator quantity and the styrene mass present in the mixture. The expression for the instantaneous weighted molecular weight distribution, in case of termination only by combination, has the proportionality reported in eq.(87) (GIUDICI, 2013):

$$
M_{w_{\text {inst }}} \propto \frac{k_{p}}{\left(k_{d} k_{t c}\right)^{0.5}}(I)^{-0.5}(M)
$$

If a good control over the polymerization is achieved, the instantaneous distribution does not differ too much from the cumulative one. Thus, the dependence of $M_{w}$ on the two aforementioned parameters can be checked: for the first one, three experiments with the same styrene content were chosen; for the second one, other three experiments with the same initiator content. The fact of having different residence times is not so influent, since molecular weights are fairly dependent on them. 
Figure 22 - Mw dependence on initiator and monomer contents

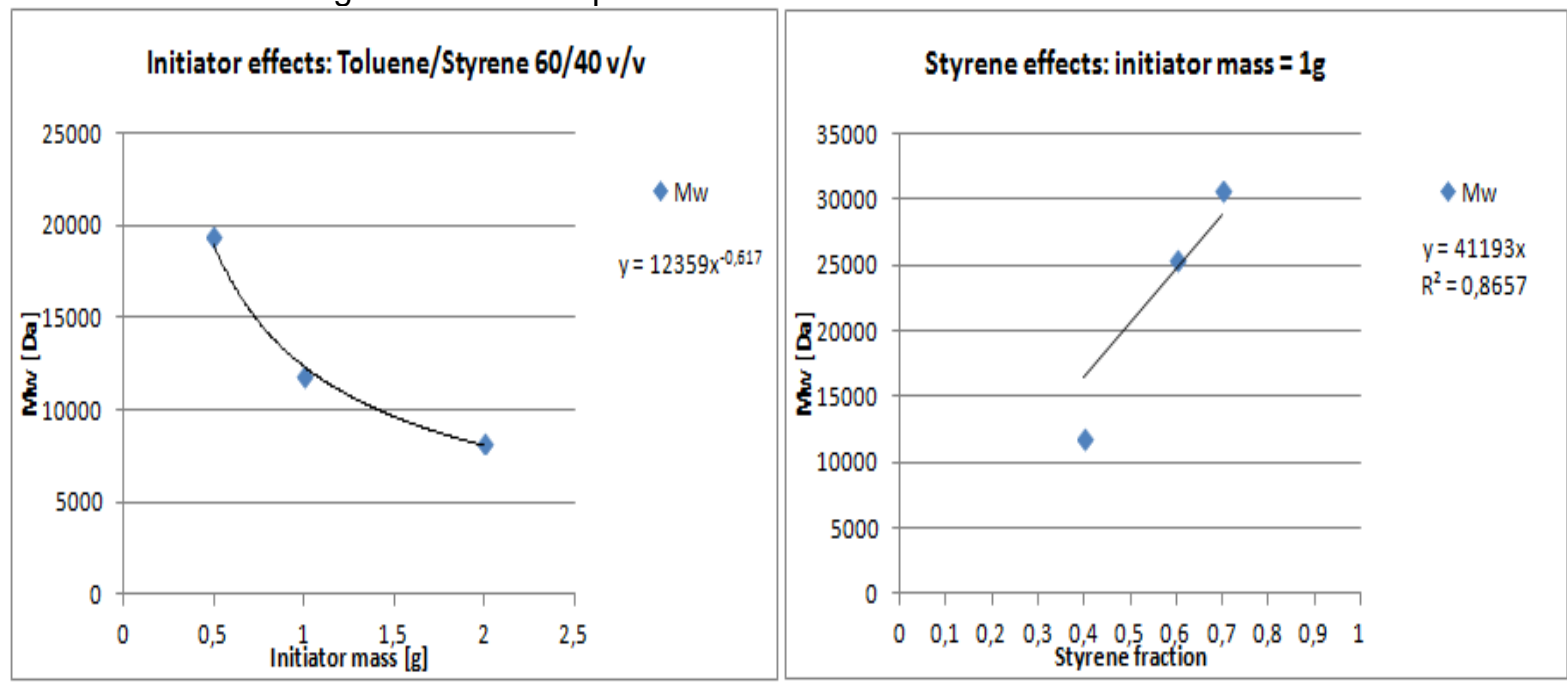

The power law regression on the left of Figure 22 shows an exponent of about -0.6 , that is close to the theoretical -0.5 ; on the right, a quite linear proportionality is found with respect to the styrene fraction.

By globally analyzing all the ten experiments, a comparison can be made among the first four experiments (or first group) and the second and third group. Conversions and molecular weights can be concluded to generally increase:

- conversion rises due to a higher mass of monomer present in the reaction mean; for the third group, also the temperature helped to enhance its value;

- molecular weights rise because the propagation rate is enhanced due to a higher monomer concentration.

The decrease of initiator mass generates less living polymers, so that they become longer. However, a smaller presence of initiator causes a reduction of conversion, too. This is why it is important to find the best agreement between favoring conversion and chain length.

Finally, the fact of PDI deviating from its ideal value of 1.5 is due to different reasons:

- chain transfer reactions between polymer and solvent or monomer;

- not perfect mixing within the reagents, due to fluid dynamic complications;

- diffusional limitations (gel effect) .

In general, however, PDI values are smaller for the first group of experiments, while they tend to rise as the monomer content rises in the second and third group. Growth of this value may be associated to a more pronounced gel effect or a less efficient mixing. 


\subsubsection{GPC results}

In order to evaluate the GPC's analysis errors, one polymer was analyzed three times, as can be seen in Table 17:

Table 17 - GPC sensitivity analysis

\begin{tabular}{ccccc}
\hline & $1^{\text {st }}$ Analysis & $2^{\text {nd }}$ Analysis & $3^{\text {rd }}$ Analysis & Averages \\
\hline PD & 1.626 & 1.507 & 1.506 & 1.546 \\
Mn [Da] & 6919 & 6616 & 7348 & 6961 \\
Mw [Da] & 11247 & 9967 & 11066 & 10760 \\
\hline
\end{tabular}

After developing a statistical analysis on these results, similar to the conversions one, the number average molecular weight of the sample can be concluded to be:

$$
M_{n}=6961 \pm 707 \mathrm{Da}
$$

Thus, the molecular weights values are reliable with an average $10 \%$ error in each analysis.

As an example, in Figure 23 are reported two GPC molecular weight distributions for the Experiments 1 and 8:

Figure 23 - GPC curves for Experiment 1 and Experiment 8

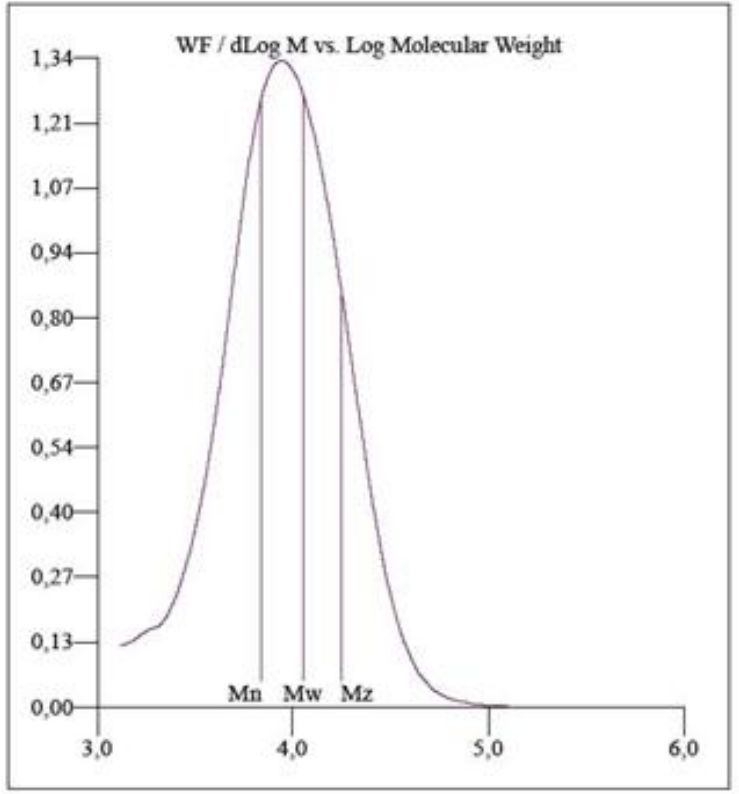

$\operatorname{Exp} 1$

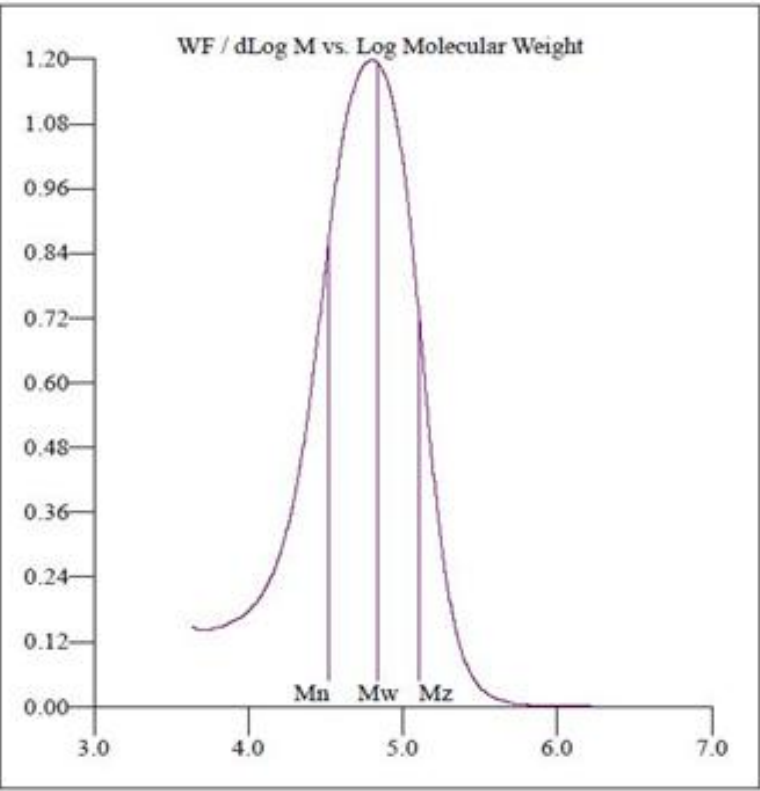

$\operatorname{Exp} 8$ 
Table 18 - GPC values for Experiment 1

\begin{tabular}{cccccc}
\hline & Mn [Da] & Mw [Da] & Mz [Da] & Mp [Da] & PDI \\
\hline Exp 1 & 6919 & 11247 & 17718 & 9926 & 1.626 \\
\hline
\end{tabular}

Table $19-$ GPC values for Experiment 8

\begin{tabular}{cccccc}
\hline & Mn [Da] & Mw [Da] & Mz [Da] & Mp [Da] & PDI \\
\hline Exp 8 & 33472 & 68740 & 128195 & 66297 & 2.054 \\
\hline
\end{tabular}

\subsection{Model results}

The Matlab simulation results using ideal plug flow model and dispersion model are here reported and compared with the average experimental values.

\subsubsection{Experimental results vs. model results using Hui and Hamielec's gel effect correlation}

Conversion, $\mathrm{Mn}$ and $\mathrm{Mw}$ values from experimental measures and Matlab simulations are summed up in Figures 24-26. The numerical results are reported in Tables 20-29, below the figures.

Figure 24 - Conversion: experiments vs. models

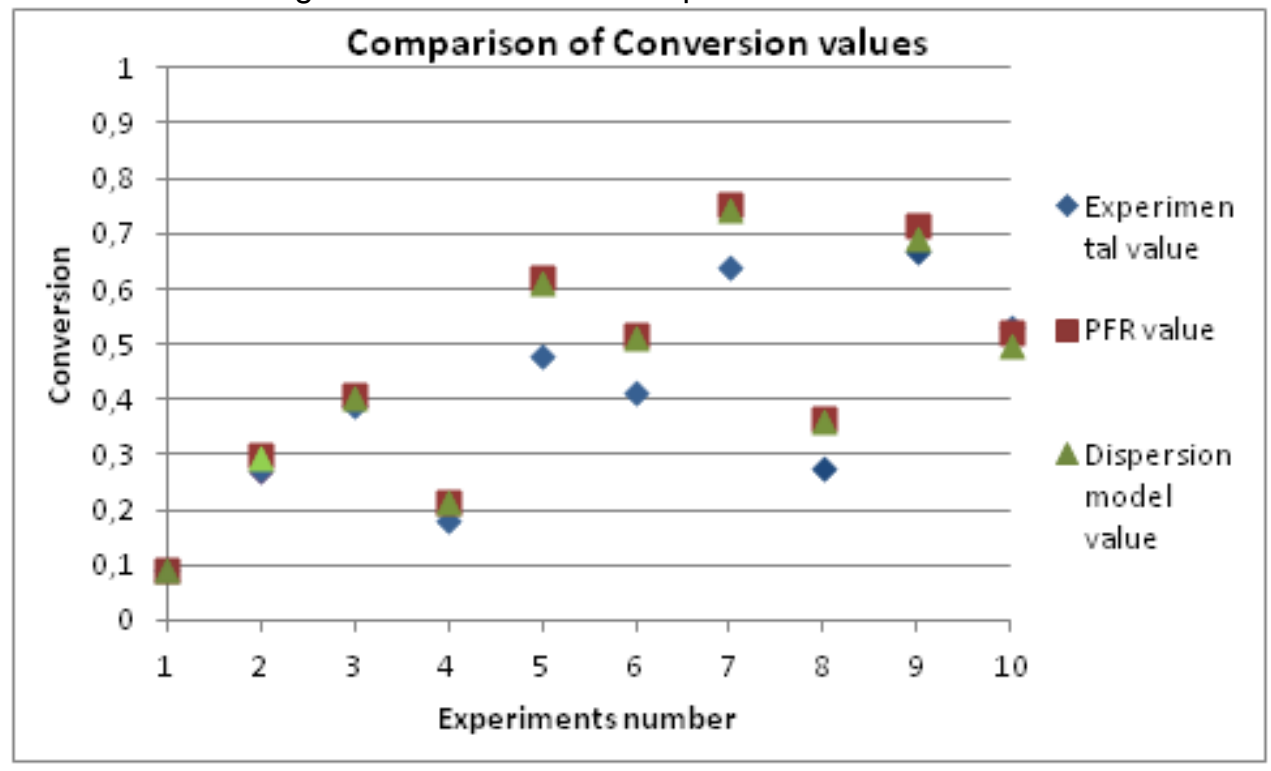


Figure 25 - Mn: experiments vs. models

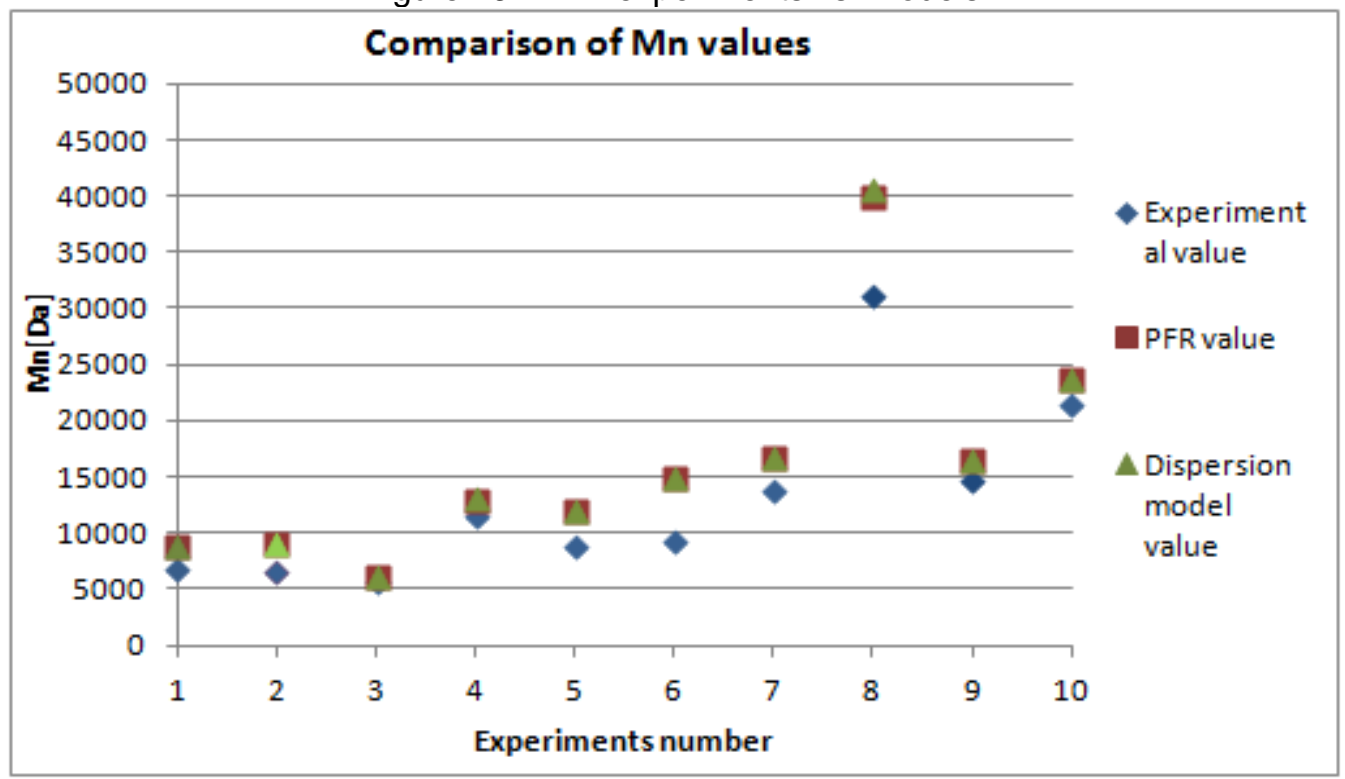

Figure $26-M w$ : experiments vs. models

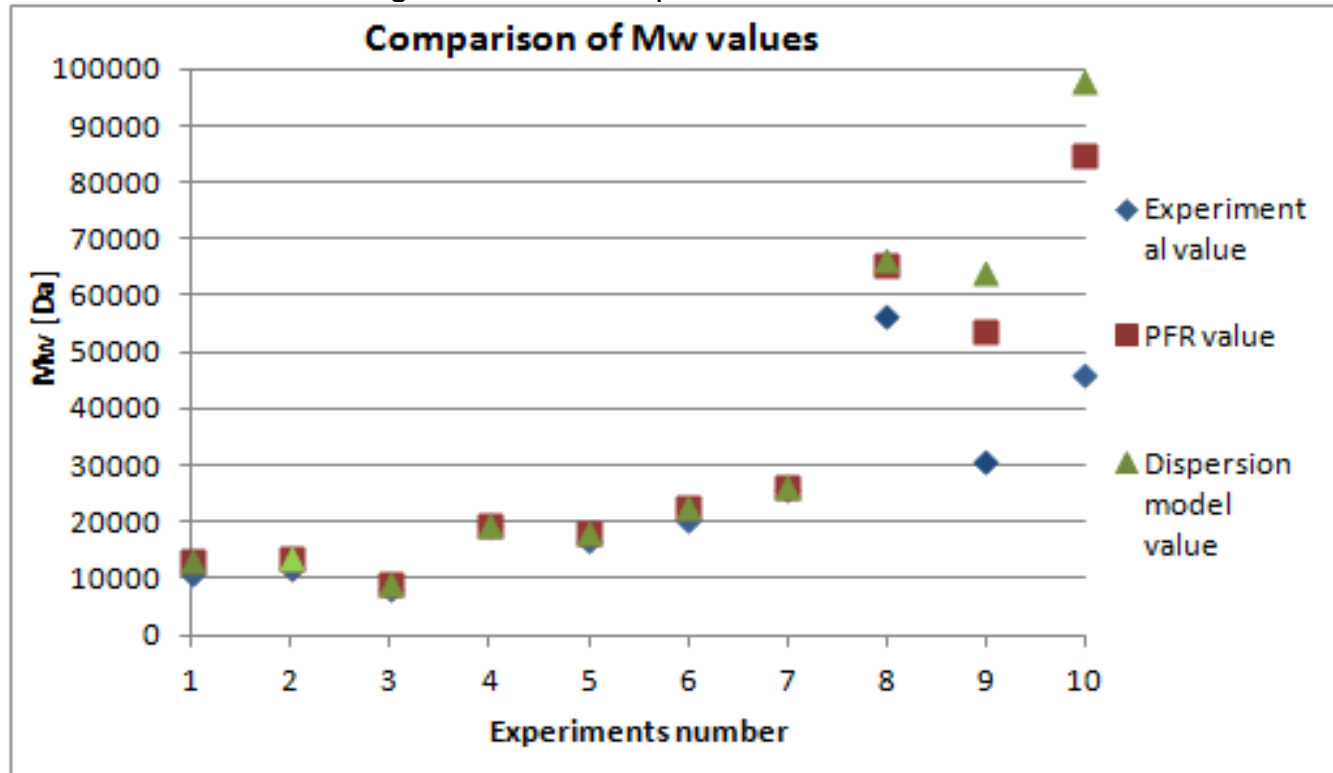

Table 20 - Results exp1

\begin{tabular}{cccc}
\hline Exp 1 & Conversion & Mw & Mn \\
\hline Experimental & 0.091 & 10607 & 6768 \\
Ideal Plug Flow & 0.09 & 13106 & 8775 \\
Model & 0.089 & 13145 & 8829 \\
\hline Dispersion Model & & & \\
\hline
\end{tabular}

Table 21 - Results exp2

\begin{tabular}{cccc}
\hline Exp 2 & Conversion & Mw & Mn \\
\hline Experimental & 0.272 & 11876 & 6587 \\
Ideal Plug Flow & 0.298 & 13422 & 8976 \\
Model & 0.296 & 13456 & 9033 \\
\hline Dispersion Model & & \\
\hline
\end{tabular}


Table 22 - Results exp3

\begin{tabular}{cccc}
\hline Exp 3 & Conversion & Mw & Mn \\
\hline Experimental & 0.391 & 8223 & 5640 \\
Ideal Plug Flow & 0.408 & 9157 & 6155 \\
Model & 0.403 & 9130 & 6154 \\
Dispersion Model & 0 & \\
\hline
\end{tabular}

Table 23 - Results exp4

\begin{tabular}{cccc}
\hline Exp 4 & Conversion & Mw & Mn \\
\hline Experimental & 0.181 & 19330 & 11531 \\
Ideal Plug Flow & 0.216 & 19452 & 12942 \\
Model & 0.215 & 19599 & 13107 \\
Dispersion Model & & & \\
\hline
\end{tabular}

Table 24 - Results exp5

\begin{tabular}{cccc}
\hline Exp 5 & Conversion & Mw & Mn \\
\hline Experimental & 0.478 & 16747 & 8907 \\
$\begin{array}{c}\text { Ideal Plug Flow } \\
\text { Model }\end{array}$ & 0.623 & 18208 & 12046 \\
Dispersion Model & 0.613 & 18035 & 11975 \\
\hline
\end{tabular}

Table 25 - Results exp6

\begin{tabular}{cccc}
\hline Exp 6 & Conversion & Mw & Mn \\
\hline Experimental & 0.414 & 20497 & 9255 \\
Ideal Plug Flow & 0.518 & 22786 & 15000 \\
Model & 0.511 & 22651 & 14972 \\
Dispersion Model & & & \\
\hline
\end{tabular}

Table 26 - Results exp7

\begin{tabular}{cccc}
\hline Exp 7 & Conversion & Mw & Mn \\
\hline Experimental & 0.638 & 25571 & 13786 \\
Ideal Plug Flow & 0.753 & 26233 & 16683 \\
Model & 0.742 & 26151 & 16697 \\
Dispersion Model & & & \\
\hline
\end{tabular}

Table 27 - Results exp8

\begin{tabular}{cccc}
\hline Exp 8 & Conversion & Mw & Mn \\
\hline Experimental & 0.275 & 56368 & 31077 \\
Ideal Plug Flow & 0.365 & 65494 & 39963 \\
Model & 0.362 & 66225 & 40660 \\
\hline Dispersion Model & & \\
\hline
\end{tabular}

Table 28 - Results exp9

\begin{tabular}{cccc}
\hline Exp 9 & Conversion & Mw & Mn \\
\hline Experimental & 0.668 & 30731 & 14735 \\
Ideal Plug Flow & 0.714 & 53840 & 16506 \\
Model & 0.691 & 63848 & 16422 \\
\hline Dispersion Model & & & 1 \\
\hline
\end{tabular}


Table 29 - Results exp10

\begin{tabular}{cccc}
\hline Exp 10 & Conversion & Mw & Mn \\
\hline Experimental & 0.531 & 45788 & 21415 \\
Ideal Plug Flow & 0.522 & 84887 & 23734 \\
Model & 0.5 & 97813 & 23758 \\
Dispersion Model & &
\end{tabular}

As can be seen from Figure 24 and Tables 21-29, the models tend to overestimate the conversions obtained. With respect to the molecular weights, the $M_{n}$ prediction is above the GPC values. Moreover, the simplifications made tend to underestimate the polydispersity index. In fact, its theoretical instantaneous value in a polymerization in which termination happens only by combination is 1.5 ; for the first and second group of experiments the model always gave a PDI very close to 1.5 , while this value rises in the last two experiments (the PDI is 3.26 and 3.89 in Experiment 9 for the PFR model and the dispersion model respectively; it is 3.58 and 4.12 in Experiment 10), due to the higher temperature and monomer content that enhance the gel effect. However, in Experiment 9 and 10, the PDI measured by GPC was close to 2 (the average value was 2.04 for Experiment 9 and 2.17 for Experiment 10), while the gel effect correlation used in the models predicted a much higher value.

Since Cabral et al. forecast a too strong gel effect empirical correlation for a styrene polymerization in solution, a comparison with simulations with the second gel effect correlation by Fontoura et al. (2003) were made.

\subsubsection{Experimental results vs. model results using Fontoura et al.'s gel effect correlation}

Conversion, $\mathrm{Mn}$ and $\mathrm{Mw}$ values from experimental measures and Matlab simulations are summed up in Figures 27-29. The numerical results are reported in Tables 30-39, below the figures. 
Figure 27 - Conversion: experiments vs. models

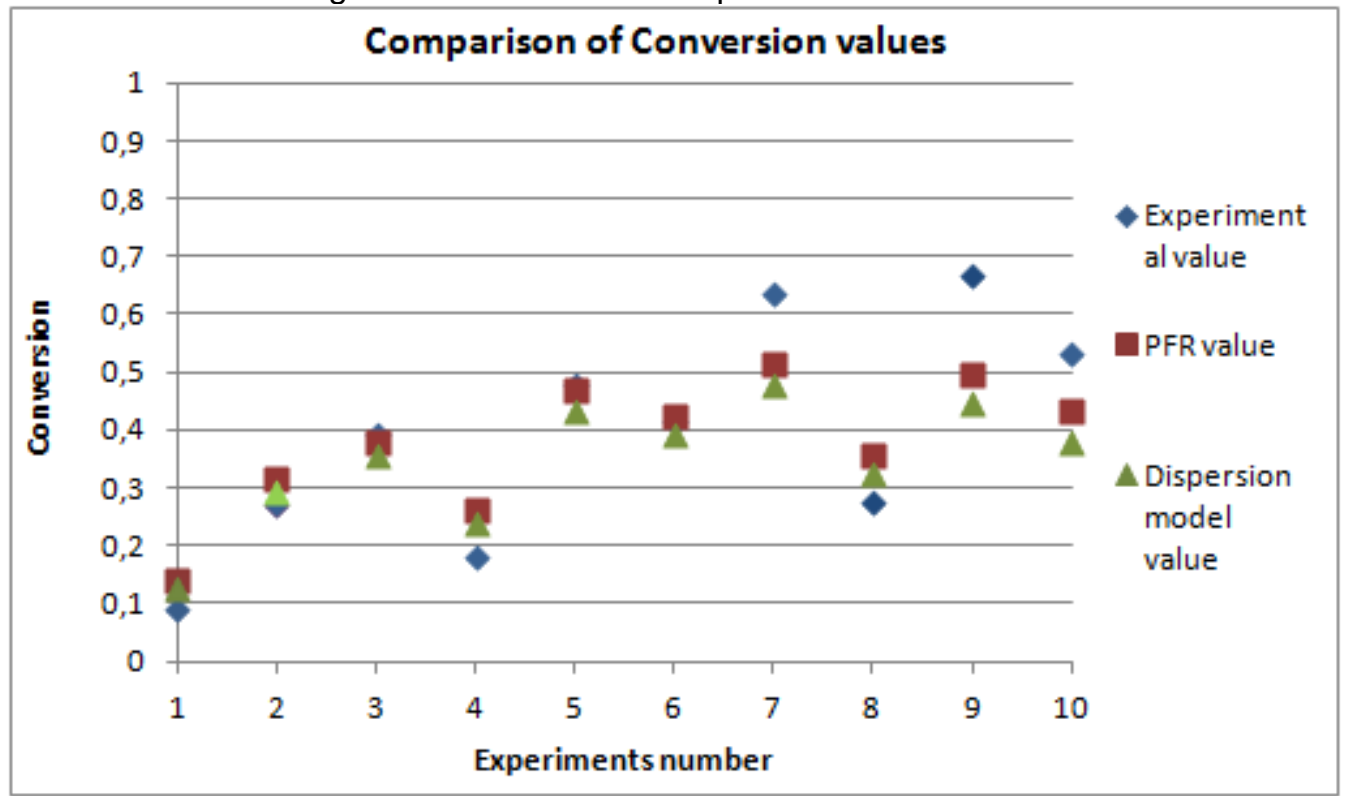

Figure 28 - Mn: experiments vs. models

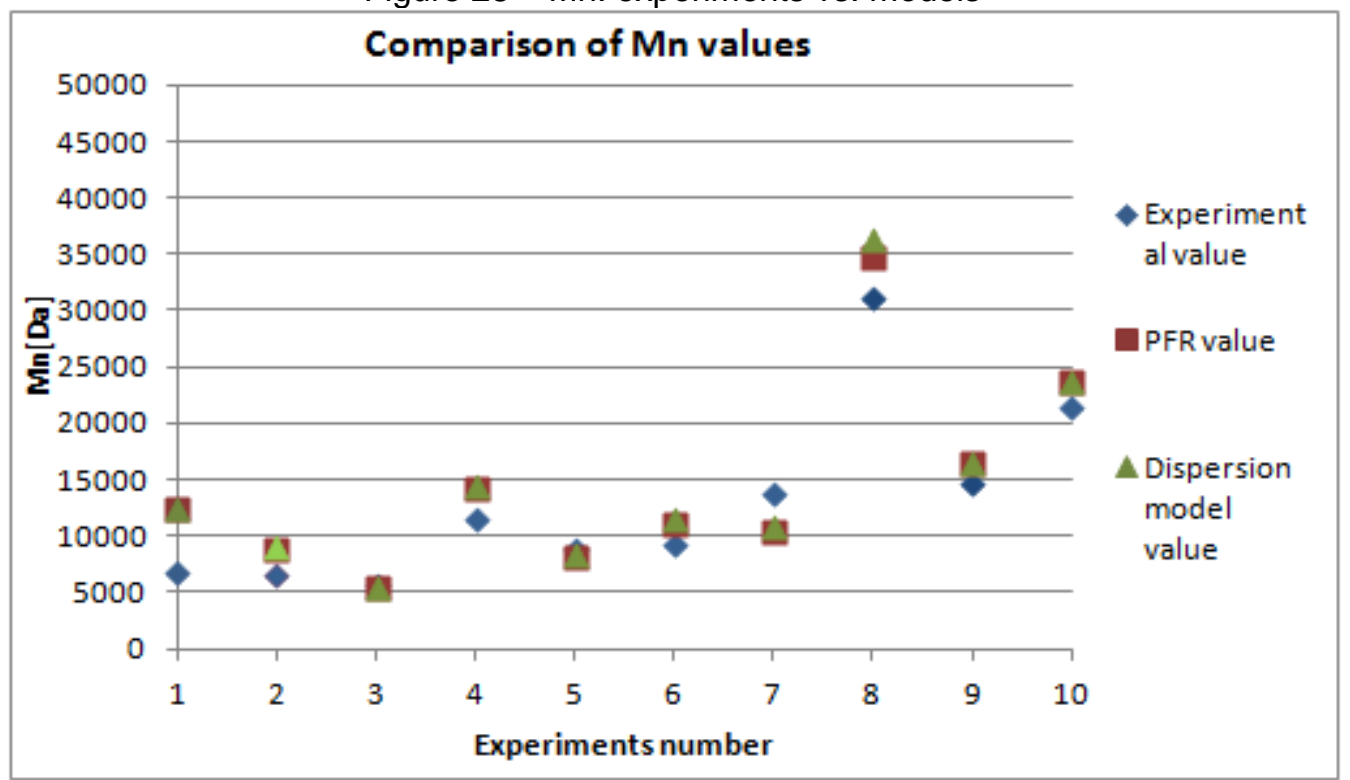


Figure $29-M w$ : experiments vs. models

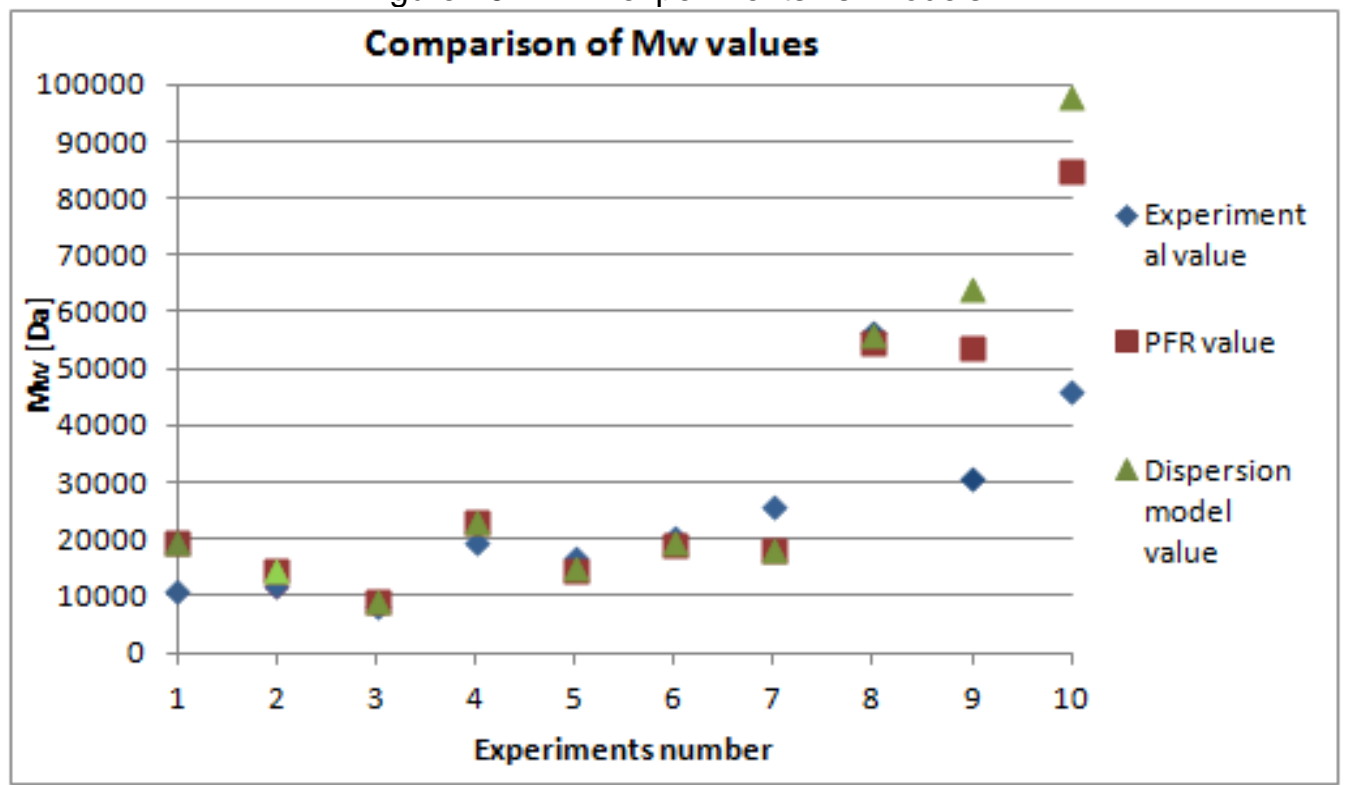

Table 30 - Results exp1

\begin{tabular}{cccc}
\hline Exp 1 & Conversion & Mw & Mn \\
\hline Experimental & 0.091 & 10607 & 6768 \\
Ideal Plug Flow & 0.141 & 19279 & 12475 \\
Model & 0.127 & 19231 & 12475 \\
\hline Dispersion Model & & & \\
\hline
\end{tabular}

Table 31 - Results exp2

\begin{tabular}{cccc}
\hline Exp 2 & Conversion & Mw & Mn \\
\hline Experimental & 0.272 & 11876 & 6587 \\
Ideal Plug Flow & 0.317 & 14573 & 8783 \\
Model & 0.294 & 14646 & 8950 \\
\hline Dispersion Model & Table 32 - Results exp3 & Mn \\
\hline Exp 3 & Conversion & Mw & 5640 \\
\hline Experimental & 0.391 & 8223 & 5347 \\
Ideal Plug Flow & 0.381 & 9250 & 5428 \\
Model & 0.356 & 9256 & \\
\hline
\end{tabular}

Table 33 - Results exp4

\begin{tabular}{cccc}
\hline Exp 4 & Conversion & Mw & Mn \\
\hline Experimental & 0.181 & 19330 & 11531 \\
Ideal Plug Flow & 0.260 & 22838 & 14219 \\
Model & 0.239 & 23054 & 14549 \\
Dispersion Model & & & \\
\hline
\end{tabular}


Table 34 - Results exp5

\begin{tabular}{cccc}
\hline Exp 5 & Conversion & Mw & Mn \\
\hline Experimental & 0.478 & 16747 & 8907 \\
Ideal Plug Flow & 0.468 & 14575 & 8220 \\
Model & 0.432 & 14701 & 8432 \\
\hline Dispersion Model & & & \\
\hline
\end{tabular}

Table 35 - Results exp6

\begin{tabular}{cccc}
\hline Exp 6 & Conversion & Mw & Mn \\
\hline Experimental & 0.414 & 20497 & 9255 \\
Ideal Plug Flow & 0.426 & 19139 & 11142 \\
Model & 0.391 & 19361 & 11459 \\
Dispersion Model & & & \\
\hline
\end{tabular}

Table 36 - Results exp7

\begin{tabular}{cccc}
\hline Exp 7 & Conversion & Mw & Mn \\
\hline Experimental & 0.638 & 25571 & 13786 \\
Ideal Plug Flow & 0.516 & 17902 & 10452 \\
Model & 0.478 & 18133 & 10758 \\
\hline Dispersion Model & & & \\
\hline
\end{tabular}

Table 37 - Results exp8

\begin{tabular}{cccc}
\hline Exp 8 & Conversion & Mw & Mn \\
\hline Experimental & 0.275 & 56368 & 31077 \\
Ideal Plug Flow & 0.355 & 54418 & 34708 \\
Model & 0.323 & 55999 & 36230 \\
\hline Dispersion Model & & & \\
\hline
\end{tabular}

Table 38 - Results exp9

\begin{tabular}{cccc}
\hline Exp 9 & Conversion & Mw & Mn \\
\hline Experimental & 0.668 & 30731 & 14735 \\
Ideal Plug Flow & 0.495 & 20700 & 10256 \\
Model & 0.448 & 21876 & 10668 \\
\hline Dispersion Model & Table 39- Results & exp10 & Mn \\
\hline Exp 10 & Conversion & Mw & 21415 \\
\hline Experimental & 0.531 & 45788 & 17125 \\
Ideal Plug Flow & 0.433 & 35462 & 18102 \\
Model & 0.381 & 38747 & \\
\hline
\end{tabular}

This second correlation, however, tends to give contrasting results depending on the dilution. The more diluted the system is, the more overestimated the conversion and molecular weights are; with regards to the more concentrated systems, the opposite behavior occurs, giving dampened values of conversion and Mn. The positive characteristic of using this correlation is that it always gave little PDI values, close to 
1.5 for the first two groups of experiments and close to 2 in the third group (thus more similar to the GPC values).

\subsubsection{Experimental results vs. model results without gel effect}

A last attempt was made by eliminating the gel effect contribution. Since in styrene polymerization it appears for high conversion values, generally above $65 \%$, it could be meaningless using a gel effect correlation with the experimental conditions performed, which always gave values less or equal to this threshold. In confirmation of this, the work by Curteanu (2003) shows batch polymerizations at $120^{\circ} \mathrm{C}$ in which the typical change in conversion slope arrives at about $\chi=0.65$. For the plug flow model, the volume contraction was maintained.

Conversion, $\mathrm{Mn}$ and $\mathrm{Mw}$ values from experimental measures and Matlab simulations are summed up in Figures 30-32. The numerical results are reported in Tables 40-49, below the figures.

Figure 30 - Conversion: experiments vs. models

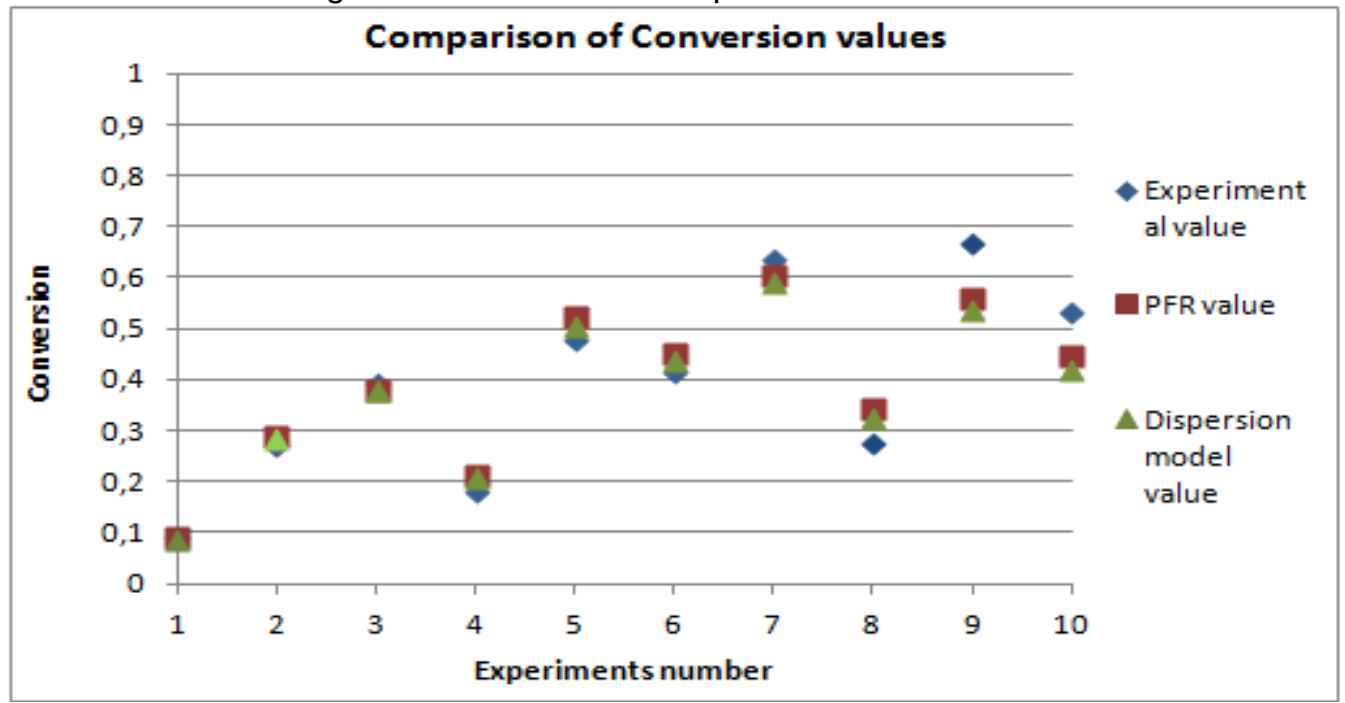


Figure $31-\mathrm{Mn}$ : experiments vs. models

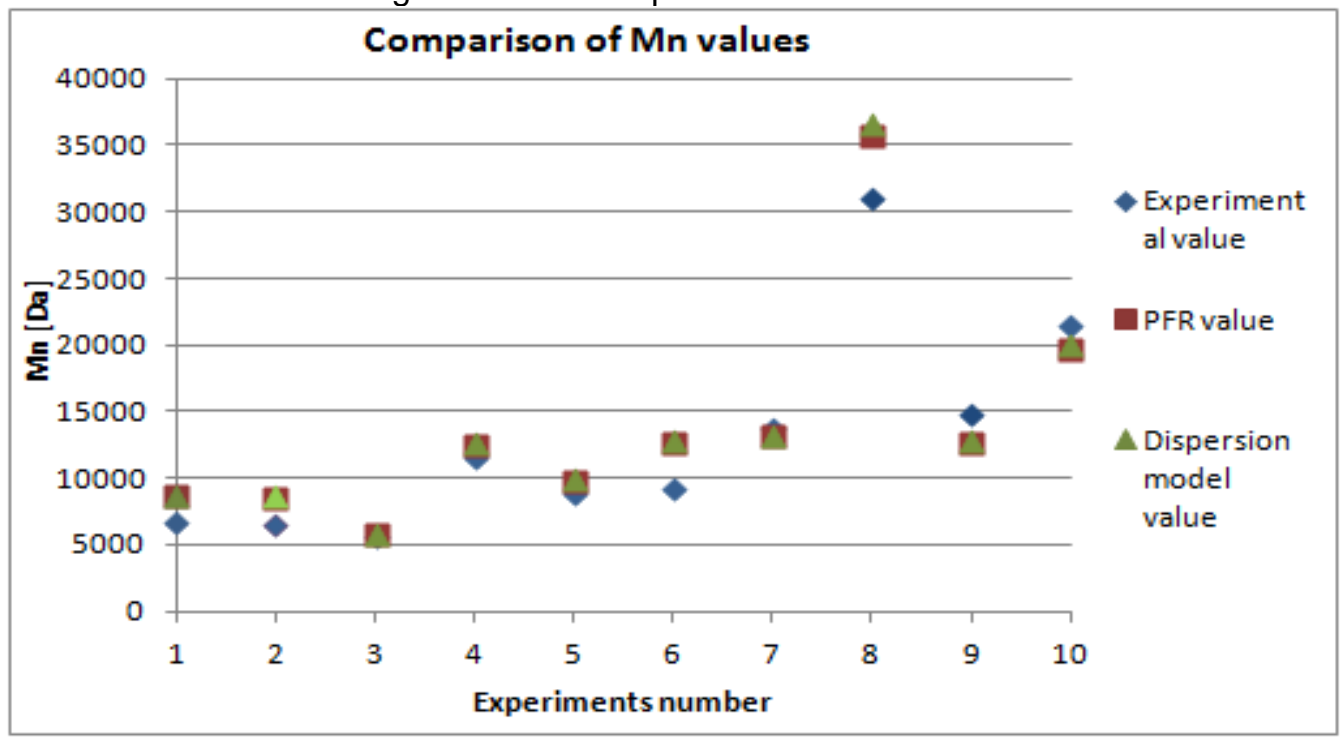

Figure $32-M w$ : experiments vs. models

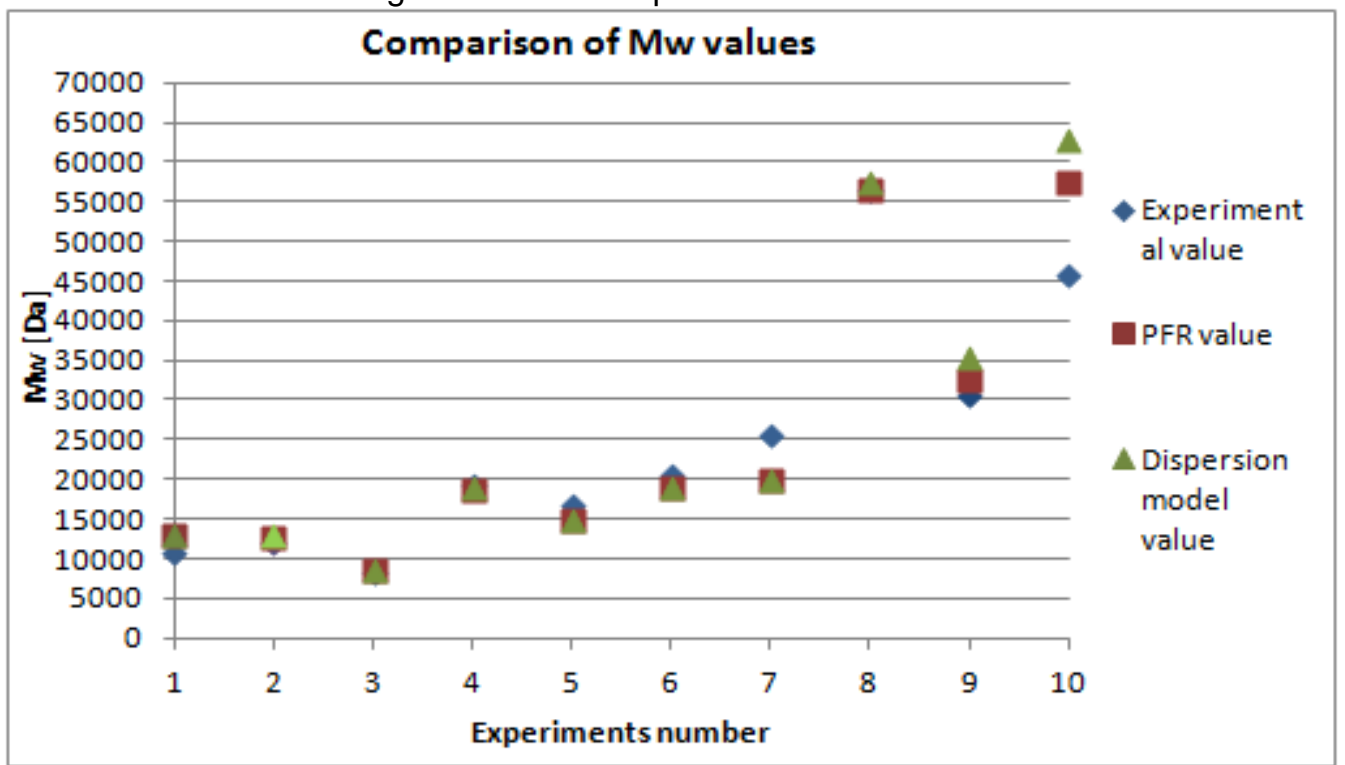

Table 40 - Results exp1.

\begin{tabular}{cccc}
\hline Exp 1 & Conversion & Mw & Mn \\
\hline Experimental & 0.091 & 10607 & 6768 \\
(averages) & 0.091 & 12888 & 8630 \\
Plug Flow Model & 0.088 & 12804 & 8713 \\
Dispersion Model & & \\
\hline
\end{tabular}

Table 41 - Results exp2

\begin{tabular}{cccc}
\hline Exp 2 & Conversion & Mw & Mn \\
\hline Experimental & 0.272 & 11876 & 6587 \\
(averages) & 0.288 & 12714 & 8511 \\
Plug Flow Model & 0.282 & 12804 & 8602 \\
\hline Dispersion Model & & \\
\hline
\end{tabular}


Table 42 - Results exp3

\begin{tabular}{cccc}
\hline Exp 3 & Conversion & Mw & Mn \\
\hline Experimental & 0.391 & 8223 & 5640 \\
(averages) & 0.381 & 8501 & 5707 \\
Plug Flow Model & 0.377 & 8541 & 5749 \\
\hline Dispersion Model & 0 & \\
\hline
\end{tabular}

Table 43 - Results exp4

\begin{tabular}{cccc}
\hline Exp 4 & Conversion & Mw & Mn \\
\hline $\begin{array}{c}\text { Experimental } \\
\text { (averages) }\end{array}$ & 0.181 & 19330 & 11531 \\
Plug Flow Model & 0.213 & 18716 & 12474 \\
Dispersion Model & 0.208 & 18908 & 12664 \\
\hline
\end{tabular}

Table 44 - Results exp5

\begin{tabular}{cccc}
\hline Exp 5 & Conversion & Mw & Mn \\
\hline $\begin{array}{c}\text { Experimental } \\
\text { (averages) }\end{array}$ & 0.478 & 16747 & 8907 \\
Plug Flow Model & 0.521 & 14697 & 9829 \\
Dispersion Model & 0.507 & 14755 & 9890 \\
\hline
\end{tabular}

Table 45 - Results exp6

\begin{tabular}{cccc}
\hline Exp 6 & Conversion & Mw & Mn \\
\hline $\begin{array}{c}\text { Experimental } \\
\text { (averages) }\end{array}$ & 0.414 & 20497 & 9255 \\
Plug Flow Model & 0.453 & 19003 & 12695 \\
Dispersion Model & 0.437 & 19106 & 12798 \\
\hline
\end{tabular}

Table 46 - Results exp7

\begin{tabular}{cccc}
\hline Exp 7 & Conversion & Mw & Mn \\
\hline $\begin{array}{c}\text { Experimental } \\
\text { (averages) }\end{array}$ & 0.638 & 25571 & 13786 \\
Plug Flow Model & 0.604 & 19762 & 13122 \\
Dispersion Model & 0.589 & 19910 & 13257 \\
\hline Exp 8 & Table 47-Results exp8 & Mn \\
\hline Experimental & Conversion & Mw & 31077 \\
(averages) & 0.275 & 56368 & 35776 \\
Plug Flow Model & 0.342 & 56434 & 36604 \\
\hline Dispersion Model & 0.326 & 57477 & \\
\hline
\end{tabular}

Table 48 - Results exp9

\begin{tabular}{cccc}
\hline Exp 9 & Conversion & Mw & Mn \\
\hline $\begin{array}{c}\text { Experimental } \\
\text { (averages) }\end{array}$ & 0.668 & 30731 & 14735 \\
Plug Flow Model & 0.561 & 32672 & 12639 \\
Dispersion Model & 0.537 & 35399 & 12784 \\
\hline
\end{tabular}


Table 49 - Results exp10

\begin{tabular}{cccc}
\hline Exp 10 & Conversion & Mw & Mn \\
\hline Experimental & 0.531 & 45788 & 21415 \\
(averages) & 0.446 & 57389 & 19736 \\
Plug Flow Model & 0.420 & 62898 & 19972 \\
\hline Dispersion Model & & & \\
\hline
\end{tabular}

All the conversion predictions of the model (both plug flow and dispersion model) matched with the experimental results for the first and second block of experiments. The statistical analysis in Figure 33 confirms this matching with respect to the dispersion model:

Figure 33 - Comparison between dispersion model results and experiments; the model results are represented by markers, the experimental ones by their confidence interval

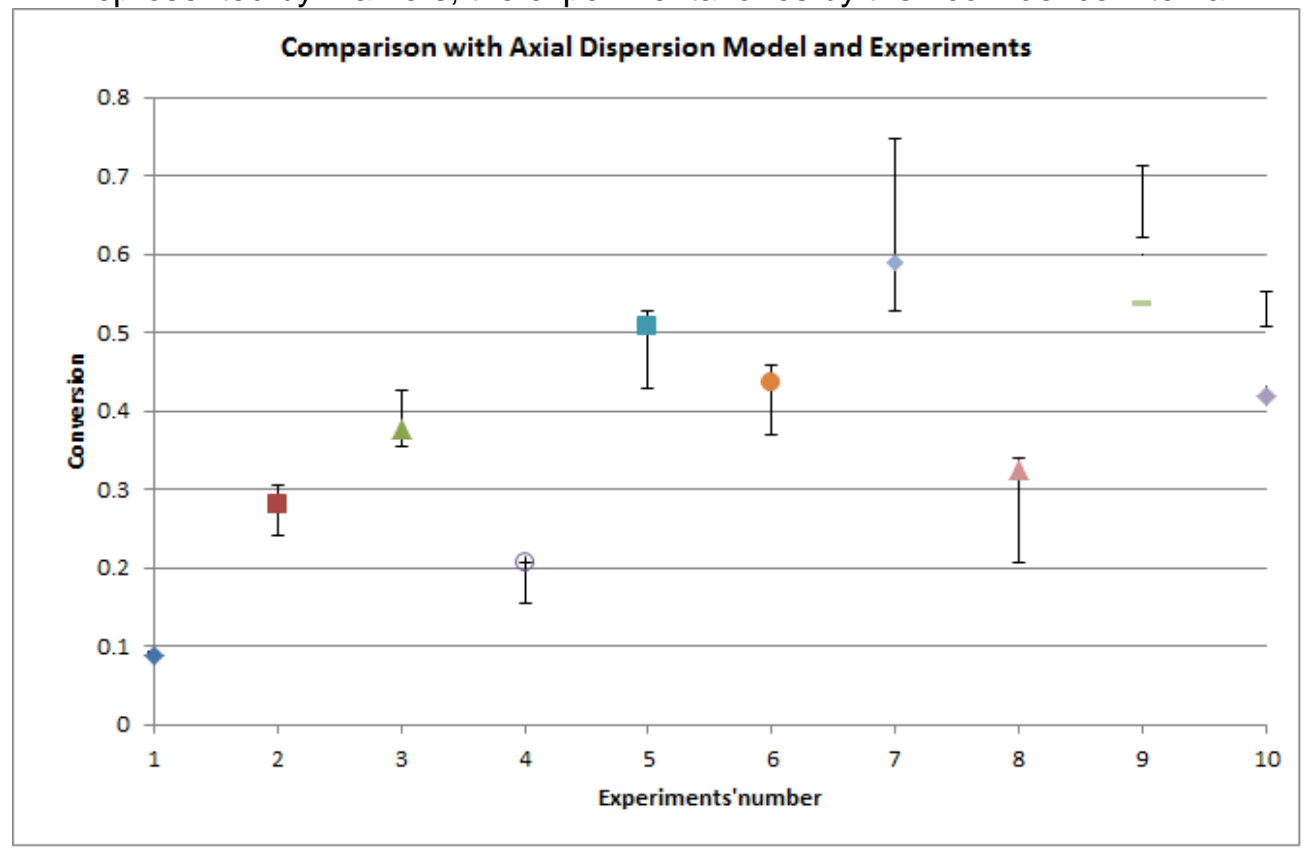

However, in the last two experiments, performed at higher temperature and monomer conversion, it seems that the gel effect contribution cannot be neglected. In fact, in Table 16 the viscosities measures had already shown that these were the experiments in which diffusion limitations could influence the most.

Thus, from the necessity of newly introducing the gel effect only for Experiment 9 and 10, the modified correlation proposed by Hamer et al. (1981) was tested.

The obtained results are shown in Tables 50-51 and statistically analyzed in Figure 34. 
Table 50 - Results exp9

\begin{tabular}{cccc}
\hline Exp 9 & Conversion & Mw & Mn \\
\hline $\begin{array}{c}\text { Experimental } \\
\text { (averages) }\end{array}$ & 0.668 & 30731 & 14735 \\
Plug Flow Model & 0.707 & 51121 & 16146 \\
Dispersion Model & 0.687 & 63230 & 16348 \\
\hline & Table 51 - Results exp10 & \\
\hline Exp 10 & Conversion & Mw & Mn \\
\hline Experimental & 0.531 & 45788 & 21415 \\
(averages) & 0.527 & 83563 & 23557 \\
Plug Flow Model & 0.498 & 97077 & 23677 \\
\hline Dispersion Model & &
\end{tabular}

Figure 34 - Comparison between dispersion model results and experiments 9 and 10, with gel effect; the model results are represented by markers, the experimental ones by their confidence interval

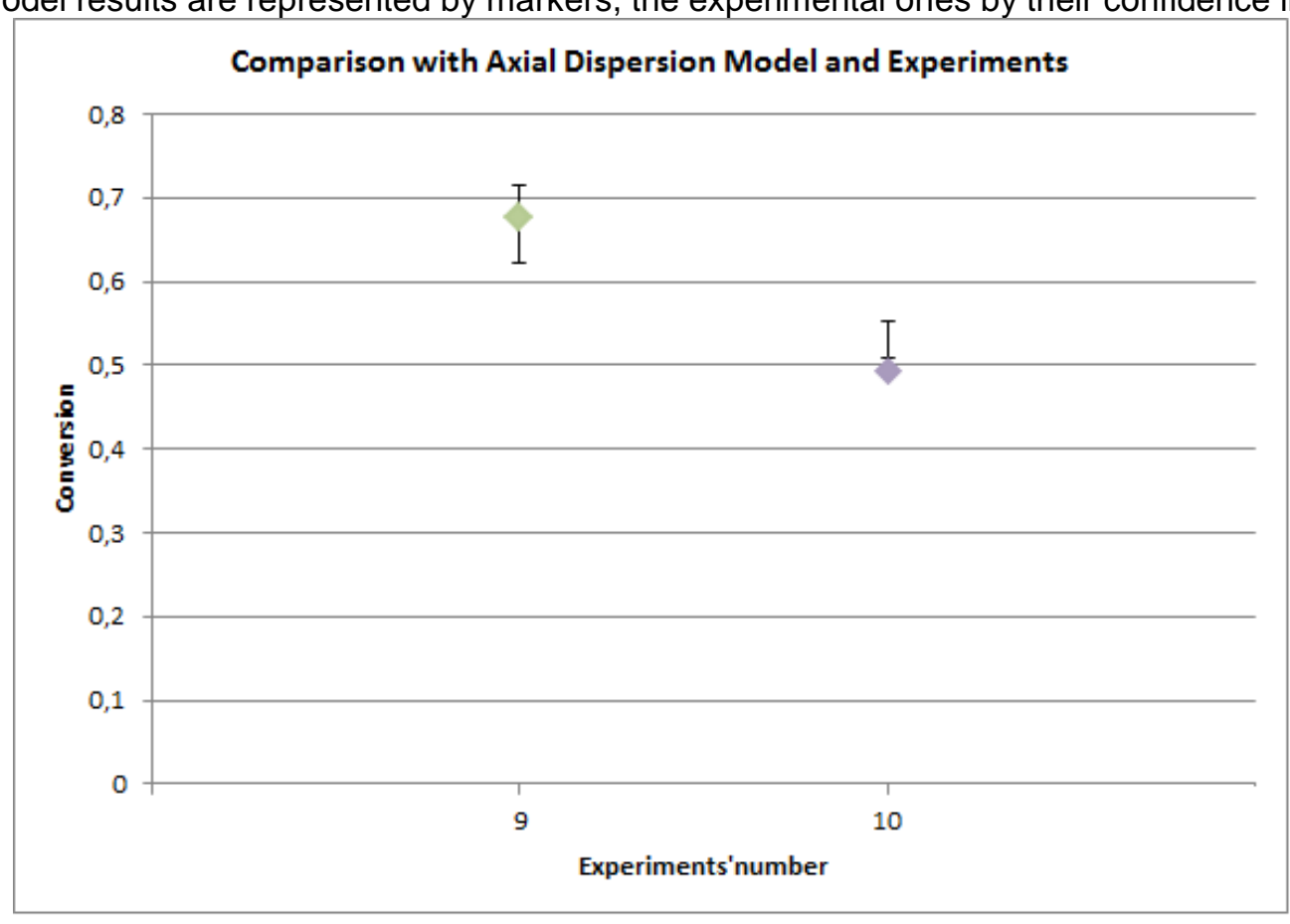

Conversions results are now predicted with more accuracy. However, molecular weights values are better predicted by the models without gel effect, as can be seen in Table 48 and in Table 49.

A possible explanation for this behavior may be found in the mixing degree inside the millireactor. The high viscosity lowers the radicals mobility, thus increasing their concentration; the polymerization rate rises, favoring also conversion. On the other hand, what seems to guarantee a uniform growth of the polymeric chains in the reactor is its degree of mixedness. Namely that the millireactor, with its specific 
geometric characteristics, manages to uniform the flow, thus maintaining the PDI values low, even though not exactly 1.5 as it would be for perfect uniformity.

\subsubsection{Mixing considerations}

As introduced in section 2.2.6, it could be useful to describe the millireactor by an "effective dispersion coefficient" that depends on the efficiency of micromixing of polymer chains and monomer units. This parameter would be strictly related to both the Asia geometric characteristics and the particular polymerization conditions inside the reactor; it can also be associated to the "millireactor mixing time".

In order to develop the previous concepts, it is necessary to solve a constrained optimization problem: finding the best axial dispersion value that minimizes the residues of conversion and molecular weights:

$$
F=\left(1-\frac{\chi_{\text {model }}}{\chi_{\text {exp }}}\right)^{2}+\left(1-\frac{M_{n_{\text {model }}}}{M_{n_{\text {exp }}}}\right)^{2}+\left(1-\frac{M_{w_{\text {model }}}}{M_{w_{\text {exp }}}}\right)^{2}
$$

Adopting the Matlab function fmincon, with lower and upper boundary conditions applied to the velocity value, the "effective dispersion coefficients" were calculated. However, the objective function turned to be hard to minimize; in fact, in order to succeed in its minimization, it was necessary to set soft tolerances. In various cases, the minimum found was just local.

Since during the simulations the molecular weights values appeared not to be strongly affected by the axial dispersion parameter, it seemed to be more convenient to reduce the objective function at the only residues of conversion:

$$
F=\left(1-\frac{\chi_{\text {model }}}{\chi_{\text {exp }}}\right)^{2}
$$

The minimization of eq.(88), in fact, besides not being very successful, predicted new conversion values still different from the experimental ones.

Table 52 reports the old and the optimized axial dispersion coefficients, with the new conversion and molecular weights values obtained after optimization. 
Table 52 - Effective dispersion coefficient after optimization

\begin{tabular}{|c|c|c|c|c|c|c|c|c|c|}
\hline & & $\begin{array}{l}D_{a x} \text {, old } \\
{\left[\mathrm{m}^{2} / \mathrm{s}\right]}\end{array}$ & $\begin{array}{c}D_{\mathrm{ax}} \\
\text { optimized } \\
{\left[\mathrm{m}^{2} / \mathrm{s}\right]}\end{array}$ & $X_{\text {exp }}$ & $\mathbf{X}_{\text {optimized }}$ & $\begin{array}{c}\mathrm{Mn}_{\exp } \\
\text { [Da] }\end{array}$ & $\begin{array}{l}\text { Mn }{ }_{\text {optimized }} \\
\text { [Da] }\end{array}$ & $\begin{array}{c}M w_{\text {exp }} \\
\text { [Da] }\end{array}$ & $\begin{array}{c}\text { Mw } \mathbf{w}_{\text {optimized }} \\
\text { [Da] }\end{array}$ \\
\hline \multirow{4}{*}{ 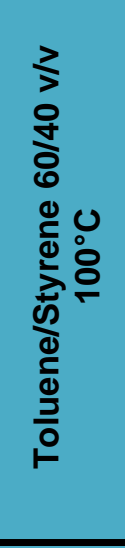 } & $\begin{array}{c}\text { Exp 1* } \\
\tau=5 m i n \\
m_{\text {init }}=1 g\end{array}$ & $6.0 \mathrm{E}-03$ & $6.0 \mathrm{E}-03$ & 0.091 & $0.088^{*}$ & 6768 & 8713 & 10626 & 12971 \\
\hline & $\begin{array}{c}\text { Exp } 2 \\
\tau=20 m i n \\
m_{\text {init }}=1 g\end{array}$ & $\begin{array}{c}\text { 3.754E- } \\
04\end{array}$ & $\begin{array}{c}\text { 3.380E- } \\
02\end{array}$ & 0.272 & 0.272 & 6587 & 8585 & 11857 & 12778 \\
\hline & $\begin{array}{c}\text { Exp 3* } \\
\tau=20 \min \\
m_{\text {init }}=2 g\end{array}$ & $\begin{array}{c}\text { 3.754E- } \\
04\end{array}$ & $\begin{array}{c}3.754 \mathrm{E}- \\
04\end{array}$ & 0.391 & $0.377^{\star}$ & 5640 & 5749 & 8234 & 8541 \\
\hline & $\begin{array}{c}\text { Exp } 4 \\
\tau=20 m i n \\
m_{\text {init }} \\
=0.5 \mathrm{~g}\end{array}$ & $\begin{array}{c}3.754 \mathrm{E}- \\
04\end{array}$ & $\begin{array}{c}\text { 6.348E- } \\
01\end{array}$ & 0.181 & 0.181 & 11531 & 12832 & 19372 & 19154 \\
\hline \multirow{4}{*}{ 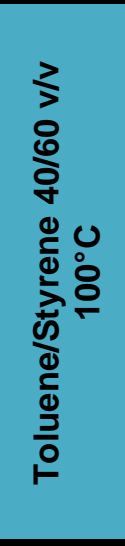 } & $\begin{array}{c}\text { Exp } 5 \\
\tau=40 \min \\
m_{\text {init }} \\
=1.5 \mathrm{~g}\end{array}$ & $\begin{array}{c}9.386 \mathrm{E}- \\
05\end{array}$ & $\begin{array}{c}\text { 1.191E- } \\
01\end{array}$ & 0.478 & 0.478 & 8907 & 9835 & 17101 & 14663 \\
\hline & $\begin{array}{c}\text { Exp } 6 \\
\tau=40 m i n \\
m_{\text {init }}=1 \mathrm{~g}\end{array}$ & $\begin{array}{c}9.386 \mathrm{E}- \\
05\end{array}$ & $\begin{array}{c}1.194 \mathrm{E}- \\
01\end{array}$ & 0.414 & 0.414 & 9255 & 12775 & 20824 & 19070 \\
\hline & $\begin{array}{c}\operatorname{Exp} 7^{*} \\
\tau=80 \min \\
m_{\text {init }}=1 \mathrm{~g}\end{array}$ & $\begin{array}{c}2.347 \mathrm{E}- \\
05\end{array}$ & $\begin{array}{c}2.347 \mathrm{E}- \\
05\end{array}$ & 0.638 & $0.589^{*}$ & 13786 & 13257 & 25642 & 19911 \\
\hline & $\begin{array}{c}\text { Exp } 8 \\
\tau=80 m i n \\
m_{\text {init }} \\
=0.2 \mathrm{~g}\end{array}$ & $\begin{array}{c}2.347 \mathrm{E}- \\
05\end{array}$ & $\begin{array}{c}1.716 \mathrm{E}- \\
01\end{array}$ & 0.279 & 0.279 & 31077 & 38384 & 56249 & 57682 \\
\hline \multirow{2}{*}{ 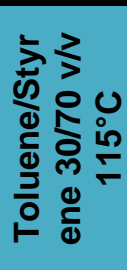 } & $\begin{array}{c}\text { Exp } 9 \\
\tau=80 m i n \\
m_{\text {init }}=1 g\end{array}$ & $\begin{array}{c}2.347 E- \\
05\end{array}$ & - & 0.668 & - & 14735 & - & 31607 & - \\
\hline & $\begin{array}{l}\text { Exp } 10 \\
\tau=80 \mathrm{~min} \\
\boldsymbol{m}_{\text {init }} \\
\quad=0.5 \mathrm{~g}\end{array}$ & $\begin{array}{c}2.347 \mathrm{E}- \\
05\end{array}$ & - & 0.531 & - & 21415 & - & 46471 & - \\
\hline
\end{tabular}

In some cases, however, the minimization process was still not effective. In Experiments 1, 3 and 7, marked with a star, the variation of the axial dispersion parameter did not succeed in matching the experimental conversion value, always returning the starred one (see Table 52). Conversion would match only if the mean axial velocity changed, but this could be eventually justified merely for Experiment 7 , in which viscosity increased significantly (as can be seen in Table 16): this may have caused a velocity reduction, leading to higher conversions, too.

Neither has the optimization been successful in Experiments 9 and 10, due to difficulties related to the fsolve function of Matlab (which did not manage to solve the algebraic systems of the mass balances for other axial dispersion values). Probably 
the reason of this failure should be searched in the stiffness of the problem, enhanced by a higher temperature value.

In all the other cases, the experiments seem to be better represented by a greater axial dispersion coefficient by two, three or four orders of magnitude with respect to the expression in eq.(66); it appears that the slower the flow, the stronger the axial dispersion is. This could be explained by the fact of the fluid spending more time in the reactor, thus enhancing this process of molecular and convective mixing.

For laminar uniaxial flows, the mixing length $l_{m i x}$ is found to be proportional to $P e$ times the channel width (HESSEL et al., 2005). After having developed the axial dispersion model, it would be a better choice to calculate $P e$ as the inverse of the axial dispersion number (eq.(69)). Thus, it is possible to state:

$$
l_{m i x} \propto P e * d_{t}=\frac{v_{z} L}{D_{a x}} * d_{t}
$$

From the parameter of eq.(89), one can estimate the characteristic mixing time of the millireactor under different experimental conditions, by calculating:

$$
t_{m i x} \propto \frac{l_{m i x}^{2}}{D_{a x}}
$$

This value will be assumed as the micromixing time of the reactor for those very reactive conditions.

For comparison, it is necessary to calculate the reaction time in the reactor, which can be associated to the characteristic time of monomer consumption or radical growth. From eq.(28), the time needed by a radical chain to grow by a factor of 1000 can be deduced :

$$
\tau_{\text {polymerizaion }}=\frac{1000}{k_{p} M}
$$

$k_{p}$ is $0.72 \frac{\mathrm{m}^{3}}{\mathrm{mol*s}}$ at $100{ }^{\circ} \mathrm{C}$ and $1.042 \frac{\mathrm{m}^{3}}{\mathrm{mol*s}}$ at $115^{\circ} \mathrm{C}$; the styrene concentration varied from about $3500 \frac{\mathrm{mol}}{\mathrm{m}^{3}}$ to $6100 \frac{\mathrm{mol}}{\mathrm{m}^{3}}$. Thus one has:

$$
\tau_{\text {polymerization }} \approx \frac{1000}{[0.72 \rightarrow 1] *[3500 \rightarrow 6100]} s=\frac{1000}{[2520 \rightarrow 6100]} s=0.16 s \rightarrow 0.4 s
$$

Another temporal value that may be compared to $t_{\text {mix }}$ is the reactor residence time: 


$$
\tau=5 \mathrm{~min} \rightarrow 80 \mathrm{~min}=300 \rightarrow 4800 \mathrm{~s}
$$

Hence, all the temporal scales that can be distinguished inside a reactor are considered, as mentioned in section 2.2 .5 by the work by Wissler (1969).

In Table 53 and Table 54 the mixing lengths and mixing times of the millireactor are reported, as calculated from eq.(90) and eq.(91):

Table 53 - Mixing lengths and times for the first group of experiments

\begin{tabular}{ccccc}
\hline & Exp 1 & Exp 2 & Exp 3 & Exp 4 \\
\hline $\begin{array}{c}\boldsymbol{l}_{\text {mixing }}[\mathrm{m}] \\
{[\mathrm{m}]}\end{array}$ & - & $5.110 \mathrm{E}-03$ & - & $3.291 \mathrm{E}-04$ \\
\hline $\begin{array}{c}\boldsymbol{t}_{\text {mixing }} \\
{[\mathrm{s}]}\end{array}$ & - & $7.73 \mathrm{E}-04$ & - & $2.064 \mathrm{E}-07$ \\
\hline
\end{tabular}

Table 54 - Mixing lengths and times for the second group of experiments

\begin{tabular}{ccccc} 
& Exp 5 & Exp 6 & Exp 7 & Exp 8 \\
\hline $\begin{array}{c}\boldsymbol{l}_{\text {mixing }}[\mathrm{m}] \\
{\left[\begin{array}{c}\boldsymbol{t}_{\text {mixing }} \\
{[\mathrm{s}]}\end{array}\right.}\end{array}$ & $4.675 \mathrm{E}-03$ & $4.652 \mathrm{E}-03$ & - & $2.516 \mathrm{E}-05$ \\
\hline
\end{tabular}

The mixing times are always smaller by at least two orders of magnitude with respect to the reaction times; this difference is even greater with regard to residence times. Therefore, this comparison confirmed an efficient mixing inside the millireactor and reduced diffusional limitations; polydispersities are thus decreased in relation to conventional reactors.

\subsection{Efficiency comparison among the millireactor and other reactors performance}

In order to complete the analysis of the Syrris millireactor, its performance should be evaluated in terms of conversion and polymer productivity.

The space time yield, as defined by Gritzner and Kreysa (1993), represents the mass of a product $\mathrm{P}$ formed per volume of the reactor and time:

$$
\sigma_{P}=\frac{m_{p o l}}{V * t}\left[\frac{k g}{m^{3} s}\right]
$$


This parameter could be used to compare efficiencies in batch and continuous reactors, by adopting the time $t$ for the first reactors type and residence time $\tau$ for the second one.

The mass of polymer can be calculated by the conversion value, using eq.(96) for batch reactors and eq.(97) for continuous reactors:

$$
\begin{aligned}
& m_{P}=\chi * n_{s t y, 0} * M W_{s t y} \\
& \dot{m}_{P}=\chi * n_{s t y, 0} * M W_{s t y}
\end{aligned}
$$

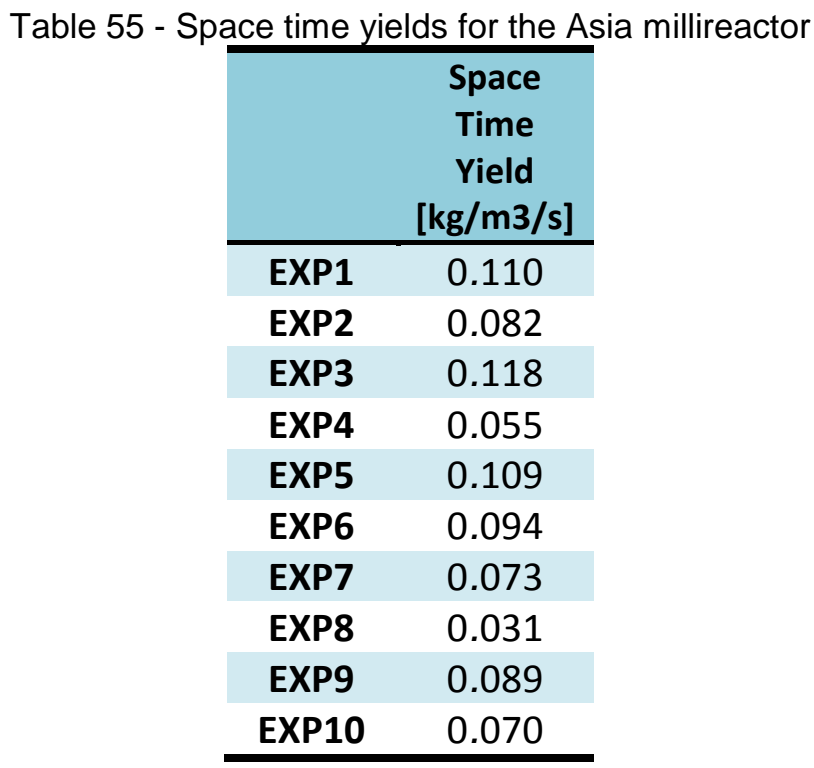

In order to compare the styrene polymerization yield of the Asia Syrris reactor with other reactors, the same parameter can be calculated. Different experimental references have been analyzed: in Table 56, Vianna's (2003) results using three different tubular reactors; in Table 57, various tubular, batch, CSTR reactors and microreactors, too. 
Table 56 - Space time yields obtained by Vianna (2003)

\begin{tabular}{cccccc}
\hline Reactor type & $\begin{array}{c}\text { Conversio } \\
\mathrm{n}\end{array}$ & $\begin{array}{c}\text { Residence } \\
\text { time }[\mathrm{min}]\end{array}$ & $\begin{array}{c}\boldsymbol{n}_{\text {sty, }} \\
{[\mathrm{mol} / \mathrm{min}]}\end{array}$ & $\begin{array}{c}\text { Reactor } \\
\text { Volume }[\mathrm{m} 3]\end{array}$ & $\begin{array}{c}\text { Space Time Yield } \\
{[\mathrm{kg} / \mathrm{m3} / \mathrm{s}]}\end{array}$ \\
\hline $\begin{array}{c}\text { Empty tubular reactor } \\
\text { I }\end{array}$ & 0.2 & 77.3 & 0.007 & 0.0001546 & 0.016 \\
\hline $\begin{array}{c}\text { Empty tubular reactor } \\
\text { II }\end{array}$ & 0.35 & 77.3 & 0.007 & 0.0001546 & 0.027 \\
\hline $\begin{array}{c}\text { Reactor with } \\
\text { continuous filling I }\end{array}$ & 0.22 & 69.6 & 0.007 & 0.0001391 & 0.019 \\
\hline $\begin{array}{c}\text { Reactor with } \\
\text { continuous filling II }\end{array}$ & 0.4 & 69.6 & 0.007 & 0.0001391 & 0.035 \\
\hline $\begin{array}{c}\text { Reactor with } \\
\text { uncontinuous filling I }\end{array}$ & 0.2 & 71.5 & 0.007 & 0.000143 & 0.017 \\
\hline $\begin{array}{c}\text { Reactor with } \\
\text { uncontinuous filling II }\end{array}$ & 0.35 & 71.5 & 0.007 & 0.000143 & 0.030 \\
\hline
\end{tabular}

Source: Vianna (2003)

Table 57 - Space time yields obtained by various authors with different reactors

\begin{tabular}{|c|c|c|c|c|c|c|}
\hline Reference & Reactor type & $\begin{array}{l}\text { Conve } \\
\text { rsion }\end{array}$ & $\begin{array}{c}\text { Reaction } \\
\text { time } \\
\text { [min] }\end{array}$ & $\begin{array}{l}\mathrm{N}_{\text {sty }, 0}[\mathrm{~mol}] \\
\text { or } n_{\text {sty }, 0} \\
{[\mathrm{~mol} / \mathrm{min}]}\end{array}$ & $\begin{array}{l}\text { Reactor } \\
\text { volume } \\
\text { [m3] }\end{array}$ & $\begin{array}{c}\text { Space Time } \\
\text { Yield }[\mathrm{kg} / \mathrm{m} 3 / \mathrm{s}]\end{array}$ \\
\hline \multirow{2}{*}{$\begin{array}{c}\text { Cabral et al., } \\
2004\end{array}$} & $\begin{array}{c}\text { Tubular Reactor, } \\
\text { styrene/toluene } \\
40 / 60 \mathrm{v} / \mathrm{v}\end{array}$ & 0.5 & 190 & 0.007 & 0.00038 & 0.016 \\
\hline & $\begin{array}{c}\text { Tubular Reactor, } \\
\text { styrene/toluene } \\
60 / 40 \mathrm{v} / \mathrm{v}\end{array}$ & 0.6 & 190 & 0.0105 & 0.00038 & 0.029 \\
\hline \multirow{2}{*}{$\begin{array}{c}\text { Hamielec, } \\
\text { Hodgins and } \\
\text { Tebbens, } 1967\end{array}$} & $\begin{array}{l}\text { Batch Reactor, } \\
30 \% \text { w styrene }\end{array}$ & 0.25 & 60 & 2.618 & 0.001 & 0.019 \\
\hline & $\begin{array}{c}\text { Batch Reactor, } \\
\text { bulk }\end{array}$ & 0.425 & 60 & 8.727 & 0.001 & 0.107 \\
\hline $\begin{array}{c}\text { Duerksen, } \\
\text { Hamielec and } \\
\text { Hodgins, } 1967\end{array}$ & $\begin{array}{l}\text { Cstr Reactor, } \\
30 \% \text { w styrene }\end{array}$ & 0.3 & 160 & 2.346 & 0.0009817 & 0.097 \\
\hline $\begin{array}{c}\text { Hui and } \\
\text { Hamielec, } 1968\end{array}$ & Batch Reactor & 0.77 & 360 & 6.51 & 0.001 & 0.0242 \\
\hline $\begin{array}{c}\text { Wallis, Ritter and } \\
\text { Andre, } 1975\end{array}$ & Tubular Reactor & 0.321 & 134 & 0.3637 & 0.002629 & 0.00058 \\
\hline $\begin{array}{c}\text { Fontoura et al., } \\
2002\end{array}$ & $\begin{array}{l}\text { Batch Reactor, } \\
70 \% \text { w styrene }\end{array}$ & 0.6 & 420 & 6.109 & 0.001 & 0.015 \\
\hline $\begin{array}{c}\text { Leveson, Dunk } \\
\text { and Jachuck, } \\
2004\end{array}$ & $\begin{array}{c}\text { Microreactor } \\
\text { and tubular } \\
\text { reactor, } \\
\text { styrene/toluene } \\
83 / 17 \mathrm{v} / \mathrm{v}\end{array}$ & $\sim 0.29$ & 39 & 0.0872 & 7.856E-06 & 5.65 \\
\hline \multirow{4}{*}{$\begin{array}{l}\text { Iwasaki and } \\
\text { Yoshida, } 2005\end{array}$} & \multirow{2}{*}{$\begin{array}{c}\text { Microreactor, } \\
\text { styrene/toluene } \\
50 / 50 \mathrm{v} / \mathrm{v}\end{array}$} & 0.144 & 5 & 0.0079 & $1.77 \mathrm{E}-06$ & 0.222 \\
\hline & & 0.342 & 15 & 0.0079 & $1.77 \mathrm{E}-06$ & 0.176 \\
\hline & \multirow{2}{*}{$\begin{array}{c}\text { Batch Reactor, } \\
\text { styrene/toluene } \\
50 / 50 \mathrm{v} / \mathrm{v}\end{array}$} & 0.057 & 5 & 0.072 & $16.5 \mathrm{E}-06$ & 0.086 \\
\hline & & 0.294 & 15 & 0.072 & $16.5 \mathrm{E}-06$ & 0.148 \\
\hline
\end{tabular}


As can be seen from the yield results, the millireactor, despite its small size, is able to guarantee better efficiency in polymer productivity than most conventional reactors; similar efficiencies are also given by the Iwasaki and Yoshida's microreactor. In the case of Leveson; Dunk and Jachuck (2004), the great efficiency is due to the high feed flow and high residence time permitted by their millireactor. 


\section{Chapter 6 CONCLUSIONS}

The most concerning point of dealing polymerization in a micro or millireactor is to allow the highest performance and to avoid clogging. In the experiments performed, the reactor behavior was explored; it managed to guarantee a better efficiency in polymer productivity and no fouling occurred.

In general, the millireactor Asia can be concluded to control polymerization reactions well (giving low PDI values), besides giving satisfactory conversions values (considering its small size). From the molecular weight results, it is possible to state that small diameters really help to enhance micromixing inside the tubes, dampening the tendency of fluid segregation when viscosity rises too much. Thus, the advantages of millireactors compared to macrotubular ones are surely most evident in more aggressive situations (low-diluted system, high temperatures), as seen in the last two experiments. Experiment 10, in particular, gave the most interesting results: high conversion, a reasonable $\mathrm{Mn}$ value and a PDI of 2, with only $30 \%$ of solvent.

Succeeding in controlling polymerizations allows a reactor of such characteristics being scaled up and employed in greater productivities, ensuring good polymers qualities.

Considering the models used in the simulations, despite the simplifications, they succeeded in estimating an increasing polydispersity in the second and third block of reactions. Also the conversion values were consistent with the variation of parameters such as initiator, monomer content or residence time, besides lying inside the interval of confidence of the experimental results.

Certainly, in order to evaluate the fluid dynamic with higher precision and to choose the more adequate model, RTD experiments would be necessary. Therefore, future studies on this reactor should be oriented to find a method of developing the RTD experiments in this unconventional equipment. In addition, since computational flow dynamic is becoming more and more widespread and used to describe flows in reactors, a CFD study could also help to clarify what happens inside the millireactor. However, it could be already concluded that the analyzed millireactor shows promising characteristics in the field of polymer chemistry. This is why it would be interesting to test it with respect to other polymerization reactions, such as emulsion or suspension polymerizations. 


\section{Chapter 7 BIBLIOGRAPHY}

1. AL-HENGARI, S. Process intensification: a study of micromixing and residence time distribution characteristics in the spinning disc reactor. 2011, 399 p. Ph.D. Thesis - Newcastle University, Newcastle upon Tyne, 2011.

2. ASIA modules - Syrris, available at: http://syrris.com/flow-products/asiamodules, visited on 04/06/2014.

3. BEERS, K.J. Numerical Methods for Chemical Engineering. Applications in Matlab. New York: Cambridge University Press, 2007. 488 p.

4. BILLMEYER, F. W. Textbook of polymer science. Wiley, 1984. 600 p.

5. BISCHOFF, K.B.; LEVENSPIEL, O. Fluid dispersion-generalization and comparison of mathematical models-II Comparison of models. Chemical Engineering Science, v. 17, p. 257-264, 1962.

6. BOX, G.E.P.; HUNTER, J.S.; HUNTER, W.G. Statistics for Experimenters. Design, Innovation and Discovery. John Wiley and Sons, 2005. 655 p.

7. BRAUN, D. Polymer Synthesis: Theory and Practice: Fundamentals, Methods, Experiments. Springer, 2005, $385 \mathrm{p}$.

8. BRUUS, H. Theoretical Microfluidics. Oxford University Press, 2008. 346 p.

9. CABRAL, P.A.; MELO, P. A.; BISCAIA, E. C.; LIMA, E. L.; PINTO, J. C. Free-radical solution polymerization of styrene in a tubular reactor-effects of recycling. Polymer Engineering \& Science, v. 43, n. 6, p. 1163-1179, 2004.

10. CHEN, C.C.; NAUMAN, E.B. Verification of a complex, variable viscosity model for a tubular polymerization reactor. Chemical Engineering Science, v. 44 , n. 1 , p. $179-188,1989$.

11. CONSTANTINIDES, A.; MOSTOUFI, N. Methods for Chemical Engineering with Matlab Applications. Prentice Hall, 2000. 581 p.

12. CURTEANU, S. Modeling and simulation of free radical polymerization of styrene under semibatch reactor conditions. Central European Journal of Chemistry, v. 1, n. 1, p. 69-90, 2003.

13. DUERKSEN, J. H., HAMIELEC, A. E.; HODGINS, J. W. Polymer reactors and molecular weight distribution: Part $\mathrm{I}$. Free radical polymerization in a continuous stirred-tank reactor. AIChE J., v. 13, p. 1081-1086, 1967.

14. ENRIGHT, T. E.; CUNNINGHAM, M. F.; KEOSHKERIAN, B. Nitroxide-Mediated Polymerization of Styrene in a Continuous Tubular Reactor. Macromolecular rapid communications, v. 26, n. 4, p. 221-225, 2005. 
15.FAN, L.T.; HWANG, W.S. Dispersion of Ostwald-de Waele fluid in laminar flow through a cylindrical tube. Proc. R. Soc. Lond. Series A, Mathematical and Physical Science, v.283 (1395), p. 576-582, 1965.

16. FONTOURA, J. M. R.; SANTOS, A. F.; SILVA, F. M.; LENZI, M. K.; LIMA, E. L.; PINTO, J. C. Monitoring and control of styrene solution polymerization using NIR spectroscopy. Journal of applied polymer science, v. 90, n. 5, p. 1273-1289, 2003.

17. GHAINI, A., MESCHER, A., AGAR, D. W. Hydrodynamic studies of liquidliquid slug flows in circular microchannels. Chemical Engineering Science, v. 66, n. 6, p. 1168-1178, 2011.

18. GIUDICI, R. Projeto de Reatores para Processos de Polimerização. São Paulo: EPUSP, Departamento de Engenharia Química , 2013. 153 p. Lecture notes for the master's discipline - Engenharia de reações de polimerização I.

19. GRITZNER, G.; KREYSA, G. Nomenclature, symbols and definitions in electrochemical engineering. Pure and applied chemistry, v. 65, p. 10091009, 1993.

20. HAMIELEC, A. E.; HODGINS, J. W.; TEBBENS, K. Polymer reactors and molecular weight distribution: Part II. Free radical polymerization in a batch reactor. AIChE J., v. 13, p. 1087-1091, 1967.

21. HESSEL, V.; HARDT, S.; LÖWE, H. Chemical Micro Process Engineering: Fundamentals, Modelling and Reactions, pp. 67-68, John Wiley \& Sons, Inc., 2004.

22. HESSEL, V.; LÖWE, H.; SCHÖNFELD, F. Micromixers-a review on passive and active mixing principles. Chemical Engineering Science, v. 60, n. 8, p. 2479-2501, 2005.

23. HORNUNG, C. H.; MACKLEY, M. R. The measurement and characterisation of residence time distributions for laminar liquid flow in plastic microcapillary arrays. Chemical Engineering Science, v. 64, n. 17, p. 3889-3902, 2009.

24. HUI, A.W.; HAMIELEC, A.E., Polymer Reactors and Molecular Weight Distribution. Part V. Free-Radical Polymerization in a Transient Stirred-Tank Reactor Train. J. Polymer Science. Part C, v. 25, p. 167-189, 1968.

25. ILLG, T.; LÖB, P.; HESSEL, V. Flow chemistry using milli-and microstructured reactors-From conventional to novel process windows. Bioorganic \& medicinal chemistry, v. 18, n. 11, p. 3707-3719, 2010.

26. IWASAKI, T.; KAWANO, N.; YOSHIDA, J. Radical polymerization using microflow system: numbering-up of microreactors and continuous operation. Organic process research \& development, v. 10, p. 1126-1131, 2006. 
27. IWASAKI, T.; YOSHIDA, J. Free radical polymerization in microreactors. Significant improvement in molecular weight distribution control. Macromolecules, v. 38, n. 4, p. 1159-1163, 2005.

28. JÄNISCH, V., et al. Chemistry in Microstructured Reactors. Angew. Chem. Int., v. 43, p. 406-446, 2004.

29. JIJI, L.M. Heat Convection. Springer, 2006. 434 p.

30. KIM, K. J.; CHOI, K. Y. Steady state behavior of a continuous stirred tank reactor for styrene polymerization with bifunctional free radical initiators. Chemical engineering science, v. 43, n. 4, p. 965-977, 1988.

31. KIPARISSIDES, C. Polymerization reactor modeling: a review of recent developments and future directions. Chemical Engineering Science, v. 51, n. 10, p. 1637-1659, 2009.

32. KOCKMANN, N. Transport Phenomena in Micro Process Engineering. Springer, 2008. $365 \mathrm{p}$.

33. LEVENSPIEL, O. Chemical Reaction Engineering. John Wiley and Sons, 1999.

34. LEVESON, P.; DUNK, W. A. E.; JACHUCK, R. J. Investigation of shear effects on styrene free radical polymerization using a narrow channel reactor. Journal of applied polymer science, v. 94, n. 4, p. 1365-1369, 2004.

35. LEVIEN, K. L.; LEVENSPIEL, O. Optimal product distribution from laminar flow reactors: Newtonian and other power-law fluids. Chemical engineering science, v. 54, n. 13, p. 2453-2458, 1999.

36. LYNN, S. Comments on polymerization of styrene in a tubular reactor. AIChE Journal, v. 23, n. 3, p. 387-389, 1977.

37. LYNN, S.; HUFF, J.E. Polymerization in a Tubular Reactor. AIChE Journal, v. 17, n. 2, p.475-481, 1971.

38. MANDAL, M. M.; SERRA, C.; HOARAU, Y.; NIGAM, K. D. P. Numerical modeling of polystyrene synthesis in coiled flow inverter. Microfluidics and nanofluidics, v. 10, n. 2, p. 415-423, 2011.

39.MANO, E. B. M. Introdução a Polímeros. $2^{\mathrm{a}}$ Ed., Rio de Janeiro: Edgard Blucher, 1999. $191 \mathrm{p}$.

40.MASS, R. O.; TOMKINSON, D, L. Polymerization method employing tubular reactor. U.S. Patent No 4,046,718, 1977. 
41.MATHESON, M. S.; AUER, E. E.; BEVILACQUA, E. B.; HART, E. J. Rate Constants in Free Radical Polymerization. III. Styrene1. Journal of the American Chemical Society, v. 73, n. 4, p. 1700-1706, 1951.

42.MATYASZEWSKI, K.; DAVIS, T. Handbook of Radical Polymerization, Technology \& Engineering, 2003. 920 p.

43.MEYER, T.; KEURENTJES, J. Handbook of Polymer Reaction Engineering, Wiley, 2005. $1137 \mathrm{p}$.

44. MORBIDELLI, M. Polymer reaction and colloid engineering. Zurich: ETH, Institute for Chemical and Bioengineering , 2012. $139 \mathrm{p}$. Lecture notes for the master's discipline - Polymer reaction and colloid engineering.

45.NAGY, K. D.; SHEN, B.; JAMISON, T. F.; JENSEN, K. F. Mixing and Dispersion in Small-Scale Flow Systems. Organic Process Research \& Development, v. 16, n. 5, p. 976-981, 2012.

46. NAUMAN, E. B. Mixing in polymer reactors. Journal of Macromolecular Science-Reviews in Macromolecular Chemistry, v. 10, n. 1, p. 75-112, 1974.

47. NI, X. Continuous oscillatory baffled reactor technology. Innovations in Pharmaceutical Technology, v. 20, p. 90-96, 2006.

48. ODIAN, G. Principles of Polymerization. Fourth Edition, John Wiley \& Sons, Inc., 2004. $840 \mathrm{p}$.

49. OKUBO, Y.; MAKI, T.; NAKANISHI, F.; HAYASHI, T.; MAE, K. Precise control of polymer particle properties using droplets in the microchannel. Chemical Engineering Science, v. 65, n. 1, p. 386-391, 2010.

50.PORTILLO, M. Free-Radical Polymerization of Polystyrene Using Microreaction Technology. 2011. 192 p. Ph.D. Thesis - École Polytechnique de Montréal, Montréal, 2011.

51. RESCHETILOWSKI, W. Microreactors in Preparative Chemistry: Practical Aspects in Bioprocessing, Nanotechnology, Catalysis and more. Wiley, 2013. $300 \mathrm{p}$.

52. ROSENFELD, C.; SERRA, C.; BROCHON, C.; HADZIIOANNOU, G. Hightemperature nitroxide-mediated radical polymerization in a continuous microtube reactor: towards a better control of the polymerization reaction. Chemical Engineering Science, v. 62, n.18, p. 5245-5250, 2007.

53. SERRA, C.; SARY, N.; SCHLATTER, G.; HADZIIOANNOU, G.; HESSEL, V. Numerical simulation of polymerization in interdigital multilamination micromixers. Lab on a Chip, v. 5, n. 9, p. 966-973, 2005. 
54.STEINBACHER, J.L.; MCQUADE, D.T. Polymer chemistry in flow: New polymers, beads, capsules, and fibers. Journal of Polymer Science Part A: Polymer Chemistry, v. 44, n. 22, p. 6505-6533, 2006.

55. TEUSCHEL, $U$. What is a microreactor? It is a miniature version of the traditional, large-scale reactor that most people are familiar with. Reviews in Molecular Biotechnology, v. 82, n. 2, p. 87-88, 2001.

56. TULIG, T. J.; TIRRELL, M. Molecular theory of the Trommsdorff effect. Macromolecules, v. 14, n. 5, p. 1501-1511, 1981.

57. VEGA, M.P.; LIMA, E.L.; PINTO, J.C. Modeling and control of tubular solution polymerization reactors, Computers \& Chemical Engineering, v. 21, p. S1049-S1054, 1997.

58. VIANNA JR, A.S. Characterizing a tubular polymerization reactor by washout initiator perturbation. Lat. Am. appl. res., v. 41, n. 1, 2011.

59. VIANNA JR., A. S. Reatores tubulares para polimerização: caracterização da fluidodinâmica, modelagem e simulação. 2003. 212 p. Ph.D. Thesis COPPE/UFRJ, D.Sc.,Engenharia Química, Universidade Federal do Rio de Janeiro, COPPE, Rio de Janeiro, 2003.

60.WALLIS, J. P. A.; RITTER, R. A.; ANDRE, H. Continuous production of polystyrene in a tubular reactor: Part I. AIChE Journal, v. 21, n. 4, p. 686$691,1975$.

61.WANG, X.; YONG, Y.; FAN, P.; YU, G.; YANG, C.; MAO, Z. S. Flow regime transition for cocurrent gas-liquid flow in micro-channels. Chemical Engineering Science, v. 69, n. 1, p. 578-586, 2012.

62. WEGNER, J.; CEYLAN, S.; KIRSCHNING, A. Ten key issues in modern flow chemistry. Chemical Communications, v. 47, n. 16, p. 4583-4592, 2011.

63.WILMS, D.; KLOS, J.; FREY, H. Microstructured Reactors for Polymer Synthesis: A Renaissance of Continuous Flow Processes for Tailor-Made Macromolecules?. Macromolecular chemistry and physics, v. 209, n. 4, p. 343-356, 2008.

64. WISSLER, E. H. On the applicability of the Taylor-Aris axial diffusion model to tubular reactor calculations. Chemical Engineering Science, v. 24, n. 3, p. 527-539, 1969.

65.WU, T.; MEI, Y.; CABRAL, J. T.; XU, C.; BEERS, K. L. A new synthetic method for controlled polymerization using a microfluidic system. Journal of the American Chemical Society, v. 126, n. 32, p. 9880-9881, 2004.

66. WULKOW, M. The simulation of molecular weight distributions in polyreaction kinetics by discrete Galerkin methods. Macromolecular theory and simulations, v. 5, n. 3, p. 393-416, 2006. 
67. YOON, W.J. Experimental study and model simulation of a two-stage continuous polymerization process for polystyrene. Korean J. of Chemical Engineering, v.13, n. 1, p. 88-96, 1996.

68. YOU-QI, Y. A. N. G. Microscale and nanoscale process systems engineering: challenge and progress. The Chinese Journal of Process Engineering, v. 8, n. 3, p. 616-624, 2008. 


\section{APPENDIX A}

Summary of all the experimental results:

\begin{tabular}{|c|c|c|c|c|c|c|c|c|c|c|c|}
\hline & \multicolumn{4}{|c|}{ Toluene/Styrene $60 / 40 \mathrm{v} / \mathrm{v}$} & \multicolumn{4}{|c|}{ Toluene/Styrene $40 / 60 \mathrm{v} / \mathrm{v}$} & \multicolumn{2}{|c|}{$\begin{array}{l}\text { Toluene/Styre } \\
\text { ne } 30 / 70 \mathrm{v} / \mathrm{v}\end{array}$} \\
\hline & & 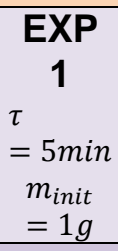 & $\begin{array}{l}\text { EXP } \\
\quad \mathbf{2} \\
\tau \\
=20 \mathrm{~min} \\
m_{\text {init }} \\
=1 \mathrm{~g}\end{array}$ & $\begin{array}{l}\text { EXP } \\
\quad \mathbf{3} \\
\tau \\
=20 \mathrm{~min} \\
m_{\text {init }} \\
=2 \mathrm{~g}\end{array}$ & 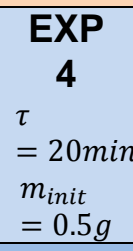 & $\begin{array}{l}\quad \text { EXP } \\
\quad \mathbf{5} \\
\tau \\
=40 \mathrm{~min} \\
m_{\text {init }} \\
=1.5 \mathrm{~g}\end{array}$ & $\begin{array}{l}\text { EXP } \\
\quad \mathbf{6} \\
\tau \\
=40 \mathrm{~min} \\
m_{\text {init }} \\
=1 \mathrm{~g}\end{array}$ & $\begin{array}{l}\text { EXP } \\
\quad 7 \\
\begin{array}{l}\tau \\
= \\
m_{\text {init }} \\
=1 \mathrm{~min} \\
=1 \mathrm{~g}\end{array}\end{array}$ & $\begin{array}{l}\quad \text { EXP } \\
\quad \mathbf{8} \\
\tau \\
=80 \mathrm{~min} \\
m_{\text {init }} \\
=0.2 \mathrm{~g}\end{array}$ & $\begin{array}{l}\text { EXP } \\
\quad \mathbf{9} \\
\tau \\
=80 \mathrm{~min} \\
m_{\text {init }} \\
=1\end{array}$ & $\begin{array}{l}\text { EXP } \\
\quad \mathbf{1 0} \\
\tau \\
=80 \mathrm{~min} \\
m_{\text {init }} \\
=0.5 \mathrm{~g}\end{array}$ \\
\hline \multirow{4}{*}{ 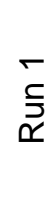 } & $\begin{array}{c}\text { Convers } \\
\text { ion }\end{array}$ & $\begin{array}{c}0.089 \\
6 \\
\end{array}$ & 0.241 & 0.372 & 0.158 & 0.462 & 0.397 & 0.56 & 0.233 & 0.653 & 0.528 \\
\hline & PDI & 1.63 & 1.874 & 1.47 & 1.67 & 1.56 & 1.91 & 2.19 & 1.61 & 1.83 & 1.94 \\
\hline & $\mathrm{Mn}[\mathrm{Da}]$ & 6919 & 5892 & 5210 & 10334 & 10280 & 15542 & 13802 & 35385 & 8512 & 26088 \\
\hline & $\mathrm{Mw}[\mathrm{Da}]$ & 11247 & 11043 & 7656 & 17274 & 15982 & 29607 & 30161 & 57106 & 15603 & 50576 \\
\hline \multirow{4}{*}{ 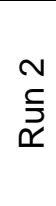 } & $\begin{array}{c}\text { Convers } \\
\text { ion }\end{array}$ & 0.093 & 0.266 & 0.408 & 0.18 & 0.473 & 0.411 & 0.658 & 0.234 & 0.689 & 0.524 \\
\hline & PDI & 1,51 & 1.7 & 1.45 & 1.85 & 1.83 & 1.59 & 1.73 & 1.78 & 1.86 & 2.13 \\
\hline & $\mathrm{Mn}[\mathrm{Da}]$ & 6616 & 6463 & 6069 & 11905 & 8205 & 10264 & 13388 & 24375 & 17676 & 19721 \\
\hline & Mw [Da] & 9967 & 10990 & 8790 & 22062 & 15043 & 16313 & 23214 & 43259 & 32787 & 41920 \\
\hline \multirow{4}{*}{$\begin{array}{l}\stackrel{m}{1} \\
\stackrel{5}{\not}\end{array}$} & $\begin{array}{c}\text { Convers } \\
\text { ion }\end{array}$ & 0.083 & 0.312 & 0.37 & 0.187 & 0.5 & 0.433 & 0.722 & 0.361 & 0.663 & 0.541 \\
\hline & PDI & 2.16 & 1.52 & 3.51 & 2.03 & 2.27 & 2.4 & 1.88 & 2.05 & 2.43 & 2.43 \\
\hline & $\mathrm{Mn}[\mathrm{Da}]$ & 2838 & 6430 & 2536 & 14908 & 7670 & 8886 & 11927 & 33472 & 11793 & 18436 \\
\hline & $\mathrm{Mw}[\mathrm{Da}]$ & 6133 & 9781 & 8892 & 30213 & 17419 & 21315 & 22385 & 68740 & 28674 & 44867 \\
\hline \multirow{4}{*}{ 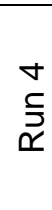 } & $\begin{array}{c}\text { Convers } \\
\text { ion }\end{array}$ & 0.098 & 0.268 & 0.413 & 0.198 & & & 0.61 & 0.289 & & \\
\hline & PDI & 1.85 & 1.84 & & 1.51 & & & 1.65 & 2.09 & & \\
\hline & $\mathrm{Mn}[\mathrm{Da}]$ & 3912 & 7406 & & 12354 & & & 14169 & 19419 & & \\
\hline & $\mathrm{Mw}$ [Da] & 7234 & 13595 & & 18665 & & & 23337 & 40595 & & \\
\hline \multirow{3}{*}{ 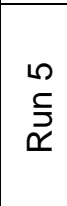 } & $\begin{array}{c}\text { Convers } \\
\text { ion }\end{array}$ & & 0.275 & & & & & & & & \\
\hline & PDI & & 4.13 & & & & & & & & \\
\hline & $\frac{\mathrm{Mn}[\mathrm{Da}]}{\mathrm{Mw}[\mathrm{Da}]}$ & & $\frac{6982}{28818}$ & & & & & & & & \\
\hline
\end{tabular}

